Cochrane Database of Systematic Reviews

\title{
Repositioning for pressure injury prevention in adults (Review)
}

Gillespie BM, Walker RM, Latimer SL, Thalib L, Whitty JA, McInnes E, Chaboyer WP

Gillespie BM, Walker RM, Latimer SL, Thalib L, Whitty JA, McInnes E, Chaboyer WP.

Repositioning for pressure injury prevention in adults.

Cochrane Database of Systematic Reviews 2020, Issue 6. Art. No.: CD009958.

DOI: 10.1002/14651858.CD009958.pub3.

www.cochranelibrary.com 
TABLE OF CONTENTS

HEADER 1

ABSTRACT

PLAIN LANGUAGE SUMMARY

SUMMARY OF FINDINGS

BACKGROUND

OBJECTIVES

METHODS

RESULTS

Figure 1.

Figure 2.

Figure 3.

Figure 4.

DISCUSSION

AUTHORS' CONCLUSIONS

ACKNOWLEDGEMENTS

REFERENCES

CHARACTERISTICS OF STUDIES

DATA AND ANALYSES

Analysis 1.1. Comparison 1: 2-hourly repositioning versus 4-hourly repositioning on any type of support surface, Outcome 1:

Pressure injury occurrence (stage 1 to 4 )

Analysis 2.1. Comparison 2: $30^{\circ}$ tilt 3-hourly overnight versus $90^{\circ}$ tilt overnight, Outcome 1: Pressure injury occurrence (stage 1 to 4)

APPENDICES

WHAT'S NEW

HISTORY

CONTRIBUTIONS OF AUTHORS

DECLARATIONS OF INTEREST

SOURCES OF SUPPORT

DIFFERENCES BETWEEN PROTOCOL AND REVIEW

INDEX TERMS

1

2

4

7

8

8

12

13

15

18

19

22

24

25

26

30

58 
[Intervention Review]

\section{Repositioning for pressure injury prevention in adults}

Brigid M Gillespie1,2,3, Rachel M Walker1,3,4, Sharon L Latimer1,2,3, Lukman Thalib5 , Jennifer A Whitty ${ }^{6}$, Elizabeth Mclnnes ${ }^{7}$, Wendy P Chaboyer1,3

1School of Nursing and Midwifery, Griffith University, Brisbane, Australia. ${ }^{2}$ Gold Coast University Hospital, Gold Coast Health, Gold Coast, Australia. ${ }^{3}$ Menzies Health Institute Queensland, Griffith University, Gold Coast Campus, Southport, Australia. ${ }^{4}$ Division of Surgery, Princess Alexandra Hospital, Metro South Health, Brisbane, Australia. 5Department of Public Health, College of Health Sciences, QU Health, Qatar University, Doha, Qatar. ${ }^{6}$ Health Economics Group, Norwich Medical School, Faculty of Medicine and Health Sciences, University of East Anglia, Norwich, UK. 7 Nursing Research Institute, St Vincent's Health Australia Sydney, St Vincent's Hospital Melbourne \& Australian Catholic University, Fitzroy, Melbourne, Australia

Contact address: Brigid M Gillespie, b.gillespie@griffith.edu.au.

Editorial group: Cochrane Wounds Group.

Publication status and date: New search for studies and content updated (no change to conclusions), published in Issue 6, 2020.

Citation: Gillespie BM, Walker RM, Latimer SL, Thalib L, Whitty JA, McInnes E, Chaboyer WP. Repositioning for pressure injury prevention in adults. Cochrane Database of Systematic Reviews 2020, Issue 6. Art. No.: CD009958. DOI: 10.1002/14651858.CD009958.pub3.

Copyright ( 2020 The Cochrane Collaboration. Published by John Wiley \& Sons, Ltd.

\section{A B S T R A C T}

\section{Background}

A pressure injury (PI), also referred to as a 'pressure ulcer', or 'bedsore', is an area of localised tissue damage caused by unrelieved pressure, friction, or shearing on any part of the body. Immobility is a major risk factor and manual repositioning a common prevention strategy. This is an update of a review first published in 2014.

\section{Objectives}

To assess the clinical and cost effectiveness of repositioning regimens(i.e. repositioning schedules and patient positions) on the prevention of $\mathrm{PI}$ in adults regardless of risk in any setting.

\section{Search methods}

We searched the Cochrane Wounds Specialised Register, the Cochrane Central Register of Controlled Trials (CENTRAL), Ovid MEDLINE, Ovid Embase, and EBSCO CINAHL Plus on 12 February 2019. We also searched clinical trials registries for ongoing and unpublished studies, and scanned the reference lists of included studies as well as reviews, meta-analyses, and health technology reports to identify additional studies. There were no restrictions with respect to language, date of publication, or study setting.

\section{Selection criteria}

Randomised controlled trials (RCTs), including cluster-randomised trials (c-RCTs), published or unpublished, that assessed the effects of any repositioning schedule or different patient positions and measured PI incidence in adults in any setting.

\section{Data collection and analysis}

Three review authors independently performed study selection, 'Risk of bias' assessment, and data extraction. We assessed the certainty of the evidence using GRADE.

\section{Main results}

We identified five additional trials and one economic substudy in this update, resulting in the inclusion of a total of eight trials involving 3941 participants from acute and long-term care settings and two economic substudies in the review. Six studies reported the proportion 
of participants developing PI of any stage. Two of the eight trials reported within-trial cost evaluations. Follow-up periods were short (24 hours to 21 days). All studies were at high risk of bias. Funding sources were reported in five trials.

\section{Primary outcomes: proportion of new PI of any stage}

Repositioning frequencies: three trials compared different repositioning frequencies

We pooled data from three trials (1074 participants) comparing 2-hourly with 4-hourly repositioning frequencies (fixed-effect; $I^{2}=45 \%$; pooled risk ratio (RR) 1.06, 95\% confidence interval (CI) 0.80 to 1.41). It is uncertain whether 2-hourly repositioning compared with 4-hourly repositioning used in conjunction with any support surface increases or decreases the incidence of PI. The certainty of the evidence is very low due to high risk of bias, downgraded twice for risk of bias, and once for imprecision.

One of these trials had three arms (967 participants) comparing 2-hourly, 3-hourly, and 4-hourly repositioning regimens on high-density mattresses; data for one comparison was included in the pooled analysis. Another comparison was based on 2-hourly versus 3-hourly repositioning. The RR for PI incidence was 4.06 (95\% $\mathrm{Cl} 0.87$ to 18.98). The third study comparison was based on 3-hourly versus 4 -hourly repositioning ( $\mathrm{RR} 0.20,95 \% \mathrm{Cl} 0.04$ to 0.92 ). The certainty of the evidence is low due to risk of bias and imprecision.

In one c-RCT, 262 participants in 32 ward clusters were randomised between 2-hourly and 3-hourly repositioning on standard mattresses and 4-hourly and 6-hourly repositioning on viscoelastic mattresses. The RR for PI with 2-hourly repositioning compared with 3-hourly repositioning on standard mattress is imprecise ( $\mathrm{RR} 0.90,95 \% \mathrm{Cl} 0.69$ to 1.16 ; very low-certainty evidence). The $\mathrm{Cl}$ for $\mathrm{PI}$ include both a large reduction and no difference for the comparison of 4-hourly and 6-hourly repositioning on viscoelastic foam ( $\mathrm{RR} 0.73,95 \% \mathrm{Cl} 0.53$ to 1.02). The certainty of the evidence is very low, downgraded twice due to high risk of bias, and once for imprecision.

\section{Positioning regimens: four trials compared different tilt positions}

We pooled data from two trials (252 participants) that compared a $30^{\circ}$ tilt with a $90^{\circ}$ tilt (random-effects; $I^{2}=69 \%$ ). There was no clear difference in the incidence of stage 1 or $2 \mathrm{PI}$. The effect of tilt is uncertain because the certainty of evidence is very low (pooled RR 0.62 , $95 \% \mathrm{Cl} 0.10$ to 3.97 ), downgraded due to serious design limitations and very serious imprecision.

One trial involving 120 participants compared $30^{\circ}$ tilt and $45^{\circ}$ tilt with 'usual care' and reported no occurrence of PI events (low certainty evidence). Another trial involving 116 ICU patients compared prone with the usual supine positioning for PI. Reporting was incomplete and this is low certainty evidence.

\section{Secondary outcomes}

No studies reported health-related quality of life utility scores, procedural pain, or patient satisfaction.

\section{Cost analysis}

Two included trials also performed economic analyses.

A cost-minimisation analysis compared the costs of 3-hourly and 4-hourly repositioning with 2-hourly repositioning schedule amongst nursing home residents. The cost of repositioning was estimated at CAD 11.05 and CAD 16.74 less per resident per day for the 3-hourly or 4hourly regimen, respectively, compared with the 2-hourly regimen. The estimates of economic benefit were driven mostly by the value of freed nursing time. The analysis assumed that 2-, 3-, or 4-hourly repositioning is associated with a similar incidence of $\mathrm{PI}$, as no difference in incidence was observed.

A second study compared the nursing time cost of 3-hourly repositioning using a $30^{\circ}$ tilt with standard care (6-hourly repositioning with a $90^{\circ}$ lateral rotation) amongst nursing home residents. The intervention was reported to be cost-saving compared with standard care (nursing time cost per patient EUR 206.60 versus EUR 253.10, incremental difference EUR $-46.50,95 \% \mathrm{CI}$ EUR -1.25 to EUR -74.60 ).

\section{Authors' conclusions}

Despite the addition of five trials, the results of this update are consistent with our earlier review, with the evidence judged to be of low or very low certainty. There remains a lack of robust evaluations of repositioning frequency and positioning for PI prevention and uncertainty about their effectiveness. Since all comparisons were underpowered, there is a high level of uncertainty in the evidence base.

Given the limited data from economic evaluations, it remains unclear whether repositioning every three hours using the $30^{\circ}$ tilt versus "usual care" ( $90^{\circ}$ tilt) or repositioning 3-to-4-hourly versus 2-hourly is less costly relative to nursing time.

\section{PLAIN LANGUAGE SUMMARY}

\section{Repositioning to prevent pressure injuries}

\section{What was the aim of this review?}


The aim of this review was to compare different positions and repositioning frequencies to find out which were the most effective in preventing pressure injuries in adults regardless of risk or healthcare setting. We collected and analysed all relevant studies (i.e. randomised controlled trials, a type of study in which participants are assigned to one of two or more treatment groups using a random method, and which provides the most reliable health evidence) to answer this question and found eight relevant trials and two economic evaluations.

We found the effectiveness of repositioning frequencies to be unclear in the 2014 version of this review. This update includes the results of new trials conducted since that time.

\section{Key messages}

There is no clear evidence regarding which particular positions and repositioning frequencies are the most effective for preventing pressure injuries in adults. This is partly due to the low quality of the studies, most of which had small numbers of participants and were lacking in details about study methods. There is also limited evidence to support the cost-effectiveness of different repositioning frequencies and positions. There is a need for further research to measure the effects of repositioning on pressure injury development and to find the best repositioning regimen relative to frequency and position.

\section{What was studied in this review?}

Pressure injuries, also called pressure ulcers, pressure sores, decubitus ulcers, and bedsores, are caused by pressure and rubbing on the bony weight-bearing points of the body. A pressure injury is indicated by an area of localised damage to the skin or underlying tissue over a bony prominence. Pressure injuries occur most commonly in the elderly, or those who are immobile.

Repositioning is one strategy used alongside other strategies to prevent the development of pressure injuries. Repositioning involves moving the person into a different position to redistribute pressure from a particular part of the body. We wanted to know which repositioning regimen was most effective in preventing pressure injuries in adults. We looked at the effect of different repositioning on peoples' perceived satisfaction, pain, and quality of life. We were also interested in comparing the cost-effectiveness of different repositioning approaches.

\section{What were the main results of this review?}

We identified eight clinical trials and two economic analyses published between 2004 and 2018 involving 3941 participants. Participant age ranged from 55 to 90 years. Three clinical trials compared repositioning frequencies using 2-, 3-, 4-, or 6-hourly repositioning. Three other trials compared different tilt positions.

Two included trials also included cost-effectiveness analyses. No studies reported health-related quality of life, procedural pain, or patient satisfaction.

The evidence to support the use of one particular repositioning frequency and position over another to prevent pressure injuries is low in quality and limited in amount, therefore which position or frequency of repositioning is the most effective in reducing pressure injury development is unclear. None of the included trials reported on participant pain, satisfaction, or quality of life. Results were inconclusive, and the certainty of the evidence in the included trials is low to very low.

\section{How up-to-date is this review?}

We searched for studies published up to February 2019. 
SUMMARY OF FINDINGS

\section{Summary of findings 1. 2-hourly repositioning compared with 4-hourly repositioning for preventing pressure injury on any support surface}

2-hourly repositioning compared with 4-hourly repositioning for preventing pressure injury on any support surface (standard, high-density foam, viscoelastic, or alternating air pressure mattresses)

\section{Patient or population: adults}

Settings: any health setting

Intervention: 2-hourly repositioning on any support surface

Comparison: 4-hourly repositioning on any support surface

\begin{tabular}{|c|c|c|c|c|c|c|c|}
\hline Outcomes & $\begin{array}{l}\text { Illustrative co } \\
(95 \% \mathrm{CI})\end{array}$ & arative risks* & $\begin{array}{l}\text { Relative effect } \\
(95 \% \mathrm{Cl})\end{array}$ & Heterogeneity & $\begin{array}{l}\text { No. of partici- } \\
\text { pants } \\
\text { (studies) }\end{array}$ & $\begin{array}{l}\text { Certainty of } \\
\text { the evidence } \\
\text { (GRADE) }\end{array}$ & Comments \\
\hline $\begin{array}{l}\text { Pressure injury } \\
\text { (stages } 1 \text { to 4) }\end{array}$ & 4-hourly & 2-hourly & \multirow{2}{*}{$\begin{array}{l}\text { RR } 1.06 \text { ( } 0.80 \text { to } \\
1.41)\end{array}$} & \multirow{2}{*}{$\begin{array}{l}\text { Chi' }=3.65, d f=2, \\
(P=0.16), I^{2}= \\
45 \%\end{array}$} & \multirow{2}{*}{$\begin{array}{l}1074 \\
\text { (3 RCTs) }\end{array}$} & \multirow{2}{*}{$\begin{array}{l}\oplus \odot \odot \ominus \\
\text { Very low } 1\end{array}$} & \multirow{2}{*}{$\begin{array}{l}\text { It is uncertain whether 2-hourly } \\
\text { repositioning compared with 4- } \\
\text { hourly repositioning used in con- } \\
\text { junction with any support surface } \\
\text { increases or decreases the inci- } \\
\text { dence of pressure injury. }\end{array}$} \\
\hline $\begin{array}{l}\text { Short-term fol- } \\
\text { low-up, } 4 \text { weeks } \\
\text { or less }\end{array}$ & 116 per 1000 & $\begin{array}{l}\mathbf{1 1 7} \text { per } \mathbf{1 0 0 0} \\
\text { (91 to } 146)\end{array}$ & & & & & \\
\hline
\end{tabular}

Health-related Not estimable - outcome not measured or reported for this comparison.

quality of life

Procedural Not estimable -outcome not measured or reported for this comparison.

pain

Patient satis- Not estimable - outcome not measured or reported for this comparison.

faction

Costs $\quad 1$ RCT, 967 participants

- A cost-minimisation analysis compared the costs of 3-hourly and 4-hourly repositioning with 2-hourly repositioning schedule amongst nursing home residents.

- The cost of repositioning was estimated at CAD 11.05 and CAD 16.74 less per resident per day for the 3-hourly or 4-hourly regimen, respectively, compared with the 2-hourly regimen.

- The estimates of economic benefit were driven mostly by the value of freed nursing time. The analysis assumed that 2-, 3-, or 4-hourly repositioning is associated with a similar incidence of PI, as no difference in incidence was observed. 
*The basis for the assumed risk (e.g. the median control group risk across studies) is provided in footnotes. The corresponding risk (and its $95 \% \mathrm{Cl}$ ) is based on the assumed risk in the comparison group and the relative effect of the intervention (and its $95 \% \mathrm{Cl}$ ).

Cl: confidence interval; RCT: randomised controlled trial; RR: risk ratio.

\section{GRADE Working Group grades of evidence}

High certainty: We are very confident that the true effect lies close to that of the estimate of the effect.

Moderate certainty: We are moderately confident in the effect estimate: the true effect is likely to be close to the estimate of the effect, but there is a possibility that it is substantially different.

Low certainty: Our confidence in the effect estimate is limited: the true effect may be substantially different from the estimate of the effect.

Very low certainty: We have very little confidence in the effect estimate: the true effect is likely to be substantially different from the estimate of effect.

${ }^{1}$ Downgraded twice for unclear or high risk of bias for sequence generation, allocation concealment, and blinding of outcome assessor (overall very serious risk of bias), and once for serious imprecision.

Summary of findings $2.30^{\circ}$ 3-hourly tilt compared with $90^{\circ}$ tilt for preventing pressure injury

\section{$30^{\circ}$ 3-hourly tilt compared with $90^{\circ}$ tilt for preventing pressure injury}

\section{Patient or population: adults}

Settings: any health setting

Intervention: $30^{\circ}$ tilts at 3-hourly

Comparison: $90^{\circ}$ tilts overnight

\begin{tabular}{|c|c|c|c|c|c|c|c|}
\hline Outcomes & $\begin{array}{l}\text { Illustrative co } \\
(95 \% \mathrm{CI})\end{array}$ & parative risks* & $\begin{array}{l}\text { Relative effect } \\
(95 \% \mathrm{CI})\end{array}$ & Heterogeneity & $\begin{array}{l}\text { No. of partic- } \\
\text { ipants } \\
\text { (studies) }\end{array}$ & $\begin{array}{l}\text { Certainty of } \\
\text { the evidence } \\
\text { (GRADE) }\end{array}$ & Comments \\
\hline $\begin{array}{l}\text { Pressure injury } \\
\text { (stages } 1 \text { to } 4 \text { ) }\end{array}$ & $90^{\circ}$ tilt & $30^{\circ}$ tilt & \multirow{2}{*}{$\begin{array}{l}\mathbf{R R} \mathbf{0 . 6 2} \text { (0.10 to } \\
3.97 \text { ) }\end{array}$} & \multirow{2}{*}{$\begin{array}{l}\mathrm{Chi}^{2}=3.21, \mathrm{df}= \\
1, \\
(P=0.07), \mathrm{I}^{2}= \\
69 \%\end{array}$} & \multirow{2}{*}{$\begin{array}{l}252 \\
\text { (2 RCTs) }\end{array}$} & \multirow{2}{*}{$\begin{array}{l}\oplus \ominus \ominus \ominus \\
\text { Very low } \mathbf{1}\end{array}$} & \multirow{2}{*}{$\begin{array}{l}\text { It is uncertain whether } 30^{\circ} 3 \text {-hourly } \\
\text { tilts regimens increase or decrease } \\
\text { the proportion of pressure injury. } \\
\text { The true effect is likely to be sub- } \\
\text { stantially different from the estima- } \\
\text { tion of effect. }\end{array}$} \\
\hline $\begin{array}{l}\text { Short-term fol- } \\
\text { low-up, } 4 \text { weeks or } \\
\text { less }\end{array}$ & 111 per 1000 & $\begin{array}{l}\mathbf{5 1} \text { per } \mathbf{1 0 0 0} \\
\text { (19 to } 108)\end{array}$ & & & & & \\
\hline $\begin{array}{l}\text { Health-related } \\
\text { quality of life }\end{array}$ & \multicolumn{7}{|c|}{ Not estimable - outcome not measured or reported for this comparison. } \\
\hline
\end{tabular}




\begin{tabular}{|c|c|c|}
\hline 융 & Procedural pain & Not estimable - outcome not measured or reported for this comparison. \\
\hline 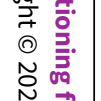 & $\begin{array}{l}\text { Patient satisfac- } \\
\text { tion }\end{array}$ & Not estimable - outcome not measured or reported for this comparison. \\
\hline & Costs & Not estimable \\
\hline 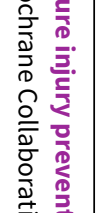 & Incremental costs & $\begin{array}{l}1 \text { RCT, } 213 \text { participants } \\
\text { - Nursing time cost of 3-hourly repositioning using a } 30^{\circ} \text { tilt with standard care (6-hourly repositioning with a } 90^{\circ} \text { lateral rotation) amongst nursing } \\
\text { home residents. } \\
\text { - The intervention was reported to be cost-saving compared with standard care (nursing time cost per patient EUR } 206.60 \text { versus EUR } 253.10 \text {, incre- } \\
\text { mental difference EUR }-46.50,95 \% \text { CI EUR }-1.25 \text { to EUR -74.60). }\end{array}$ \\
\hline
\end{tabular}

*The basis for the assumed risk (e.g. the median control group risk across studies) is provided in footnotes. The corresponding risk (and its $95 \% \mathrm{Cl}$ ) is based on the assumed risk in the comparison group and the relative effect of the intervention (and its $95 \% \mathrm{Cl}$ ).

Cl: confidence interval; RCT: randomised controlled trial; RR: risk ratio.

\section{GRADE Working Group grades of evidence}

High certainty: We are very confident that the true effect lies close to that of the estimate of the effect.

Moderate certainty: We are moderately confident in the effect estimate: the true effect is likely to be close to the estimate of the effect, but there is a possibility that it is substantially different.

Low certainty: Our confidence in the effect estimate is limited: the true effect may be substantially different from the estimate of the effect.

Very low certainty: We have very little confidence in the effect estimate: the true effect is likely to be substantially different from the estimate of effect.

1 Downgraded twice for unclear or high risk of bias for sequence generation, allocation concealment, and blinding of outcome assessor (overall very serious risk of bias), and twice for very serious imprecision. 


\section{B A C K G R O U N D}

\section{Description of the condition}

According to the National Pressure Ulcer Advisory Panel (NPUAP), the European Pressure Ulcer Advisory Panel (EPUAP), and the Pan Pacific Pressure Injury Alliance (PPPIA) (NPUAP/EPUAP/PPPIA 2014), a pressure injury (PI) (also known as pressure sore, pressure ulcer, or bedsore) is "a localised injury to skin or underlying tissue usually over a bony prominence as a result of pressure or pressure in combination with shear" (NPUAP/EPUAP/PPPIA 2014). Pressure injuries occur when the soft tissue is compressed between a bony prominence and an external surface for a prolonged period of time. In keeping with the most recent international guidelines, we have used the term pressure 'injury' rather than 'ulcer' throughout this review, as the former more accurately describes both intact and ulcerated skin (NPIAP 2019; NPUAP 2016).

Pressure injury classification systems provide an accurate and consistent means by which the severity and level of tissue injury can be described and documented (NPUAP/EPUAP/PPPIA 2014). The words 'stage' (EPUAP/NPUAP 2009), 'grade', and 'category' are used interchangeably to describe the levels of soft-tissue injury. In keeping with the most recent guidance and for consistency (NPUAP 2016), we have used the term 'stage' throughout this review. The original staging system includes stages 1 to 4 . Stage 1 reflects persistent non-blanching erythema (redness) of the skin (NPIAP 2019). Stage 2 involves partial-thickness skin loss (epidermis and dermis) (NPUAP/EPUAP/PPPIA 2014). Stage 3 reflects full-thickness skin loss involving damage, or necrosis, of subcutaneous tissue, whereas in stage 4, the damage extends to the underlying bone, tendon, or joint capsule (NPUAP/EPUAP/ PPPIA 2014). However, more recently two additional classifications have been identified, namely: 'unstageable' and 'deep tissue injury' (NPIAP 2019). Pressure injuries are associated with pain, an increased risk of infection and sepsis, longer hospital stays, and higher hospitalisation costs and mortality (Institute for Healthcare Improvement 2008).

Despite a general consensus that PIs are preventable (Chaboyer 2016; McInnes 2015; Moore 2013a), hospital-acquired PIs (HAPI) are among the top five adverse events reported. Estimates of PI incidence in hospitalised patients have ranged from less than $3 \%$ to over 30\% (Chaboyer 2016; Mulligan 2011; Schuurman 2009). Costs of treating PIs vary globally, but represent a considerable financial burden on hospital budgets wherever they occur. A costof-illness study undertaken in Australia estimated that PIs cost AUD 1,800 million per annum (Nguyen 2015). The recent international guidelines summarise previous costing data, noting that PIs are estimated to cost the US approximately USD 11000 million; the UK GBP 750 million; and the Netherlands up to USD 2,800 million annually (NPUAP/EPUAP/PPPIA 2014). Much of this cost is allocated to nursing time (Bennett 2004; Nguyen 2015).

Immobility is considered to be a major risk factor for $\mathrm{PI}$ development in hospitalised patients (Chaboyer 2016; Institute for Healthcare Improvement 2008; Lindgren 2004); however, the aged, and individuals with severely compromised states of health are particularly at risk (Institute for Healthcare Improvement 2008). For example, of the 3.55 million hospital admissions in Australia each year (excluding day cases), 50\% of patients will be at risk of PIs and $10 \%$ or more will develop a PI (Queensland Health 2017). Screening tools based on individuals' levels of activity and mobility scores have been widely used for the assessment of PI risk (Braden 2005; Jalali 2005; Thompson 2005). Various interventions are in use and are believed to reduce the incidence of PIs, with varying levels of supporting evidence, including different mattresses and overlays and regular repositioning (Mclnnes 2015).

\section{Description of the intervention}

Repositioning (i.e. turning people to change their body position to relieve or redistribute pressure) has long been a fundamental component of pressure injury prevention (PIP). Manual repositioning regimens are used in PIP programmes to redistribute pressure between the body and the support surface (Manorama 2010). The $90^{\circ}$ lateral position has been shown in laboratory studies to decrease blood flow and transcutaneous oxygen tension close to anoxic levels (extremely low levels of oxygen) and to increase interface pressure (Exton-Smith 1961). Conversely, this appears not to be the case when the patient is placed in a $30^{\circ}$ lateral inclined tilt position. Repositioning is regarded as also important for the prevention of other complications associated with prolonged immobility such as pneumonia, joint contractures, and urinary tract infections (McInnes 2015). Repositioning regimens include the schedule (or frequency, e.g. 2-hourly) and body positioning using tilt $\left(30^{\circ}, 45^{\circ}\right.$, and $90^{\circ}$ ) and/or position (e.g. lateral, supine, prone).

Best-practice guidelines developed in Europe, the USA, and Australia advocate routine repositioning of people at risk of PIs. Earlier versions of these guidelines advocate 2-hourly repositioning (NPIAP 2019). These recommendations appear to be based on small observational studies (not randomised controlled trials (RCTs)) conducted over 25 years ago, which either compared different repositioning schedules or repositioning schedules with no manual repositioning (spontaneous body movements) (Exton-Smith 1961; Norton 1962; Palmen 1987; Smith 1990). The usefulness of these studies for today's decision-making is further compromised since the standard of hospital mattresses has greatly improved.

\section{How the intervention might work}

Pressure, from lying or sitting on a particular part of the body, results in oxygen deprivation to the area (Catania 2007; NPIAP 2019; NPUAP/EPUAP/PPPIA 2014). This normally results in pain and discomfort, which stimulates the person to change position. However, if the person is unable to reposition themselves, or has impaired sensation and therefore does not experience the discomfort, assistance will be required. Repositioning reduces the duration of pressure on the tissues and so decreases tissue hypoxia (Catania 2007), and consequently the theoretical risk of pressure injury (Braden 1987).

\section{Negative aspects of frequent repositioning}

Whilst frequent repositioning underpins current clinical practice guidelines, it may also be associated with negative consequences for patients, nursing staff, and healthcare organisations (Australian Institute of Health and Welfare 2009; Bureau of Labor Statistics 2016; Carskadon 2005; Dawson 2007; Humphries 2008; Raymond 2004; Vieira 2009). For patients, repositioning can lead to disruption of sleep, in particular sleep fragmentation (Humphries 2008). In acutely ill people, disruption of sleep can lengthen recovery, suppress immune function, and predispose them to infection (Carskadon 2005; Raymond 2004). A sleep cycle, which has light and deep stages of sleep, occurs about every 90 minutes. Consequently, 
if repositioning is undertaken every two hours, it may result in fragmentation of sleep at a detrimental stage of the sleep cycle (Dawson 2007).

Other negative effects of repositioning include possible increases in patients' pain perception. Although regular movement is important, unnecessary repositioning may cause increased discomfort for people with wounds, stiff joints, bone pain, or contractures.

For nurses, frequent patient repositioning can result in musculoskeletal disorders at a rate exceeding that of workers in construction, mining, and manufacturing (Bureau of Labor Statistics 2016). These injuries are attributed partly to repeated manual patient-handling activities, often associated with repositioning patients and working in extremely awkward positions (Bureau of Labor Statistics 2016; Vieira 2009). Back pain and injury have a major impact on the efficiency of the nursing workforce (Trinkoff 2001). Registered nurses rank seventh across all occupations for back injuries involving days away from work in private industry (Bureau of Labor Statistics 2016). Back injuries and the resultant workers' compensation claims for nurses are expensive (Dawson 2007). For example, injuries in the healthcare sector cost Australia over AUD 4,300 million in 2005 to 2006 (Safe Work Australia 2012). Reducing the amount of manual handling undertaken by nurses when repositioning patients could have major nursing and hospital benefits.

\section{Why it is important to do this review}

Pressure injuries can be painful, distressing, and life-threatening (causing infection, sepsis, and even death), yet in many cases they are preventable (Moore 2013a; Schuurman 2009). Manual repositioning regimens are used in PIP programmes to alternate areas of pressure distribution between the body and the support surface, including when sitting or lying in a chair (Manorama 2010). These strategies have major implications for repositioning hospitalised patients and warrant investigation.

Whilst the potential negative aspects of repositioning have been described, the magnitude of any benefits are also uncertain, as is the optimum frequency of repositioning and the best position. Notably, some published clinical practice guidelines do not advocate 2-hourly repositioning as best practice due to a lack of empirical evidence (NPIAP 2019; NPUAP/EPUAP/PPPIA 2014). A rigorous systematic review was required to summarise current evidence for the effects of repositioning of adults, the optimal repositioning schedules, and to ensure that future practice is based on the best available evidence.

\section{O B J E C T IVES}

To assess the clinical and cost effectiveness of repositioning regimens (i.e. repositioning schedules and patient positions) on the prevention of $\mathrm{Pl}$ in adults regardless of risk in any setting.

\section{METHODS}

\section{Criteria for considering studies for this review}

\section{Types of studies}

Any RCT that used a method of random allocation of adult patients (without an existing $\mathrm{Pl}$ at baseline) between two or more alternative repositioning interventions for PIP was eligible. We also included cluster-randomised trials (c-RCTs), irrespective of the cluster group (i.e. patient, nurse, hospital). We excluded cross-over trials (even if randomised) and quasi-randomised studies (e.g. studies where treatment allocation was alternate or by date of birth).

The review of health economic evidence included comparative full and partial economic evaluations conducted within the framework of eligible RCTs (i.e. cost-effectiveness analyses, costutility analyses, cost-benefit analyses, and cost-analyses of a repositioning intervention and a relevant comparator), as well as RCTs and c-RCTs reporting more limited information, such as estimates of resource use or costs associated with repositioning and a comparator. The review considered only health economics studies conducted alongside effectiveness studies.

\section{Types of participants}

Any adult, without an existing PI, admitted to any healthcare or long-term care setting.

\section{Types of interventions}

We anticipated that comparisons would include repositioning regimens compared with other standard practices or with alternative repositioning regimens, regardless of the inclusion of standard clinical care strategies (e.g. type of support surfaces used). We included studies evaluating the following comparisons.

- Comparisons between the frequencies of repositioning, e.g. 2-, 3-, 4-hourly repositioning, etc., where the only systematic difference between groups was the frequency of repositioning.

- Comparisons between different positions for repositioning, e.g. chair positioning, $30^{\circ}$ recumbent tilt versus $90^{\circ}$ lateral rotation, where the only systematic difference between groups was the positioning.

- Comparisons of the repositioning regimen with standard practice (as defined by the author/s).

\section{Types of outcome measures}

\section{Primary outcomes}

The cumulative incidence of PI (i.e. proportion of participants with a new PI) of any stage using previously defined criteria (EPUAP 1998; EPUAP/NPUAP 2009; NPUAP 2007; NPUAP/EPUAP/PPPIA 2014), or as defined by the trial authors, anywhere on the body following recruitment into the study. Studies in which the incidence of PI was not included as a primary or secondary outcome were excluded.

\section{Secondary outcomes}

- Health-related quality of life (HRQoL), including utility scores (as reported by the author/s).

- Procedural pain (as reported by the author/s).

- Patient satisfaction (as reported by the author/s).

- Cost including: costs of PI prevention; costs of related health practitioner time or visits; costs avoided by PIP (e.g. treatment costs per patient per PI wound; costs to treat adverse events, infections, or complications of PI; duration or costs of hospital stay for PI wound healing, adverse events, and complications; indirect costs to society associated with $\mathrm{PI}$ such as lost productivity). 
- Incremental cost per event avoided, such as per additional PI prevented; incremental cost per life year gained; incremental cost per quality-adjusted life year (QALY) gained, and costbenefit ratio.

\section{Search methods for identification of studies}

\section{Electronic searches}

We searched the following electronic databases to identify reports of relevant clinical trials:

- the Cochrane Wounds Specialised Register (searched 12 February 2019);

- the Cochrane Central Register of Controlled Trials (CENTRAL; 2019, Issue 1) in the Cochrane Library (searched 12 February 2019);

- Ovid MEDLINE (1946 to 12 February 2019);

- Ovid Embase (1974 to 12 February 2019);

- EBSCO CINAHL Plus (Cumulative Index to Nursing and Allied Health Literature; 1937 to 12 February 2019);

- NHS Economic Evaluation Database (NHS EED; 2015, Issue 2) in the Cochrane Library (searched 14 March 2018 - database is now archived).

The search strategies for the Cochrane Wounds Specialised Register, CENTRAL, Ovid MEDLINE, Ovid Embase, and EBSCO CINAHL Plus are shown in Appendix 1 . We combined the Ovid MEDLINE search with the Cochrane Highly Sensitive Search Strategy for identifying randomised trials in MEDLINE: sensitivityand precision-maximising version (2008 revision) (Lefebvre 2011). We combined the Embase search with the Ovid Embase filter developed by the UK Cochrane Centre (Lefebvre 2011). We combined the CINAHL Plus searches with the trial filters developed by the Scottish Intercollegiate Guidelines Network (SIGN 2018). There were no restrictions with respect to language, date of publication, or study setting. We combined Ovid MEDLINE, Ovid Embase, and EBSCO CINAHL Plus searches with filters developed by the Centre for Reviews and Dissemination for the identification of economic studies (CRD 2013).

We also searched the following clinical trials registries:

- US National Institutes of Health Ongoing Trials Register ClinicalTrials.gov (www.clinicaltrials.gov) (searched 10 March 2019);

- World Health Organization (WHO) International Clinical Trials Registry Platform (ICTRP) (apps.who.int/trialsearch/ Default.aspx) (searched 10 March 2019);

- EU Clinical Trials Register (www.clinicaltrialsregister.eu/ctrsearch/search) (searched 10 March 2019).

Search strategies for clinical trial registries are shown in Appendix 1.

We did not restrict searches by language, study setting, date of publication, or publication status. We made every effort to obtain translations of papers that were not published in English.

\section{Searching other resources}

Details of the search strategies used for the previous version of this review are provided in Gillespie 2014a.

\section{Searching reference lists of included trials and relevant reviews}

We searched the reference lists of the included trials, as well as relevant systematic reviews, meta-analyses, and health technology assessment reports in order to identify other potentially eligible trials or ancillary publications.

\section{Searching by contacting individuals or organisations}

We contacted authors of key papers and abstracts to request further information about their trials when necessary.

\section{Conference proceedings}

We searched for conference abstracts from the following professional organisations: the American Professional Wound Care Association, Wounds Australia, and the European Wound Management Association. Our searches were carried out in Ovid MEDLINE, Ovid Embase, and EBSCO CINAHL for the period January 2000 to 20 March 2019.

\section{Adverse effects}

We did not perform a separate search for adverse effects of interventions used, considering adverse effects described in the included studies only.

\section{Data collection and analysis}

We performed data collection and analysis according to the methods stated in the published protocol for this review (Gillespie 2014b), which were based on the Cochrane Handbook for Systematic Reviews of Interventions (Higgins 2011a).

\section{Selection of studies}

Three review authors (WC, SL, RW) independently assessed all titles and abstracts of studies retrieved by the search. We retrieved the full reports of all potentially relevant trials for further assessment of eligibility based on the inclusion criteria. Differences of opinion were resolved by consensus or by referral to a fourth review author (BG). We recorded reasons for exclusion and were not blind to study authorship.

\section{Data extraction and management}

Three review authors (BG, SL, RW) independently extracted data from eligible studies using a predesigned data collection tool. A third review author (BG) adjudicated differences of opinion. For studies that included an economic component, JW (Health Economist) and BG extracted the relevant data. We included studies published in duplicate, but extracted data to ensure that information was not missed and identified the primary reference for the purpose of this review. If data were missing from reports, we attempted to contact the trial authors to obtain the missing information. One review author (BG) entered the data into Review Manager 5 software (Review Manager 2014), and two review authors (RW, SL) checked the data for accuracy. We extracted the following information:

- author, title, journal title, year of publication, country;

- healthcare setting;

- inclusion/exclusion criteria;

- sample size;

- participant characteristics by treatment group including numbers eligible and randomised; 
- completeness of follow-up and treatment of missing values (e.g. use of intention-to-treat, per-protocol, or other imputation method);

- intervention details;

- types of outcome measures in relation to primary (percentage of new PI) and secondary outcomes;

- duration of follow-up;

- analysis;

- results and conclusions relevant to review;

- funding sources.

For economic studies, we extracted additional data in relation to the following:

- estimates of specific items of resource use per person;

- estimates of unit costs (extracted separately to resource use);

- price year and currency;

- decision-making jurisdiction;

- analytic perspective;

- a point estimate and a measure of uncertainty (e.g. standard error or confidence interval) for measures of incremental resource use, costs, and cost effectiveness, if reported;

- details of any sensitivity analyses undertaken, and any information regarding the impact of varying assumptions on the magnitude and direction of results.

\section{Assessment of risk of bias in included studies}

Two review authors (BG, SL) independently assessed the risk of bias of eligible trials using the Cochrane tool for assessing risk of bias (Higgins 2011c). This tool addresses six specific domains; sequence generation, allocation concealment, blinding, incomplete outcome data, selective outcome reporting, and other potential sources of bias (see Appendix 1 for details of the criteria on which the judgements were based). We assessed domains as low risk of bias, high risk of bias, or unclear (unknown) risk of bias. In assessing bias, the review authors were not blinded to the names of trial authors, institutions, or journals.

In assessing the risk of bias, we distinguished between primary outcome (proportion of participants with a new PI), secondary subjective outcomes (HRQoL, procedural pain, patient satisfaction), and the objective economic outcome. As the primary outcome for this review, regardless of how it was measured, was subject to potential observer bias, blinding of outcome assessment was particularly important. We planned to make separate judgements for secondary outcomes for the domain of incomplete outcome data. We classified trials as being at overall high risk of bias if they were rated as 'high' for any one of three key domains (allocation concealment, blinding of outcome assessors, and incomplete outcome data).

Any disagreements between review authors were resolved by consensus or by referral to another review author (WC). Where there was a high risk of bias in any of the key domains, we endeavoured to contact the trial authors and asked open-ended questions about the design and conduct of the study. We reported bias, and within economic evaluations, planned to use the Drummond checklist (as recommended by Cochrane) to assess the methodological quality of full and partial economic evaluations (Shemilt 2011).
We presented an assessment of risk of bias using 'Risk of bias' summary figures, which detail all the judgements in a crosstabulation of study by entry. This display of internal validity indicates the weight the reader may give the results of each study. We recorded trials as being at unclear risk of bias if authors did not report validity criteria.

\section{Measures of treatment effect}

We have reported effect estimates for dichotomous outcomes (e.g. relative proportions of people developing PI during follow-up) as risk ratios (RR) with $95 \%$ confidence intervals $(\mathrm{Cl})$. Risk ratio is the proportion of participants developing PIs in the experimental group divided by the proportion in the control group and indicates the likelihood of PI development on the experimental regimen (turning frequency or position) compared with a standard practice. We have used the RR rather than odds ratio (OR), since ORs may be misinterpreted as RR, and can give an inflated impression of the effect size when event rates are greater than 20\% (Deeks 2002). We planned to use mean difference (MD) as a summary statistic in meta-analysis when outcome measurements in all studies were made on the same scale.

We have presented a tabulated analysis of the identified economic data in accordance with advice outlined in the CHEERS (Consolidated Health Economic Evaluation Reporting Standards) checklist (Husereau 2013). We planned to tabulate the main characteristics and results of the identified economic evaluation studies, and to expand on these narratively.

Given the likely lack of direct comparability in resource use and cost data between different healthcare contexts and settings, we did not intend to pool economic outcomes for any of the included studies, but instead planned to incorporate a discussion of key drivers and impact of assumptions on the available economic evaluations, scenarios that are likely to lead to the most and least cost-effective use of repositioning for PIP, as well as guidance on future research that might be required to assess the economic value of repositioning as an intervention for PIP.

\section{Costs}

For economic studies, we intended that all substantial costs that were observed to differ between people repositioned for PIP and people administered the comparator treatment be captured and reported as part of the review of economic evaluations.

We planned to report resource utilisation and unit costs separately, along with the currency and price year in each original study. These costs would then be converted to 2018 values by employing a webbased conversion tool that applies implicit price deflators for gross domestic product (GDP) of that currency and then converts into the currency most frequently observed in the articles reviewed using purchasing power parities (PPP) (Shemilt 2010).

The main costs were likely to be those associated with the development of PIs, specialist and other practitioner costs as measured by time or number of visits, potential cost-savings from a change in the number of bed days in hospital, and costs stemming from differing rates of adverse events and complications (including procedures initiated due to the failure of wounds to heal, such as amputation). We planned to identify key cost drivers that would enable users of the review to gain a clear understanding of the nature of resource use associated with repositioning for PIP. 


\section{Health state utility weights}

We planned to examine information on the change in HRQoL reported by the included trials via utilities measured by a multiattribute utility instrument (MAUI) or other approaches (such as the time trade-off, standard gamble). We planned to assess the utility data for comparability and representativeness considering issues such as the stages of $\mathrm{PI}$, the patient populations, timing of the baseline point and follow-up collection, the MAUI used, and the algorithm for scoring the MAUI. We planned to present a discussion of the potential impact on HRQoL attributable to the intervention as part of the review.

\section{Unit of analysis issues}

For all included trials, we extracted and analysed the single pressure injury outcome per person recruited in the study, taking into account the level at which randomisation occurred. For studies with a parallel-group design, we collected and analysed a single measurement for each outcome for each person. We considered instances where there were multiple observations per person for the same outcome, contacting the trial author(s) for clarification where necessary.

For c-RCTs where clustering was not taken into account in the study analysis, we considered adjusted sample sizes using the methods described in Chapter 16 of the Cochrane Handbook for Systematic Reviews of Interventions (Higgins 2011a). However, the best estimate of a relevant intraclass correlation coefficient (ICC) for estimating the design effect was so small (such as 0.001) that we used the original reported study data without adjustment.

\section{Dealing with missing data}

We planned that if we were unable to obtain all complete outcome data from study authors, we would perform an available-case analysis, based on the numbers of people for whom outcome data were known. This is a more conservative approach in this context than using numbers originally randomised and assuming that losses to follow-up did not incur for pressure injury. If standard deviations (SD) were missing, we would impute them from other studies or, where possible, compute them from standard errors (SE) using the formula $\mathrm{SD}=\mathrm{SEx} \sqrt{ }^{-} \mathrm{N}$, where these values were available (Higgins 2011a). We did not conduct planned best-case and worstcase analyses, nor did we calculate SDs from SEs using the formula $\mathrm{SD}=\mathrm{SE} \times \sqrt{ }^{-} \mathrm{N}$ (Higgins 2011a).

\section{Assessment of heterogeneity}

We considered clinical and methodological heterogeneity in relation to the primary outcome, PI incidence, and secondary outcomes such as HRQoL, patient satisfaction, and procedural pain. For c-RCTs, we assessed the outcome at the same level as the group allocation (Deeks 2011).

We assessed clinical heterogeneity by examining the types of participants and/or groups, interventions and their duration, and the outcomes of each study. If appropriate, we pooled data in a meta-analysis using Review Manager 5 (Review Manager 2014). We did not plan to pool studies for economic outcomes as the variability in, and generalisability of, these outcomes were considered problematic.

A fixed-effect meta-analysis provides a result that may be viewed as a 'typical intervention effect' from the studies included in the analysis. However, when there is heterogeneity, exploring the possible causes of heterogeneity is more useful. Given that there were too few studies in the review to pool, exploring the causes of heterogeneity was a challenge. As such, when heterogeneity cannot readily be explained, one analytical approach is to incorporate the studies using a random-effects model, whilst acknowledging that a random-effects model does not 'take account' of the heterogeneity.

We assessed methodological heterogeneity in the meta-analyses visually and by using the $\mathrm{Chi}^{2}$ statistic with significance being set at $P$ value less than 0.10 . In addition, we investigated the degree of heterogeneity by calculating the $\mathrm{I}^{2}$ statistic (Deeks 2002). The $I^{2}$ statistic examines the percentage of total variation across studies due to heterogeneity rather than to chance. We planned that we would not pool studies when we encountered substantial heterogeneity such as an $\mathrm{I}^{2}$ exceeding $75 \%$ (Higgins 2011b). However, such figures are only a guide, and it has been recognised that statistical tests and metrics may miss important heterogeneity. Consequently, whilst we evaluated these measurements, our overall assessment of heterogeneity used these measures in combination with the methodological and clinical assessment of heterogeneity.

\section{Assessment of reporting biases}

We planned that if there were at least 10 studies we would assess potential publication bias using funnel plots and evaluate funnel plot asymmetry visually (Sterne 2011). However, as only eight studies were included in the review, this was not appropriate.

\section{Data synthesis}

We were unable to pre specify the amount of clinical, methodological, and statistical heterogeneity in the included studies, and thus used a random-effects approach for metaanalysis. Conducting meta-analysis with a fixed-effect model in the presence of even minor heterogeneity can provide overly narrow confidence intervals. We used a fixed-effect approach when there was minimal clinical and methodological heterogeneity and the assumption that a single underlying treatment effect was being estimated held. We used the $\mathrm{Chi}^{2}$ and $\mathrm{I}^{2}$ statistics to quantify heterogeneity but did not use these to determine the model for meta-analysis. Where studies were clinically similar and outcome measurements were comparable, we pooled results using a random-effects model and reported the pooled estimate together with its $95 \% \mathrm{Cl}$. We presented data using forest plots where possible. For dichotomous outcomes, we presented the summary estimate as an RR with $95 \% \mathrm{Cl}$.

For continuous outcomes, we planned to calculate standardised mean difference (SMD) and MD plus $95 \% \mathrm{Cl}$. The decision to pool data in a meta-analysis depended on the availability of outcome data and the assessment of between-trial heterogeneity. We explored the robustness of meta-analyses using appropriate metaanalytical models, such as fixed-effect or random-effects models. The type of model used was based on the level of heterogeneity as outlined in the Cochrane Handbook for Systematic Reviews of Interventions (Deeks 2011).

Where statistical synthesis of data from more than one study was not possible or considered inappropriate, we conducted a narrative review of eligible studies. We described the included studies in a structured narrative summary based on comparators and entered quantitative data into Review Manager 5 (Review Manager 2014). 


\section{Subgroup analysis and investigation of heterogeneity}

We planned a subgroup analysis to examine the effect of potentially influential factors on outcome with regard to the type of patient and care setting. We did not attempt this as there was low heterogeneity and variation between estimates.

\section{Sensitivity analysis}

We planned to perform sensitivity analyses where necessary to test whether findings were robust to the method used to obtain them, and compared the results of two or more meta-analyses using different assumptions (Higgins 2011c). However, as all included trials were assessed as being at high risk of bias (i.e. having low- or very low-certainty evidence), this analysis was not undertaken.

\section{Summary of findings and assessment of the certainty of the evidence}

The main results of the review are presented in 'Summary of findings' tables, which provide key information about the certainty of the evidence, the magnitude of the effects of the interventions examined, and the sum of the available data for the primary outcome and secondary outcomes listed below (Schünemann 2011). The 'Summary of findings' tables also include an overall grading of the body of evidence related to these outcomes using the GRADE assessment (Ryan 2016; Schünemann 2017). GRADE assesses the certainty of a body of evidence as high, moderate, low, or very low, which represents the extent to which one can be confident that an estimate of effect is close to the true effect (Schünemann 2017). The level of certainty can be downgraded according to the following factors (Ryan 2016; Schünemann 2017):

- risk of bias (i.e. allocation concealment, randomisation, blinding, selective reporting);

- precision of the effect estimate;

- consistency of individual study results;

- how directly the evidence answers the question(s) of interest;

- risk of reporting and publication biases.

Assessing the certainty of the evidence using GRADE involves consideration of the 'Risk of bias' criteria (as listed above) and assessment of methodological heterogeneity. We linked Cochrane 'Risk of bias' ratings to the GRADE assessment using an adaptation by Ryan 2016, as follows.

- High certainty: very confident that the true effect lies close to that of the estimate of the effect.

- Moderate certainty: moderately confident in the effect estimate: the true effect is likely to be close to the estimate of the effect, but there is a possibility that it is substantially different.

- Low certainty: confidence in the effect estimate is limited: the true effect may be substantially different from the estimate of the effect.
- Very low certainty: very little confidence in the effect estimate: the true effect is likely to be substantially different from the estimate of effect.

We used the following decision rules for downgrading the evidence:

- baseline quality (e.g. high for RCTs);

- if no serious concern existed, no downgrade;

- if serious concern existed, we downgraded the evidence one level, e.g. from high to moderate $(-1)$;

- if very serious concern existed, we downgraded the evidence two levels, e.g. from high to low (-2) (Ryan 2016).

We included the following primary and secondary outcomes (both desirable and undesirable) in the 'Summary of findings' tables:

- development of a new PI;

- HRQoL;

- pain;

- patient satisfaction

- costs;

- incremental cost.

We have used GRADE to assess the synthesised findings of the body of evidence related to the review questions in a structured manner, and considered the key factors as listed above. We have presented 'Summary of findings' tables based on the following comparisons:

- different repositioning schedules, i.e. 2-hourly compared to 4hourly turning regimens;

- different positions, i.e. various degrees of tilt positions $\left(30^{\circ}\right.$ compared to $\left.90^{\circ}\right)$.

We conducted GRADE assessments for those outcomes that could not be pooled, which are presented narratively for each individual trial in the Results section.

\section{RE S U L T S}

\section{Description of studies}

See Characteristics of included studies; Characteristics of excluded studies; and Characteristics of ongoing studies. Sections of one study, published in Chinese (Zhou 2014), were translated into English and included in this review.

\section{Results of the search}

We searched for both intervention studies and economic evaluations for this update. The results of these searches are reported separately. The study flow diagram of clinical studies is shown in Figure 1, and the study flow diagram of economic evaluations is shown in Figure 2. For this update we assessed 463 intervention records and 237 economic evaluation records. We also identified a total of 18 records from clinical trial registries. 
Figure 1. Study flow diagram for clinical studies.

3 studies included in the previous

version of review (Gillespie 2014a)

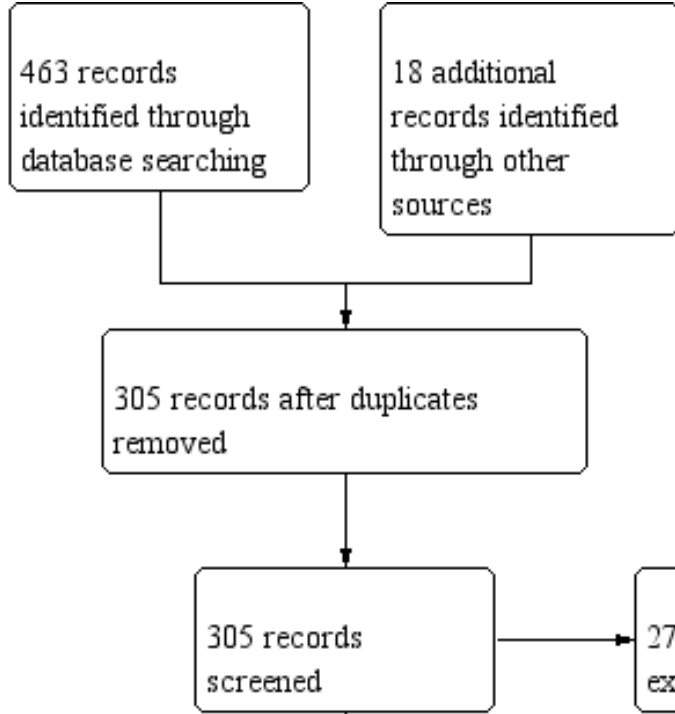

273 records

excluded

6 full-text studies

excluded:

1. Participants positioned using a positioning device $(\mathrm{n}=1)$

2. PI was not measured as a primary or secondary outcome $(\mathrm{n}=1)$

14 full-text studies assessed for eligibility

3. Patients with existing PI included at baseline $(n=4)$

18 clinical trial registry records 
Figure 1. (Continued)

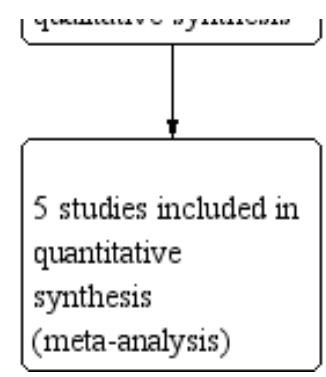


Figure 2. Study flow diagram for economic studies.

study included in the previous ersion of review (Gillespie 2014a)

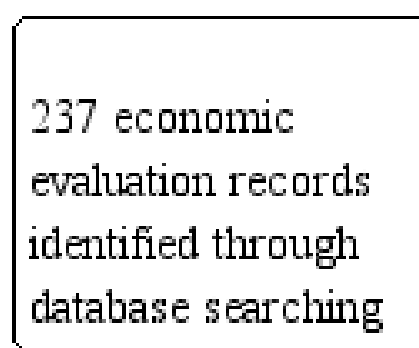

3 additional records
identified through
other sources

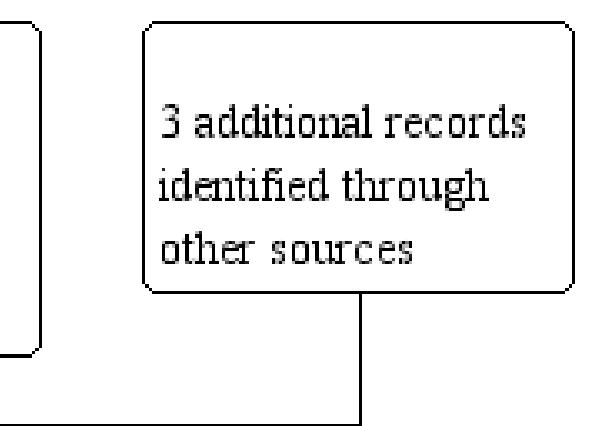

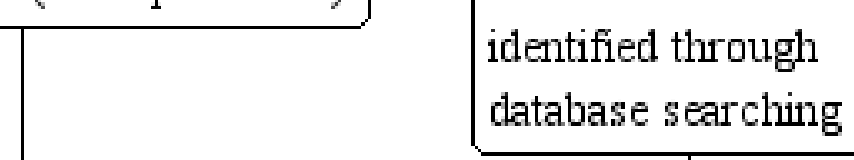
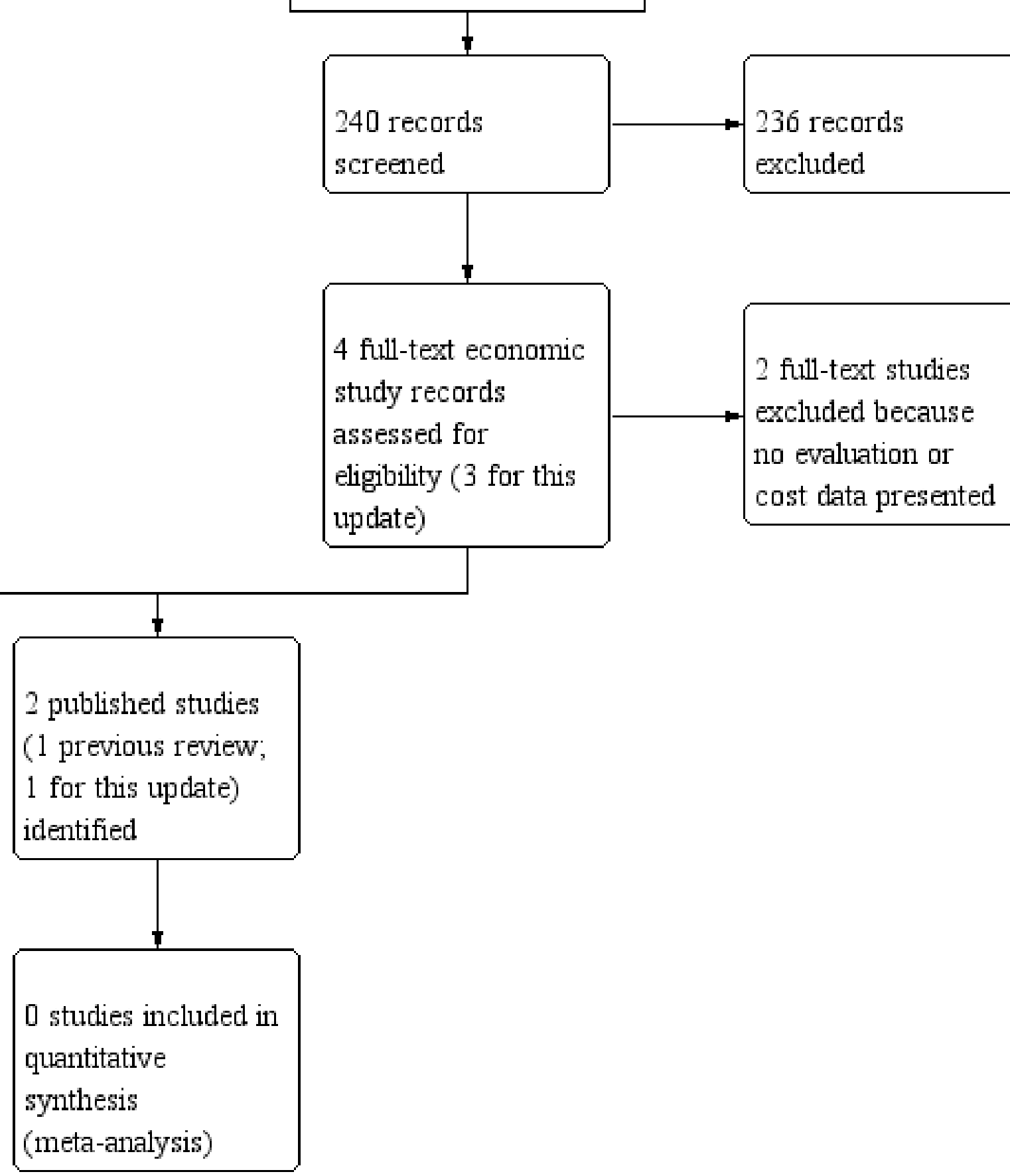
In this update, electronic searches yielded 463 intervention records (plus a further 18 from other sources), giving 305 unique records after de-duplication. We excluded 273 records because they did not meet one or more of our inclusion criteria. We retrieved full-text versions of 14 papers and 18 records from clinical trial registries for inspection, and included five additional trials in the review (Bergstrom 2013; Ghezeljeh 2017; Manzano 2014; Pickham 2018; Zhou 2014). We identified two full-text articles regarding the Turning for Ulcer Reduction (TURN) trial (Bergstrom 2013; Bergstrom 2014), one of which was published in an international journal (Bergstrom 2013), and the other as a technical report (Bergstrom 2014). We used the Bergstrom 2013 paper published as a journal article as the primary source for data extraction and data synthesis (see Figure 1). All the included trials had been published in the last 14 years.

\section{Clinical trials registries search}

For this update, we identified five relevant ongoing trials (NCT02479425; NCT02690753; NCT02996331; NCT03048357; NCT03454230); however, results from those studies were not published at the time of publication of this review. We did not contact investigators from these trials. We are not aware of any other relevant ongoing trials (EU Clinical Trials Register and WHO ICTRP registries, searched 10 March 2019).

\section{Economic analysis search}

Electronic searches for this update yielded 237 economic evaluation records. We excluded 236 records because they did not meet our inclusion criteria. Two economic substudies by Moore 2013b and Paulden 2014 (newly included in this update) met our inclusion criteria. (see Figure 2).

We included a total of eight trials, Bergstrom 2013; Defloor 2005; Ghezeljeh 2017; Manzano 2014; Moore 2011; Pickham 2018; Young 2004; Zhou 2014, and two economic substudies, Moore 2013b; Paulden 2014, in this update.

\section{Included studies}

\section{See Characteristics of included studies}

\section{Types of participants}

A total of 3941 participants were enrolled in the eight trials included in this review (Bergstrom 2013; Defloor 2005; Ghezeljeh 2017; Manzano 2014; Moore 2011; Pickham 2018; Young 2004; Zhou 2014). Total numbers randomised in the included studies were 967 (Bergstrom 2013), 838 (Defloor 2005), 120 (Ghezeljeh 2017), 329 (Manzano 2014), 213 (Moore 2011), 1312 (Pickham 2018), 46 (Young 2004), and 116 (Zhou 2014).

Two of the eight included trials were c-RCTs (Defloor 2005; Moore 2011). While Moore 2011 reported an ICC of 0.001, Defloor 2005 did not report the ICC. As such we used the ICC from a falls study with a similar patient group and care context (Cumming 2008) to impute the ICC for Defloor 2005

The Defloor 2005 trial used 32 clusters based on wards, whilst the Moore 2011 trial used 12 clusters based on study site. We did not adjust sample sizes for clustering in the two c-RCTs (Defloor 2005; Moore 2011). In the Defloor 2005 trial, while a total of 521 participants were included in the trial, only 262 participants were randomised to arms relevant to this review.
Four trials were conducted in Europe (Spain (Manzano 2014), Belgium (Defloor 2005), Ireland (Moore 2011), and Wales (Young 2004)); two in North America (US and Canada (Bergstrom 2013; Pickham 2018)); and two in Asia (China (Zhou 2014) and Iran (Ghezeljeh 2017)). Most trial participants were residents of longterm care settings (Bergstrom 2013; Defloor 2005; Moore 2011), whilst four studies were undertaken in intensive care unit (ICU) settings (Ghezeljeh 2017; Manzano 2014; Pickham 2018; Zhou 2014), and a further study recruited participants from a single acute care facility (Young 2004).

Participants in four trials were aged over 65 years (Bergstrom 2013; Defloor 2005; Moore 2011; Young 2004).

\section{Types of interventions}

\section{Repositioning frequencies}

Three of the eight included trials assessed various combinations of repositioning frequencies (2-, 3-, 4-, and 6-hourly) (Bergstrom 2013; Defloor 2005; Manzano 2014). The Bergstrom 2013 trial had three arms and compared 2-, 3-, and 4-hourly turning schedules in nursing home residents. Across the three intervention arms, repositioning was required within 30 minutes according to the frequency whilst in bed. PIP strategies such as the use of high-density foam mattresses, positioning aids, skin protection, skin assessment/care, documentation continued during the study (Bergstrom 2013). High-density foam mattresses were used as standard care for all trial participants in one trial (Bergstrom 2013).

The Defloor 2005 trial, conducted in 11 nursing homes, compared different repositioning frequencies (2-, 3-, 4-, and 6-hourly) using a semi-Fowler's or lateral position, in combination with a standard institutional mattress or a viscoelastic foam mattresses. The participants receiving the 2-hourly and 3-hourly repositioning all received the standard institutional mattress, whilst those receiving the 4-hourly and 6-hourly repositioning received viscoelastic foam mattresses (Defloor 2005). In this study there was also a large "standard care" arm comprising 576 people allocated care based on nurses' clinical judgement (a range of support surfaces but no repositioning) (Defloor 2005). We excluded this treatment arm for the purposes of this review as it differed systematically from the other four arms in both the allocation of support surface and repositioning. In the other four groups, co-interventions such as the use of nutritional supplements, skin care, and allocation of pressure-relieving cushions during chair sitting were also used (Defloor 2005).

The Manzano 2014 trial compared 2-hourly and 4-hourly repositioning in conjunction with using $30^{\circ}$ head of bed (HOB) tilt positions (alternating left/right/supine) and alternating airpressure mattresses (standard care across patients in both groups) in ICU participants. The Pickham 2018 trial, which included 1312 ICU participants, assessed whether the feedback provided from a wearable patient sensor would increase turning compliance to reflect use of a 2-hourly turning regimen with $20^{\circ}$ tilt.

\section{Positioning}

Three of the eight included trials compared different tilt positions $\left(30^{\circ}, 45^{\circ}\right.$, or $90^{\circ}$ ) (Ghezeljeh 2017; Moore 2011; Young 2004).

The trial by Ghezeljeh 2017 compared $30^{\circ} \mathrm{HOB}$ tilt with a $45^{\circ} \mathrm{HOB}$ tilt in ICU participants. Participants in the intervention groups were positioned using either $30^{\circ}$ or $45^{\circ} \mathrm{HOB}$ elevation, whilst participants 
in the "control" group were given the "routine" position (Ghezeljeh 2017), although this was not described in the study. All participants across the three groups were repositioned 2-hourly, underwent skin checks/care, had bed linen changes when required, and were lifted during position changes for three days following ICU admission (Ghezeljeh 2017).

In two trials (Moore 2011; Young 2004), a $30^{\circ}$ tilt position was compared with a standard $90^{\circ}$ supine/lateral position. Participants in both the intervention and control groups were tilted left side, back, right side, and back. The Moore 2011 and Young 2004 trials essentially compared the same tilts $\left(30^{\circ}\right.$ versus $\left.90^{\circ}\right)$ and the same repositioning frequency for the $30^{\circ}$ tilt; however, there was a difference in the frequency of repositioning overnight for the $90^{\circ}$ tilt groups. In the Moore 2011 trial, participants in the $90^{\circ}$ tilt group were repositioned 6-hourly overnight compared with 2 - to 3-hourly overnight in the Young 2004 trial.

The Zhou 2014 trial compared a prone position with a standard supine position. Participants in the intervention group were positioned prone for 10 hours, then repositioned in the supine position for 4 to 6 hours, and then repositioned to the prone position (Zhou 2014). Study participants in the control group were positioned in the supine position (standard care) (Zhou 2014).

\section{Types of outcomes}

The primary outcome in five of the included trials was the proportion of participants developing a new PI (Bergstrom 2013; Defloor 2005; Manzano 2014; Moore 2011; Pickham 2018; Young 2004). In one trial (Manzano 2014), the primary outcome was the occurrence of stage 2 or greater $\mathrm{PI}$, with a follow-up period of 24 hours. Two trials reported the incidence of $\mathrm{PI}$ and included stages 1 to 4 over a 28-day period (Defloor 2005; Moore 2011), whilst the
Bergstrom 2013 trial reported PI occurrence over 21 days. Young 2004 used a briefer follow-up period of 24 hours and reported only stage $1 \mathrm{PI}$ (i.e. non-blanchable erythema). The follow-up period in the Pickham 2018 trial was 72 hours.

In two trials (Ghezeljeh 2017; Zhou 2014), the occurrence of PI was a secondary outcome; the primary outcome in Ghezeljeh 2017 was the incidence of ventilator-acquired pneumonia (VAP), and in Zhou 2014 clinical complications associated with adult respiratory distress syndrome.

\section{Excluded studies}

\section{See Characteristics of excluded studies}

We excluded a total of six studies from the review because they did not meet the inclusion criteria (Beuret 2002; Girard 2014; Su 2015; Taccone 2009; Vanderwee 2007; Voggenreiter 2005).

In the 2014 version of this review (Gillespie 2014a), we excluded one trial after full-text screening (Vanderwee 2007). In this trial participants who had pre-existing stage $1 \mathrm{PI}$ (non-blanchable erythema) at baseline were included, whilst those who did not have non-blanchable erythema were excluded. In this current update, we excluded a further five trials after full-text review for the following reasons: the trials included patients with a PI at baseline (Beuret 2002; Girard 2014; Voggenreiter 2005); the trial focused on the use of a postioning device rather than a position or repositioning (Su 2015); and the occurrence of a PI was not included (i.e. measured) as a primary or secondary outcome (Taccone 2009).

\section{Risk of bias in included studies}

We have presented an assessment of the risk of bias using a 'Risk of bias' summary figure (Figure 3 ) and graph (Figure 4). 
Figure 3. Risk of bias summary: review authors' judgements about each risk of bias item for each included clinical study.

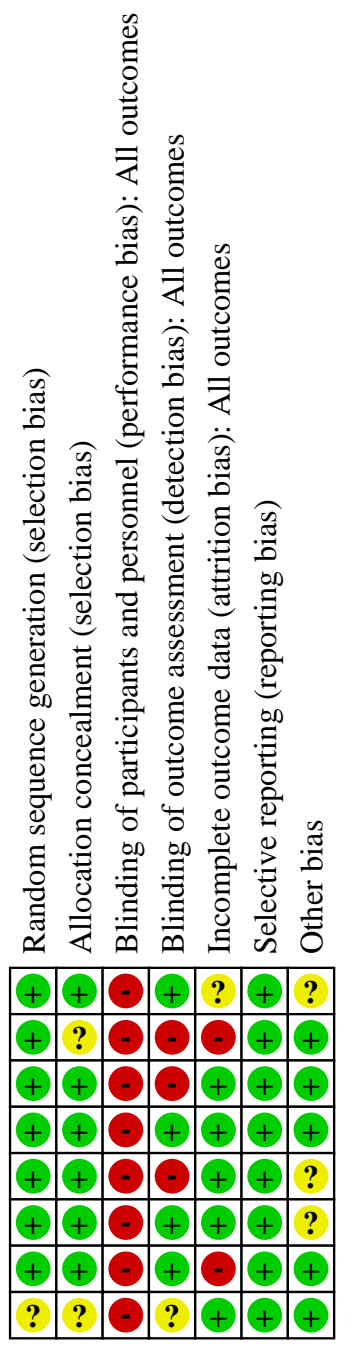


Figure 4. Risk of bias graph: review authors' judgements about each risk of bias item presented as percentages across all included clinical studies.

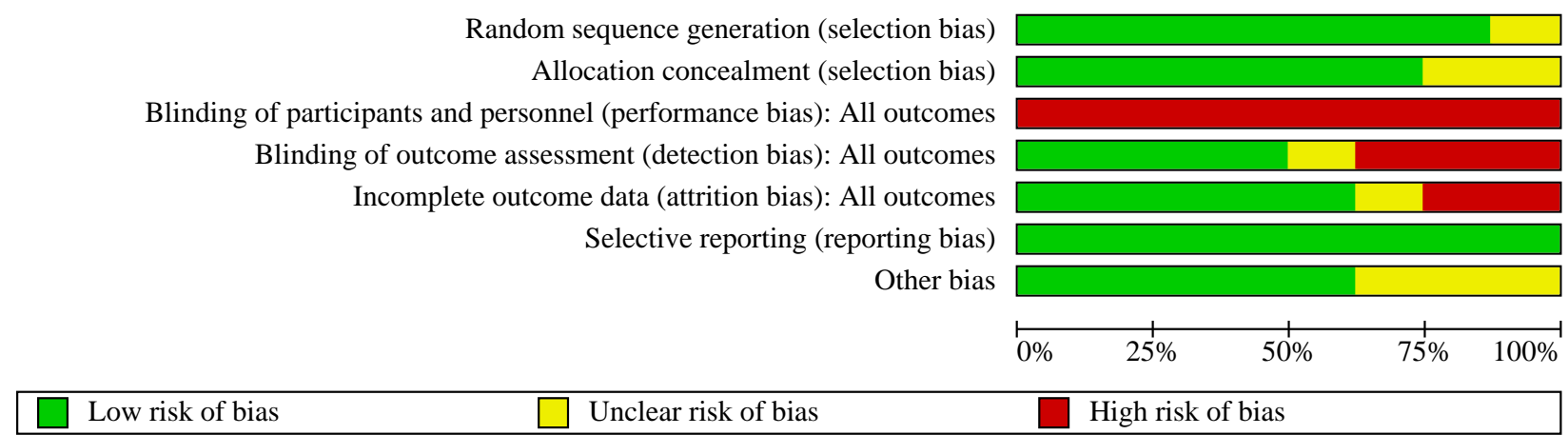

'Risk of bias' judgements are provided in the Characteristics of included studies tables.

All trials were assessed as being at high risk of bias in at least one domain (Bergstrom 2013; Defloor 2005; Ghezeljeh 2017; Manzano 2014; Moore 2011; Pickham 2018; Young 2004; Zhou 2014). For all but three studies (Ghezeljeh 2017; Manzano 2014; Young 2004), the risk of bias was unclear for at least one domain. Overall, the quality of reporting was limited due to lack of clarity and detail, as described below.

\section{Allocation}

\section{Random sequence generation}

All studies were at low risk of bias except one (Zhou 2014), with its risk of bias unclear. Seven trials described a process to generate the random allocation list (Bergstrom 2013; Defloor 2005; Ghezeljeh 2017; Manzano 2014; Moore 2011; Pickham 2018; Young 2004). Two trials used a computer-based random number generator (Defloor 2005; Moore 2011). Four trials used sequentially numbered envelopes that contained a randomisation code (Bergstrom 2013; Ghezeljeh 2017; Pickham 2018; Young 2004). In Defloor 2005, randomisation also occurred over a second four-week period. During this second period, each ward used a different prevention scheme than used in the first four-week period (Defloor 2005). A randomisation table was used in the Zhou 2014 trial, however the process of randomisation was not described.

\section{Allocation concealment}

All studies except two (Defloor 2005; Zhou 2014) were at low risk of bias, and for these two the risk of bias was unclear. Assessment of allocation concealment in the eight included trials involved examination of whether trial authors described how the assignment sequence was protected before and until allocation. We assessed six trials as being at low risk of bias for allocation concealment (Bergstrom 2013; Ghezeljeh 2017; Manzano 2014; Moore 2011; Pickham 2018; Young 2004). We could not adequately assess the extent of allocation concealment for Defloor 2005 since the randomisation was influenced during the trial by resources, and therefore rated this study as at unclear risk of bias for this domain. We assessed Zhou 2014 as at unclear risk of bias as the process of allocation concealment was not described.

\section{Blinding}

\section{Blinding of participants and personnel}

As it is hard to envisage how blinding of participants and personnel to the frequency and nature of the repositioning regimen could be possible, all trials were likely to be at risk of performance bias. Hence, we judged all included trials as at high risk of bias for blinding of participants and personnel (Bergstrom 2013; Defloor 2005; Ghezeljeh 2017; Manzano 2014; Moore 2011; Pickham 2018; Young 2004; Zhou 2014).

\section{Blinding of outcome assessors}

Four studies (Bergstrom 2013; Manzano 2014; Pickham 2018; Young 2004) were at low risk of bias, three (Defloor 2005; Ghezeljeh 2017; Moore 2011) were at high risk, and for one (Zhou 2014), the risk of bias was unclear.

There was considerable variability in assessment of all stages of PI amongst the included trials (Bergstrom 2013; Defloor 2005; Ghezeljeh 2017; Manzano 2014; Moore 2011; Pickham 2018; Young 2004; Zhou 2014). Such variability is problematic as the use of a subjective primary outcome measure is open to ascertainment bias. We assessed four trials as being at low risk of bias for blinding of outcome assessors (Bergstrom 2013; Manzano 2014; Pickham 2018; Young 2004). In Defloor 2005; Ghezeljeh 2017, and Moore 2011, blinding was not possible because nursing staff delivering patient care were also tasked with assessing the primary outcome. We assessed Zhou 2014 as at unclear risk of bias for blinding of outcome assessors, as this was not reported.

\section{Incomplete outcome data}

We evaluated attrition bias by determining whether reasons for attrition or exclusion were reported, if there was re-inclusion of participants, and whether completeness of data for each main outcome was described.

Five studies were at low risk of bias (Ghezeljeh 2017; Manzano 2014; Moore 2011; Pickham 2018; Zhou 2014), two were at high risk (Defloor 2005; Young 2004) and for one (Bergstrom 2013), the risk of bias was unclear.

In two trials (Defloor 2005; Young 2004), participants were excluded from the analysis in sufficient numbers to raise the possibility of bias. Defloor 2005 excluded 77 (9.2\%) of 838 randomised 
participants from the analysis. In Young 2004, seven (15.2\%) of the 46 randomised participants were excluded: two in the control group due to death and five in the experimental group who were unable to tolerate the intervention and for whom outcome data collection then ceased. For both Young 2004 and Defloor 2005, we conducted a complete-case analysis (which makes no assumption about the outcomes for participants lost to follow-up, as this was considered to be more conservative than analysing losses as if they had not sustained a PI). Bergstrom 2013 excluded 25 (2.6\%) of 967 randomised participants.

\section{Selective reporting}

All studies were at low risk of bias.

All included studies reported all prespecified outcomes as defined in the results section of the papers. Only one trial, Pickham 2018, had a published protocol available (Pickham 2016).

\section{Other potential sources of bias}

Five studies were at low risk of bias (Defloor 2005; Ghezeljeh 2017; Manzano 2014; Young 2004; Zhou 2014) and for the remaining three (Bergstrom 2013; Moore 2011; Pickham 2018), the risk of bias was unclear.

We planned to assess potential publication bias using funnel plots and to assess funnel plot asymmetry visually; however, as only eight studies were included in the review, this was not appropriate (Sterne 2011). Five of the eight included trials declared funding sources (Bergstrom 2013, Ghezeljeh 2017; Manzano 2014; Moore 2011; Pickham 2018). One of these trials reported co-funding by product manufacturers (Pickham 2018), whilst another reported that the trialist was a co-owner of a website that promotes use of the scale that was used in the trial to assess PI risk (Bergstrom 2013).

\section{Effects of interventions}

See: Summary of findings 1 2-hourly repositioning compared with 4-hourly repositioning for preventing pressure injury on any support surface; Summary of findings $230^{\circ} 3$-hourly tilt compared with $90^{\circ}$ tilt for preventing pressure injury

The eight included trials randomised a total of 3941 participants.

The main comparison based on 2-hourly repositioning compared with 4-hourly repositioning to prevent $\mathrm{PI}$, using any support surface, and the comparison based on $30^{\circ} 3$-hourly tilt compared with $90^{\circ}$ tilt overnight to prevent $\mathrm{PI}$, are presented in Summary of findings 1 and Summary of findings 2. We have organised findings by comparison and a priori outcome measures.

Whilst there was some clinical and methodological heterogeneity, we undertook meta-analysis where there was similarity in the primary intervention (repositioning frequencies and tilt regimens).

\section{Comparison 1: frequencies of repositioning}

We included data from four trials with 2870 participants in this comparison (Bergstrom 2013; Defloor 2005; Manzano 2014; Pickham 2018). Bergstrom 2013; Defloor 2005 and Manzano 2014 all contributed to at least one pooled estimate. We included one cRCT in this comparison (Defloor 2005), however we did not adjust the data for clustering as the ICC of 0.001 (from Moore 2011 and
Cumming 2008 for Defloor 2005 ) was so small as to make no difference.

\section{Primary outcomes}

\section{Proportion of new pressure injuries of any stage}

\section{Frequency of repositioning: 2-hourly versus 3-hourly}

We were unable to pool data based on the two studies for this comparison due to high statistical heterogeneity $\left(1^{2}=77 \%\right)$ (Bergstrom 2013; Defloor 2005).

The Bergstrom 2013 trial (967 participants, 27 nursing homes in the US and Canada) compared repositioning regimens using 2-hourly ( $n=210)$ versus 3-hourly $(n=209)$ frequencies, with all participants being nursed on high-density foam mattresses. There were no clear differences in the risk of PI for 2-hourly versus 3-hourly frequencies (risk ratio (RR) $4.06,95 \%$ confidence interval ( $\mathrm{Cl}) 0.87$ to 18.98). The certainty of evidence is low, downgraded twice: once due to risk of performance bias (lack of blinding of personnel) and once for imprecision (low number of events and wide confidence intervals).

The Defloor 2005 trial (262 participants, 11 nursing homes in Belgium) compared repositioning regimens of different frequencies (2-hourly and 3-hourly) and support surfaces (viscoelastic foam and standard institutional mattresses). There were no clear differences in the risk of PI between 2-hourly $(n=63)$ repositioning and 3-hourly ( $\mathrm{n}=58$ ) repositioning (RR $0.90,95 \% \mathrm{Cl} 0.69$ to 1.16 ). The certainty of evidence is very low due to high risk of bias, downgraded three times due to serious limitations in design (lack of blinding of outcome assessors and personnel and missing outcome data).

\section{Frequency of repositioning: 2-hourly versus 4-hourly}

We pooled three trials (1074 participants) comparing 2-hourly with 4-hourly repositioning (fixed-effect; $I^{2}=45 \%$, pooled RR 1.06, 95\% $\mathrm{Cl} 0.80$ to 1.41) (Bergstrom 2013; Defloor 2005; Manzano 2014). It is uncertain whether 2-hourly repositioning compared with 4hourly repositioning used in conjunction with any support surface increases or decreases the incidence of PI. The certainty of evidence is very low due to high risk of bias, downgraded twice for lack of blinding of nursing staff and missing data, and once for imprecision (low number of events) (Analysis 1.1) (Summary of findings 1)

The Bergstrom 2013 trial (967 participants, 27 nursing homes in the US and Canada) compared repositioning regimens using 2-hourly $(n=210)$ and 4-hourly $(n=198)$ frequencies, with all participants being nursed on high-density foam mattresses. There were no clear differences in the risk of $\mathrm{PI}$ between groups (RR $0.82,95 \% \mathrm{Cl} 0.32$ to 2.09).

The Defloor 2005 trial compared 2-hourly ( $n=63$ ) versus 4-hourly ( $n=66$ ) frequencies for PI (RR $1.36,95 \% \mathrm{Cl} 0.98$ to 1.89). While the point estimate suggests a $36 \%$ increase in PI for 4-hourly rotation compared with 2-hourly rotation, however the confidence intervals include the possibility of benefit as well as harm or no difference between groups.

The Manzano 2014 trial (329 participants, two ICUs in southern Spain) compared 2-hourly with 4-hourly repositioning frequencies, with all participants being nursed on alternating air-pressure mattresses. There was no clear difference in the number of participants who developed a PI between groups (RR $0.77,95 \% \mathrm{Cl}$ 0.42 to 1.39 ). 


\section{Frequency of repositioning: 3-hourly versus 4-hourly}

The Bergstrom 2013 trial compared repositioning regimens using 3-hourly ( $n=209)$, and 4-hourly $(n=198)$ frequencies, with all participants being nursed on high-density foam mattresses. There may be a reduction in $\mathrm{PI}$ incidence with 3-hourly compared with 4hourly repositioning ( $\mathrm{RR} 0.20,95 \% \mathrm{Cl} 0.04$ to 0.92 ). The certainty of evidence is low, downgraded twice: once due to risk of performance bias (lack of blinding of personnel) and once for imprecision (low number of events and wide confidence intervals).

\section{Other frequency comparisons}

The Defloor 2005 trial also compared the number of new PIs of any stage in participants being nursed on viscoelastic foam mattresses receiving 4-hourly $(n=66)$ repositioning compared with those receiving 6 -hourly $(n=63)$ repositioning. Although there was a reported $27 \%$ reduction associated with 4 -hourly repositioning (RR $0.73,95 \% \mathrm{Cl} 0.53$ to 1.02 ), the certainty of evidence is very low due to high risk of bias, downgraded three times due to serious limitations in design (lack of blinding of outcome assessors and personnel and missing outcome data) and imprecision (wide confidence intervals which include the possibility of harm as well as benefit and no effect).

The Pickham 2018 trial (1312 participants, two ICUs in the US) compared a 2-hourly turning regimen using a $20^{\circ}$ tilt with "standard care" (although standard care was not clearly defined). Participants in the intervention group developed fewer PIs compared to the control group (RR $0.28,95 \% \mathrm{Cl} 0.10$ to 0.75 ). The certainty of the evidence is moderate, downgraded once due to a lack of blinding of clinical personnel. This trial is not included in the 'Summary of findings' table because "standard care" was not defined, and comparisons had different repositioning frequencies to those included in this review.

\section{Secondary outcomes}

\section{Health-related quality of life}

No trial reported HRQoL.

\section{Procedural pain}

No trial reported procedural pain.

\section{Patient satisfaction}

No trial reported patient satisfaction.

\section{Cost}

Bergstrom 2013 included within-trial cost evaluations published by Paulden 2014 following the reporting of trial outcomes.

Paulden 2014 performed a cost-minimisation analysis comparing the costs of 3-hourly $(n=326)$ and 4-hourly $(n=295)$ repositioning to a 2-hourly $(n=321)$ repositioning schedule. The evaluation used data collected alongside the Bergstrom 2013 trial, which was undertaken in nursing home residents who were at moderate to high risk of developing a PI, recruited from 20 facilities in the US and 7 facilities in Canada. All trial participants used a high-density foam mattress. Costs were considered from the perspective of the Ontario Ministry of Health and Long-Term Care and included those associated with nursing time for repositioning and incontinent supplies. Nursing time was estimated from a small observational study undertaken alongside the trial and assumed that $20 \%$ of residents would require two nursing staff (costed as personal support workers) for each occasion of repositioning, with the remaining $80 \%$ requiring one staff member. Costs were reported in 2012 Canadian dollars. The cost of repositioning was estimated to be CAD 11.05 or CAD 16.74 lower per resident per day for the 3hourly or 4-hourly regimens, respectively, compared to the 2-hourly regimen. The estimates of economic benefit were driven mostly by the value of freed nursing time. The analysis assumed 2-, 3-, or 4-hourly repositioning was associated with a similar incidence of $\mathrm{PI}$, as no difference in incidence was observed between these strategies in the Bergstrom 2013 trial.

\section{Comparison 2: different positions for repositioning}

We included data from four trials with 495 participants in this comparison (Ghezeljeh 2017; Moore 2011; Young 2004; Zhou 2014). Moore 2011 and Young 2004 contributed data for the pooled analysis.

\section{Primary outcomes}

\section{Proportion of new pressure injuries of any stage}

$30^{\circ}$ tilt 3-hourly compared with $90^{\circ}$ tilt overnight

Based on the similarity in interventions, we pooled the results of two trials (Moore 2011; Young 2004).

Moore 2011 and Young 2004 compared the same tilts $\left(30^{\circ}\right.$ versus $\left.90^{\circ}\right)$ using similar repositioning frequencies. We therefore pooled the data from these two studies $\left(I^{2}=69 \%\right.$, random-effects model). Overall, there was no clear difference in the incidence of stage 1 or 2 $\mathrm{PI}$ (persistent erythema) between $30^{\circ}$ and $90^{\circ}$ tilts (pooled RR 0.62 , $95 \% \mathrm{Cl} 0.10$ to 3.97 ). The certainty of evidence is very low due to high risk of bias, downgraded twice for lack of blinding of nursing staff and missing data, and twice for very serious imprecision (low number of events and wide confidence intervals) (Analysis 2.1) (Summary of findings 2).

Moore 2011 (213 participants, 12 nursing homes in Ireland) examined the use of $30^{\circ}$ 3-hourly tilt (overnight) compared with repositioning 6-hourly $90^{\circ}$ tilt (overnight) in nursing home residents. The occurrence of $\mathrm{PI}$ (stages 1 and 2) was lower in the $30^{\circ}$ tilt group (RR $0.27,95 \% \mathrm{Cl} 0.08$ to 0.91 ) compared with the $90^{\circ}$ tilt group (Analysis 2.1).

Young 2004 (46 participants, one acute care hospital in Wales) compared similar tilt and repositioning regimens and found no differences between groups (RR $1.75,95 \% \mathrm{Cl} 0.33$ to 9.34).

\section{Other tilt regimens}

There were two other trials undertaken in ICU settings that included 236 participants, however their results could not be pooled due to the differences in tilt and repositioning regimens.

Ghezeljeh 2017 (120 participants, one ICU in Iran) compared the use of $30^{\circ}$ 2-hourly $\mathrm{HOB}$ tilt with a $45^{\circ}$ 2-hourly $\mathrm{HOB}$ tilt and "standard care" in a three-group randomised sample of 120 ICU patients receiving mechanical ventilation. All participants were repositioned 2-hourly, but the study authors did not define "standard care" relative to degree of tilt routinely used. Although these participants were assessed for PI for three consecutive days following ICU admission, this was not the primary outcome of the study (Characteristics of included studies). The authors reported that "the incidence of pressure ulcers in the groups was 
documented and compared together". For the outcome of PI, the authors stated that "none of the patients who were recruited in this study developed pressure ulcers ... none of the patients in the groups suffered from pressure ulcers after 3 days". The certainty of evidence is low, downgraded twice for lack of blinding of clinical personnel and outcome assessors.

Zhou 2014 (116 participants, one ICU in China) compared the effects of prone positioning versus supine positioning on the development of PI. The incidence of stage $1 \mathrm{PI}$ was higher in participants who were positioned prone (intervention group), whilst there was no clear difference in the risk of stage $2 \mathrm{PI}$ between the two groups $(P>0.05)$; however, the authors presented no actual data. They also reported that there were no stage 3 or $4 \mathrm{PIs}$ in either the intervention group or the control group. The certainty of evidence is low due to high risk of bias, downgraded twice for lack of blinding of clinical personnel and outcome assessors.

\section{Secondary outcomes}

\section{Health-related quality of life}

No trial reported HRQoL.

\section{Procedural pain}

No trial reported procedural pain.

\section{Patient satisfaction}

No trial reported patient satisfaction.

\section{Cost}

Moore 2011) included within-trial cost evaluations that were published following the reporting of trial outcomes (Moore 2013b).

Moore 2013b performed a cost-effectiveness analysis based on data derived from their c-RCT (Moore 2011), comparing 3-hourly repositioning using the $30^{\circ}$ tilt overnight $(n=99$, unadjusted for clustering) with standard care consisting of 6-hourly repositioning using the $90^{\circ}$ lateral rotation overnight ( $\mathrm{n}=114$, unadjusted for clustering), in participants recruited from 12 long-term aged-care facilities in Ireland. They compared the nursing time costs and incidence of PI development over the four-week trial period. Nurse time was calculated from information recorded in the clinical study indicating number of turns per patient, nurses per turn, and nurse time per turn. A unit cost of EUR 23.94 per nurse hour was then applied, based on the rate for a staff nurse scale point 8 in mid-2009. Effectiveness was measured as PI incidence (the primary outcome of the clinical trial), which would appear to be represented as the number of participants developing a new PI during the fourweek trial period. Moore 2013b also reported some data for the total cost of dressings for treating Pls that developed during the trial, but did not report a unit cost and did not include dressing costs in the incremental analysis. Moore 2013a estimated that implementing a $30^{\circ}$ tilt 3-hourly regimen instead of a $90^{\circ}$ tilt 6 hourly regimen (standard care) for the 588 (53.5\%) individuals who were completely immobile or had very limited mobility across the 12 study sites would be associated with an annual cost difference favouring the intervention of EUR 512,800, equivalent to 21,462 hours of nurse time.

\section{Incremental cost per event avoided}

The $30^{\circ}$ 3-hourly tilt positioning intervention was reported to be cost-saving in nurse time compared with standard care (mean nurse time cost per patient EUR 206.60 versus EUR 253.10, incremental difference EUR $-46.50,95 \% \mathrm{Cl}$ EUR -1.25 to EUR -74.60) (Moore 2013b). The intervention dominated the control in terms of costeffectiveness, since the trial also found the intervention to be more effective than the control. The lower nurse time cost for the intervention group despite the greater repositioning frequency was due to the lower time and reduced number of nurses required for each turn (Moore 2013b).

Given that the intervention dominated the control, it was unnecessary for Moore 2013b to estimate an incremental costeffectiveness ratio, although they did. There is some inconsistency in the reporting and interpretation of the incremental analysis made by Moore 2013b, leading to a lack of clarity in the paper around the estimated cost-effectiveness. The authors of Moore 2013b suggest their efficacy outcome in the incremental analysis as both "patient free of $\mathrm{PI}$ " and "PI avoided". The rationale for alternating between outcome measures of "patient free of $\mathrm{PI}$ " and "PI avoided" is unclear. Nevertheless, in this instance these outcome measures would appear to be equivalent since the number of patients developing a PI and the number of PIs developing during the trial was the same $(n=16)$ (Moore 2011). Moore 2013b reported the incremental cost per patient free of PI (EUR -73.40) and per PI avoided (EUR -547.00). Although not explicitly stated, the estimated incremental cost-effectiveness ratios appear to be intended to represent an incremental cost per additional incremental outcome. However, these values are inconsistent with each other, given that the incidence of PIs developing was the same in the trial (Moore 2011), regardless of whether defined as number of patients developing PI or number of PIs developing during the trial. Furthermore, neither of these values could be confirmed from the data provided in the main body of the Moore 2013b paper. The former value (EUR -73.40 per patient free of $\mathrm{PI}$ ) appears to have been incorrectly estimated from the data presented in the paper. The latter value of EUR -547 per (additional) PI avoided is consistent with the efficacy data presented in the abstract, but the efficacy data presented in the abstract are inconsistent with efficacy data presented in the main body of the report, and do not precisely match the efficacy data provided in the original clinical trial report (Moore 2011).

Despite this limitation in interpretation, the reported findings suggest that for every 100 patients treated with the 3-hourly repositioning intervention rather than standard care, EUR 4650 would be saved in nurse time costs and an additional 8 patients would avoid a PI. Moore 2013b concluded that repositioning every three hours using the $30^{\circ}$ tilt is less costly in terms of nursing time and more effective than standard care involving repositioning every six hours using the $90^{\circ}$ tilt.

The cost-minimisation analysis undertaken by Paulden 2014 explicitly assumes that the 2-, 3-, and 4-hourly repositioning strategies are equally effective in preventing $\mathrm{PI}$ for nursing home residents at moderate to high risk of PI who are using a high-density foam mattress, based on the findings of the Bergstrom 2013 trial. Their analysis therefore compares the costs of these strategies only.

\section{DISCUSSION}

See Summary of findings 1; Summary of findings 2 


\section{Summary of main results}

\section{Proportion of new pressure injuries of any stage}

We included eight trials and data from a total of 3941 participants in this review. The included studies either compared two or more repositioning frequencies or positioning regimens with standard care. Two studies included parallel cost-effectiveness analyses, which are included in this review.

Our GRADE assessment judged the certainty of the evidence for the effect of repositioning as of low or very low certainty for serious risk of bias related to lack of blinding (predominantly personnel) and imprecision due to small sample sizes/low number of events, missing data, or both. Consequently, evidence was insufficient to draw a reliable conclusion regarding whether more frequent repositioning (2-hourly versus 3-hourly; 4-hourly versus 6-hourly; 2hourly versus 4-hourly) or different positions (the $30^{\circ}$ tilt compared with the $90^{\circ}$ lateral position) are more effective in preventing PI.

It is noteworthy that in Defloor 2005, $46 \%$ of participants receiving 4-hourly repositioning and $62 \%$ of those receiving 6 -hourly repositioning developed a $\mathrm{PI}$, despite being nursed on viscoelastic foam mattresses. This suggests that although another Cochrane Review found that more advanced foam mattresses reduce $\mathrm{PI}$ incidence relative to the standard hospital mattress (McInnes 2011), high rates of $\mathrm{Pl}$ occurrence are still observed and careful monitoring of skin condition is required.

Repositioning regimens are widely used and recommended in bestpractice guidelines (NPUAP/EPUAP/PPPIA 2014), however there is limited empirical evidence of their effect on the prevention of PI. Whilst the theoretical rationale for repositioning (to reduce isolated tissue ischaemia by relieving pressure) makes physiological sense, the current evidence does not permit the drawing of conclusions with regard to the optimum position or frequency of repositioning.

\section{Overall completeness and applicability of evidence}

Overall, there were weaknesses in the completeness and applicability of evidence reported in the included studies. Six of the included trials were conducted in developed nations (Defloor 2005; Manzano 2014; Moore 2011; Young 2004). Five trials were conducted in acute care settings (ward and ICU) (Ghezeljeh 2017; Manzano 2014; Pickham 2018; Young 2004; Zhou 2014). This may limit the generalisability of findings to lower-income and non-acute care (or non-hospital) settings.

The eight studies included in this review had small sample sizes, which resulted in a lack of statistical power to detect treatment effects.

The primary study outcome reported in eight trials was the occurrence of PIs. None of the included trials examined outcomes such as participant pain, quality of life, or patient satisfaction. Only two trial authors performed a parallel economic substudy (Moore 2013b; Paulden 2014).

The focus of the interventions in the included studies varied. Three trials used tilts and 3-hourly overnight repositioning (Ghezeljeh 2017; Moore 2011; Young 2004), whilst another trial compared 2hourly turning using a $20^{\circ}$ tilt versus standard care (Pickham 2018). One trial used prone positioning and examined $\mathrm{PI}$ as a secondary outcome (Zhou 2014). Three other trials used various repositioning frequencies and positions in combination with different types of mattresses (Bergstrom 2013; Defloor 2005; Manzano 2014).

Another limitation was inconsistency in follow-up periods, which included 24 hours (Manzano 2014; Young 2004), 3 days (Ghezeljeh 2017; Pickham 2018; Zhou 2014), 21 days (Bergstrom 2013), and 28 days (Defloor 2005; Moore 2011).

The variation in the types of support surfaces used across the included trials limits generalisability. Inconsistencies in terminologies used to describe support surfaces added to this limitation. For instance, it is unclear whether a 'viscoelastic' mattress is similar to a 'high density foam' mattress. Furthermore, technological developments in mattress composition and materials, as well as bed design, have occurred over the 14 years during which these trials were undertaken, which also limits the external validity of these results, as other support surfaces are now in use.

\section{Quality of the evidence}

We used GRADE to appraise the quality of the body of evidence in relation to study limitations, inconsistency of results, indirectness, imprecision, and risk of bias, as specified in the Cochrane Handbook for Systematic Reviews of Interventions (Summary of findings 1; Summary of findings 2) (Schünemann 2017).

\section{Limitations in study design and implementation}

We assessed risk of bias according to six domains: sequence generation, allocation concealment, blinding, selective outcome reporting, incomplete follow-up, and other potential sources of bias. Our assessment of the risk of bias for several of these domains showed limitations in study design and implementation, which have been reported elsewhere in the review (Figure 3). We had particular concern where blinding of the intervention was difficult or impossible. Blinding of outcome assessors was a serious limitation in three trials (Defloor 2005; Ghezeljeh 2017; Moore 2011). We judged the certainty of the evidence across most of the included trials as low or very low. The certainty of evidence from the three trials that assessed the use of different repositioning frequencies is low or very low (Summary of findings 1) (Bergstrom 2013; Defloor 2005; Manzano 2014), downgraded due to low numbers of participants with consequent imprecision together with high risk of bias. The primary outcome, PI development, requires a subjective judgement regarding whether tissue damage has occurred (at least for stage $1 \mathrm{PI}$ ), and only three of the eight included studies used blinded outcome assessment (Bergstrom 2013; Manzano 2014; Young 2004).

The certainty of evidence from the two trials that compared $30^{\circ}$ tilt and $90^{\circ}$ tilt regimens is at high risk of bias due to a lack of allocation concealment and/or blinding of personnel and outcome assessors and serious imprecision of results (related to small sample size or wide $\mathrm{Cl}$, or both) (Summary of findings 2) (Moore 2011; Young 2004).

\section{Indirectness of evidence}

There was no indirectness as the participants, interventions, and outcomes in the included studies were within the scope of the published review protocol. 


\section{Unexplained heterogeneity or inconsistency of results}

Statistical heterogeneity was low to moderate for repositioning (Analysis 1.1). While we were unable to pool data from two studies (Bergstrom 2013; Defloor 2005) due to high statistical heterogeneity $\left(1^{2}=77 \%\right)$, we do not believe that this impacted results. In comparing the main outcome relative to tilt regimens, there was moderate statistical heterogeneity (Analysis 2.1). This is likely due to the inconsistency in follow-up periods, which varied from 24 hours to 21 days, the lack of definition around 'standard care', and the inconsistency in which interventions were delivered.

\section{Imprecision of results}

Imprecision was due to most studies being small and underpowered. Confidence intervals were wide, crossing 1 , indicating uncertainty about which repositioning regimen was the most effective. While some of the studies included in this review were quite large in terms of total number of participants (Bergstrom 2013; Pickham 2018), the numbers of events in these trials was lower than expected. This suggests that, in order to detect a difference between the interventions, larger samples may be required and this may not be practicable.

\section{Publication bias}

We believe that our comprehensive electronic searches have identified all existing, published RCTs addressing the review questions, thus limiting bias in the review process. That said, we identified five unpublished ongoing studies primarily through a search of clinical trial registries, and were unable to find any further information about them. Whilst the certainty of the body of evidence on repositioning regimens using various turning schedules and tilt angles is low to very low, we did not downgrade the evidence for publication bias. Given the small number of studies in this review and the lack of results from unpublished studies, we were unable to assess publication bias using funnel plots.

\section{Potential biases in the review process}

We considered all of the evidence that could be obtained in the review, and included one study that was not published in English (Zhou 2014). We followed clearly defined, prespecified procedures to prevent potential bias in the review process. We conducted a comprehensive and systematic literature search that was both transparent and reproducible. Notwithstanding, it is possible that we missed trials published in journals that were outside our search strategy.

Whilst we had intended to conduct a sensitivity analysis to test the robustness of the results to different assumptions about the outcomes of people who were lost to follow-up, we deemed this unnecessary due to the low volume and quality of the evidence and our consequent inability to draw any conclusions (no sensitivity analysis would have helped in this regard).

\section{Agreements and disagreements with other studies or reviews}

Our results are consistent with others' assessment of the evidence for frequencies of repositioning and repositioning positions (Chew 2017; Reddy 2006). The findings from a recently published scoping review by Chew 2017 concluded that the evidence for turning and repositioning schedules is inconclusive. An earlier systematic review by Reddy 2006 was published before six of our included trials, Bergstrom 2013; Ghezeljeh 2017; Manzano 2014; Moore 2011; Pickham 2018; Zhou 2014, were undertaken. The results of this earlier review suggested that the evidence around repositioning remains inconclusive, and the methodology for PIP trials suboptimal.

\section{AUTHORS' CONCLUSIONS}

\section{Implications for practice}

There is currently insufficient evidence to recommend one repositioning schedule/regimen in preference to another. Repositioning in some form is recommended in all clinical practice guidelines, though implementation is probably variable and highly dependent on the available resources (particularly staffing levels). It is noteworthy that more recent clinical practice guidelines no longer advocate repositioning patients every two hours (NPIAP 2019). The 2019 PI clinical practice guidelines recommend determining the patient's level of activity and their ability to reposition themselves, as this should guide health professionals' decision-making in terms of the frequency and amount of assistance they provide to patients in repositioning (NPIAP 2019).

To date, there is little evidence available from randomised controlled trials (RCTs) and cluster-randomised trials (c-RCTs) that addresses the question of whether repositioning patients reduces the risk of pressure injury (PI). The lack of evidence is a cause for concern considering that estimates of incidence of hospitalacquired pressure injuries range from less than 3\% to over $48 \%$ of patients (Mulligan 2011; NPIAP 2019; NPUAP/EPUAP/PPPIA 2014; Queensland Health 2017).

The aetiology of PI development is linked to localised vascular obstruction that reduces capillary blood flow to the skin surface area (NPUAP/EPUAP/PPPIA 2014). There are reasonable grounds to expect that repositioning hospitalised patients will thus minimise the risk of oxygen deprivation and nutrients that are required for tissue repair. However, the optimal frequency with which this should occur must consider the other negative effects of repositioning such as the potential for sleep disruption, heightened increases in patient pain perception, and, for nurses, musculoskeletal injuries.

\section{Implications for research}

There is a compelling need for appropriately powered, high-quality, multicentre trials to evaluate the clinical and cost effectiveness of repositioning regimens on the prevention of PIs. The modest sample sizes in the trials reviewed here is a major limitation. Larger numbers of participants are thus needed in future trials, particularly if cluster trials are conducted. Two of the three trials reviewed here were conducted in long-term care settings, therefore there is a need to use acute care settings to address the rise in prevalence of hospital-acquired pressure injuries (NPIAP 2019). Consistency in the measures used to classify PIs of any stage is essential. Given the high costs associated with the prevention and treatment of PIs, priority should be given to robust RCTs with economic evaluations. Trialists should consider comparisons of:

- repositioning frequencies and optimal positioning;

- use of manual repositioning regimens and electronic repositioning aids; 
- effects of repositioning in high-risk patient populations (e.g. spinal cord injury);

- effects of position sensors on repositioning regimens;

- use of pressure sensor technologies to map pressure in relation to different tilt angles during repositioning;

- use of repositioning monitors to calculate/quantify patient repositioning whilst in bed;

- economic costs (including incremental costs) of PIs; and

- economic and social impacts of PIs on patients' health-related quality of life (HRQoL) using valid and reliable HRQoL measures.

Good-quality trials also need to address the methodological limitations identified in the trials included in this review. Trialists must ensure transparency of research process and adhere to the CONSORT statement for reporting RCTs (CONSORT 2010). To minimise the sources of bias, trialists need to pay careful attention to elements of research design and execution with regard to allocation concealment, randomisation, blinding, and participant attrition (Polit 2010), such as having an observer who is blinded to the outcome perform the outcome assessment. If c-RCTs are used, trialists need to also consider the potential for bias in terms of selection bias, baseline comparability, analysis, and loss of clusters (Higgins 2011a).

\section{ACKNOWLEDGEMENTS}

The authors would like to thank the following referees who provided feedback on the first version of this review: Andrea Nelson, Giovanni Casazza, Zena Moore, and Carol Dealey; Devi Prasad Mohapatra, who commented on both the original review and this update; and Zhenmi Liu, who provided feedback on this update. They would also like to thank Elizabeth Royle for copy editing the original review and Lisa Winer for copy editing this update. 


\section{R E F E R E N C E S}

\section{References to studies included in this review}

Bergstrom 2013 \{published data only\}

Bergstrom N, Horn SD, Rapp MP, Stern A, Barrett R, Watkiss M. Turning for Ulcer ReductioN: a multisite randomised clinical trial in nursing homes. Journal of the American Geriatrics Society 2013; 61(20):1705-13.

\section{Defloor 2005 \{published data only\}}

Defloor T, De Bacquer D, Grypdonck MH. The effect of various combinations of turning and pressure reducing devices on the incidence of pressure ulcers. International Journal of Nursing Studies 2005; 42(1):37-46.

\section{Ghezeljeh 2017 \{published data only\}}

Ghezeljeh T, Kalhor L, Moghadam O, Lahiji M, Haghani H. The comparison of the effect of the head of bed elevation to 30 and 45 degrees on the incidence of ventilator associated pneumonia and the risk for pressure ulcers: a controlled randomised clinical trial. Iranian Red Cresecent Medical Journal 2017; 19(7):e14224.

\section{Manzano 2014 \{published data only\}}

Manzano F, Colmenero M, Pérez-Pérez AM, Roldán D, del Mar Jiménez-Quintana M, Mañas MR, et al. Comparison of two repositioning schedules for the prevention of pressure ulcers in patients on mechanical ventilation with alternating pressure air mattresses. Intensive Care Medicine 2014; 40(11):1679-87.

Moore 2011 \{published data only (unpublished sought but not used)\}

Moore Z, Cowman S, Conroy RM. A randomised controlled clinical trial of repositioning, using the $30^{\circ}$ tilt, for the prevention of pressure ulcers. Journal of Clinical Nursing 2011; 20(17-18):2633-44.

\section{Pickham 2018 \{published data only\}}

Pickham D, Berte N, Pihulic M, Valdex A, Mayer B, Sesai M. Effect of a wearable patient sensor on care delivery for preventing pressure injuries in acutely ill adults: a pragmatic randomised clinical trial (LS-HAPI study). International Journal of Nursing Studies 2018; 80:12-9.

\section{Young 2004 \{published data only\}}

Young T. The 30 degree tilt position vs the 90 degree lateral and supine positions in reducing the incidence of non-blanching erythema in a hospital inpatient population: a randomised controlled trial. Journal of Tissue Viability 2004; 14(3):88, 90, 92-6.

\section{Zhou 2014 \{published data only\}}

Zhou X, Dawei L, Zhang G, Cui N, He H, Zhao H, et al. Effect of prone position ventilation combined with lung recruitment on the prognosis of patients with severe acute respiratory distress syndrome. Chung-Hua Nei Ko Tsa Chih [Chinese Journal of Internal Medicine] 2014; 53(6):437-41.

\section{References to studies excluded from this review}

Beuret 2002 \{published data only\}

Beuret P, Carton MJ, Nourdine K, Kaaki M, Tramoni G, Ducreauz JC. Prone position as prevention of lung injury in comatose patients: a prospective, randomised, controlled study. Intensive Care Medicine 2002; 28:564-9.

Girard 2014 \{published data only\}

Girard R, Baboi L, Ayzac L, Richard JC, Guérin C, Proseva trial group. The impact of patient positioning on pressure ulcers inpatients with severe ARDS: results from a multicentre randomised controlled trial on prone positioning. Intensive Care Medicine 2014; 40(3):397-403.

Su 2015 \{published data only\}

Su MY, Lin SQ, Zhou YW, Liu SY, Lin A. A prospective, randomised, controlled study of a suspension positioning system used with elderly bedridden patients with neurogenic fecal incontinence. Ostomy Wound Management 2015; 61(1):30-9.

\section{Taccone 2009 \{published data only\}}

Taccone P, Pesenti A, Latini R, Polli F, Vagginelli F, Mietto C, et al, Prone-Supine II Study Group. Prone positioning in patients with moderate and severe acute respiratory distress syndrome: a randomised controlled trial. JAMA 2009; 302(18):1977-84.

Vanderwee 2007 \{published data only\}

Vanderwee K, Grypdonck MH, De Bacquer D, Defloor T. Effectiveness of turning with unequal time intervals on the incidence of pressure ulcer lesions. Journal of Advanced Nursing 2007; 57(1):59-68.

\section{Voggenreiter 2005 \{published data only\}}

Voggenreiter G, Aufmkolk M, Stiletto RJ, Baacke MG, Waydhas C, Ose $\mathrm{C}$, et al. Prone positioning improves oxygenation in posttraumatic lung injury: a prospective randomised trial. Journal of Trauma, Injury, Infection, and Critical Care 2005; 59:333-43.

\section{References to ongoing studies}

NCT02479425 \{published data only\}

. Two points versus three points turning in prevention of bed sores in critically ill patients. clinicaltrials.gov/ct2/show/ NCT02479425 (first received 24 June 2015).

NCT02690753 \{published data only\}

Pressure ulcer prevention: a turn and positioning system combined with incontinence care and tailored/standard repositioning. clinicaltrials.gov/ct2/show/NCT02690753 (first received 24 February 2016)

NCT02996331 \{published data only\}

. Preventing pressure ulcers with repositioning frequency and precipitating factors. clinicaltrials.gov/ct2/show/NCT02996331 (first received 19 December 2016). 


\section{NCT03048357 \{published data only\}}

. Effectiveness of freedom bed compared to manual turning in prevention of pressure injuries in persons with limited mobility due to traumatic brain injury and/or spinal cord injury. clinicaltrials.gov/ct2/show/NCT03048357 (first recieved 9 February 2016).

\section{NCT03454230 \{published data only\}}

. Pilot study for evaluation of the procedure impact of mobilization adapted to pressure ulcer risk for patients in intensive care (PROMES-REA). clinicaltrials.gov/ct2/show/ NCT03454230 (first received 5 March 2018).

\section{Additional references}

\section{Australian Institute of Health and Welfare 2009}

Australian Institute of Health and Welfare. Australian hospital statistics 2007-08. www.aihw.gov.au/reports/hospitals/ ahs-2007-08/contents/table-of-contents.

\section{Beeckman 2014}

Beeckman D, Van Lancker A, Van Hecke A, Verhaeghe S. A systematic review and meta-analysis of incontinenceassociated dermatitis, incontinence, and moisture as risk factors for pressure ulcer development. Research in Nursing \& Health 2014; 37(3):204-18.

\section{Beeckman 2016}

Beeckman D, Van Damme N, Schoonhoven L, Van Lancker A, Kottner J, Beele $\mathrm{H}$, et al. Interventions for preventing and treating incontinence-associated dermatitis in adults. Cochrane Database of Systematic Reviews 2016, Issue 11. [DOI: 10.1002/14651858.CD011627.pub2]

\section{Bennett 2004}

Bennett G, Dealey C, Posnett J. The cost of pressure ulcers in the UK. Age and Ageing 2004; 33(3):230-5.

\section{Bergstrom 2014}

Bergstrom N, Horn SD, Rapp MP, Stern A, Barrett R, Watkiss M, et al. Preventing pressure ulcers: a multisite randomised controlled trial in nursing homes. Ontario Health Technological Assessment Series 2014; 14(11):1-32.

\section{Braden 1987}

Braden BJ, Bergstrom N. A conceptual scheme for the study of the aetiology of pressure sores. Rehabilitation Nursing 1987; 12:8-16

\section{Braden 2005}

Braden BJ, Maklebust J. Preventing pressure ulcers with the Braden scale: an update on this easy-to-use tool that assesses a patient's risk. American Journal of Nursing 2005; 105(5):70-2.

\section{Bureau of Labor Statistics 2016}

United States Department of Labor. Case and demographic characteristics for work-related injuries and illnesses involving days away from work. Resource table 10: Detailed occupation by selected parts of body affected. www.bls.gov/iif/ oshcdnew2016.htm.

\section{Carskadon 2005}

Carskadon MA, Dement WC. Normal human sleep: an overview. In: Kryger MH, Roth T, Dement WC, editors(s). Principles and Practice of Sleep Medicine. 4th edition. Philadelphia (PA): Elsevier Sanders, 2005:13-23.

\section{Catania 2007}

Catania K, James P, Moran M. PUPPI: The pressure ulcer prevention protocol interventions. American Journal of Nursing 2007; 107(4):44-52.

\section{Chaboyer 2016}

Chaboyer W, Bucknall T, Webster J, McInnes E, Gillespie MB, Banks M, et al. The effect of a patient centred care bundle intervention on pressure ulcer incidence (INTACT): a cluster randomised trial. International Journal of Nursing Studies 2016; 64:63-71.

\section{Chew 2017}

Chew H-S J, Thiara E, Lopez V, Shorey S. Turning frequency in adult bedridden patients to prevent hospital-acquired pressure ulcer: a scoping review. International Wounds Journal 2017; 15(2):225-36. [DOI: 10.1111/iwj.12855]

\section{CONSORT 2010}

CONSORT Group. The CONSORT Statement. Consolidated Standards of Reporting Trials. www.consort-statement.org (accessed 15 October 2018).

\section{CRD 2013}

Centre for Reviews and Dissemination. NHS EED search filters. www.crd.york.ac.uk/crdweb/searchstrategies.asp (accessed prior to 20 February 2020).

\section{Cumming 2008}

Cumming RG, Sherrington C, Lord SR, Simpson JM, Vogler C, Cameron ID, et al, Prevention of Older People's Injury Falls Prevention in Hospitals Research Group. Cluster randomised trial of a targeted multifactorial intervention to prevent falls among older people in hospital. BMJ 2008; 336(7547):758-60.

\section{Dawson 2007}

Dawson A, McLennan S, Schiller S, Jull GA, Hodges PW, Stewart S. Interventions to prevent back pain and back injury in nurses: a systematic review. Occupational and Environmental Medicine 2007; 64:642-50.

\section{Deeks 2002}

Deeks J. Issues in the selection of a summary statistic for meta analysis of clinical trials with binary outcomes. Statistics in Medicine 2002; 21(1):575-600.

\section{Deeks 2011}

Deeks JJ, Higgins JP, Altman DG, . Chapter 9: Analysing data and undertaking meta-analyses. In: Higgins JP, Green S, editor(s). Cochrane Handbook for Systematic Reviews of Interventions Version 5.1.0 (updated March 2011). The Cochrane Collaboration, 2011. Available from handbook.cochrane.org. 


\section{EPUAP 1998}

European Pressure Ulcer Advisory Panel Guideline (EPUAP). A policy statement on the prevention of pressure ulcers from the European Pressure Ulcer Advisory Panel. British Journal of Nursing 1998; 7:888-90.

\section{EPUAP/NPUAP 2009}

European Pressure Ulcer Advisory Panel (EPUAP), National Pressure Ulcer Advisory Panel (NPUAP). Prevention and treatment of pressure ulcers: quick reference guide. www.epuap.org/wp-content/uploads/2016/10/ final_quick_prevention.pdf (accessed 15 October 2018).

\section{Exton-Smith 1961}

Exton-Smith AN, Sherwin RW. The prevention of pressure sores: significance of spontaneous bodily movements. Lancet 1961; 278(7212):1124-6.

\section{Gillespie 2014a}

Gillespie BM, Chaboyer WP, McInnes E, Kent B, Whitty JA, Thalib L. Repositioning for pressure ulcer prevention in adults. Cochrane Database of Systematic Reviews 2014, Issue 4. [DOI: 10.1002/14651858.CD009958.pub2]

\section{Higgins 2011a}

Higgins JP, Deeks JJ, Altman DG, . Chapter 16: Special topics in statistics. In: Higgins JP, Green S, editor(s). Cochrane Handbook for Systematic Reviews of Interventions Version 5.1.0 (updated March 2011). The Cochrane Collaboration, 2011. Available from handbook.cochrane.org.

\section{Higgins 2011b}

Higgins JP, Deeks JJ. Chapter 7: Selecting studies and collecting data. In: Higgins JP, Green S, editor(s). Cochrane Handbook for Systematic Reviews of Interventions Version 5.1.0 (updated March 2011). The Cochrane Collaboration, 2011. Available from handbook.cochrane.org.

\section{Higgins 2011c}

Higgins JP, Altman DG, . Chapter 8: Assessing risk of bias in included studies. In: Higgins JP, Green S, editor(s). Cochrane Handbook for Systematic Reviews of Interventions Version 5.1.0 (updated March 2011). The Cochrane Collaboration, 2011. Available from handbook.cochrane.org.

\section{Humphries 2008}

Humphries J. Sleep disruption in hospitalised adults. MedicalSurgical Nursing 2008; 17(6):391-5.

\section{Husereau 2013}

Husereau D, Drummond M, Petrou S, Carswell C, Moher D, Greenberg D, et al. Consolidated Health Economic Evaluation Reporting Standards (CHEERS) - explanation and elaboration: a report of the ISPOR health economic evaluation publication guidelines good reporting practices task force. Value in Health 2013; 16(2):231-50.

\section{Institute for Healthcare Improvement 2008}

Institute for Healthcare Improvement. Getting started kit: prevent pressure ulcers. www.in.gov/isdh/files/
IHI_PU_Getting_Started_Supplement_for_Rural_Hospitals.pdf (accessed 15 October 2018).

\section{Jalali 2005}

Jalali R, Rezaie M. Predicting pressure ulcer risk: comparing the predictive validity of 4 scales. Advances in Skin and Wound Care 2005; 18(2):92-7.

\section{Lefebvre 2011}

Lefebvre C, Manheimer E, Glanville J. Chapter 6: Searching for studies. In: Higgins JP, Green S, editor(s). Cochrane Handbook for Systematic Reviews of Interventions Version 5.1.0 (updated March 2011). The Cochrane Collaboration, 2011. Available from handbook.cochrane.org.

\section{Lindgren 2004}

Lindgren M, Unosson M, Fredrikson M, Ek AC. Immobility - a major risk factor for development of pressure ulcers among adult hospitalised patients: a prospective study. Scandinavian Journal of Caring Sciences 2004; 18(1):57-63.

\section{Manorama 2010}

Manorama AA, Baek S, Vorro J, Sikorskii A, Bush TR. Blood perfusion and transcutaneous oxygen level characterizations in human skin with changes in normal and shear loads implications for pressure ulcer formation. Clinical Biomechanics 2010; 25(8):823-8.

\section{McInnes 2011}

McInnes E, Dumville JC, Jammali-Blasi A, Bell-Syer SE. Support surfaces for treating pressure ulcers. Cochrane Database of Systematic Reviews 2011, Issue 12. [DOI: 10.1002/14651858.CD009490]

\section{McInnes 2015}

McInnes E, Jammali-Blasi A, Bell-Syer SE, Dumville JC, Middleton V, Cullum N. Support surfaces for pressure ulcer prevention. Cochrane Database of Systematic Reviews 2015, Issue 9. [DOI: 10.1002/14651858.CD001735.pub5]

\section{Moore 2013a}

Moore Z. Patient safety and pressure ulcers. European Wound Management Association Journal 2013; 13(1):63-4.

\section{Moore 2013b}

Moore Z, Cowman S, Posnett J. An economic analysis of repositioning for the prevention of pressure ulcers. Journal of Clinical Nursing 2013; 22(15-16):2354-60.

\section{Mulligan 2011}

Mulligan S, Prentice J, Scott L. WoundsWest Wound Prevalence Survey 2011 State-wide Overview Report. Ambulatory Care Services, Department of Health: Perth, Western Australia; $2011: 1-41$.

\section{Nguyen 2015}

, Chaboyer WP, Whitty JA. Pressure injury in Australian public hospitals: a cost-of-illness study. Australian Health Review 2015; 39(3):329-36. 


\section{NIH 2018}

US National Institutes of Health Research Portfolio Online Reporting Tools (RePORT). Project information: 1R01NR016001-01A1. projectreporter.nih.gov/project_info_details.cfm? aid $=9123086 \&$ icde $=41638195 \& i c d e=41638195$ (accessed 15 October 2018).

\section{Norton 1962}

Norton D, McLaren R, Exton-Smith AN. An Investigation of Geriatric Nursing Problems in Hospital. New York (NY): Churchill Livingstone, 1962.

\section{NPIAP 2019}

European Pressure Ulcer Advisory Panel, National Pressure Injury Advisory Panel and Pan Pacific Pressure Injury Alliance, . Prevention and treatment of pressure ulcers/injuries: clinical practice guideline. Available from www.internationalguideline.com 2019; Third edition:1-405.

\section{NPUAP 2007}

National Pressure Ulcer Advisory Panel. Pressure ulcer staging system. Available from www.npuap.org 2007.

\section{NPUAP 2016}

National Pressure Ulcer Advisory Panel (NPUAP). National Pressure Ulcer Advisory Panel (NPUAP) announces a change in terminology from pressure ulcer to pressure injury and updates the stages of pressure injury. Available from www.npuap.org/ national-pressure-ulcer-advisory-panel-npuap-announcesa-change-in-terminology-from-pressure-ulcer-to-pressureinjury-and-updates-the-stages-of-pressure-injury/ (accessed 15 October 2018)

\section{NPUAP/EPUAP/PPPIA 2014}

National Pressure Ulcer Advisory Panel (NPUAP), European Pressure Ulcer Advisory Panel (EPUAP), Pan Pacific Pressure Injury Alliance (PPPIA). Prevention and treatment of pressure ulcers: quick reference guide. Available from www.npuap.org/ wp-content/uploads/2014/08/Updated-10-16-14-QuickReference-Guide-DIGITAL-NPUAP-EPUAP-PPPIA-160ct2014.pdf (accessed 15 October 2018).

\section{Palmen 1987}

Palmen NG. Prevention of Pressure Sores in a General Hospital: a Study into the Effect of a Nursing Intervention Focusing on Pressure Sore Prevention [Masters thesis]. Maastricht, the Netherlands: Maastricht University, 1987.

\section{Paulden 2014}

Paulden M, Bergstrom N, Horn SD, Rapp MP, Barrett R, Watkiss M, et al. Turning for Ulcer Reduction (TURN) study: an economic analysis. Ontario Health Technology Assessment Series 2014; 14(12):1-24.

\section{Pickham 2016}

Pickham D, Ballew B, Ebong K, Shinn J, Lough ME, Mayer B. Evaluating optimal patient-turning procedures for reducing hospital-acquired pressure ulcers (LS-HAPU): study protocol for a randomized controlled trial. Trials 2016; 6(17):190. [DOI: 10.1186/s13063-016-1313-5]

\section{Polit 2010}

Polit D, Gillespie BM. Intention-to-treat in randomised controlled trials: recommendations for a total trial strategy. Research in Nursing \& Health 2010; 33(4):355-68.

\section{Queensland Health 2017}

Queensland Health. 2016 Queensland bedside audit: statewide inpatient report. Patient Safety and Quality Improvement Service, Clinical Excellence Division, Department of Health, Brisbane, Qld, Australia; February 2017 :1-163.

\section{Raymond 2004}

Raymond I, Ancoli-Israel S, Choiniere M. Sleep disturbances, pain and analgesia in adults hospitalised for burn injuries. Sleep Medicine 2004; 5(6):551-9.

\section{Reddy 2006}

Reddy M, Gill S, Rochon P. Preventing pressure ulcers: a systematic review. JAMA 2006; 296(8):974-84.

\section{Review Manager 2014 [Computer program]}

Nordic Cochrane Centre, The Cochrane Collaboration Review Manager 5 (RevMan 5). Version 5.3. Copenhagen: Nordic Cochrane Centre, The Cochrane Collaboration, 2014.

\section{Ryan 2016}

Ryan R, Hill S. How to GRADE the quality of the evidence. Cochrane Consumers and Communication Group. Version 3.0. cccrg.cochrane.org/author-resources (accessed prior to 20 February 2020).

\section{Safe Work Australia 2012}

. The costs of work-related injury and illness for Australian employers, workers and the community: 2008-9. www.safeworkaustralia.gov.au/system/files/documents/1702/ cost_of_work-related_injury_and_disease.pdf (accessed 15 October 2018).

\section{Schuurman 2009}

Schuurman JP, Schoonhoven L, Defloor T, Van Engelshoven I, Van Ramshorst B, Buskens E. Economic evaluation of pressure ulcer care: a cost minimization analysis of preventative strategies. Nurse Economics 2009; 27(6):390-400.

\section{Schünemann 2017}

Schünemann HJ, Oxman AD, Higgins JP, Vist GE, Glasziou P, Akl $E$, et al, on behalf of the Cochrane GRADEing Methods Group and the Cochrane Statistical Methods Group. Chapter 11: Completing 'Summary of findings' tables and grading the confidence in or quality of the evidence. In: Higgins JP, Churchill R, Chandler J, Cumpston MS (editors), Cochrane Handbook for Systematic Reviews of Interventions version 5.2.0 (updated June 2017). The Cochrane Collaboration, 2017. Available from www.training.cochrane.org/handbook.

\section{Schünemann 2011}

Schünemann HJ, Oxman AD, Vist GE, Higgins JP, Deeks JJ, Glasziou P, et al. Chapter 12: Interpreting results and drawing conclusions. In: Higgins JP, Green S, editor(s). Cochrane Handbook for Systematic Reviews of Interventions Version 
5.1.0 (updated March 2011). The Cochrane Collaboration, 2011. Available from handbook.cochrane.org.

\section{Shemilt 2010}

Shemilt I, Thomas J, Morciano M. A web-based tool for adjusting costs to a specific target currency and price year. Evidence and Policy 2010; 6(1):51-9.

\section{Shemilt 2011}

Shemilt I, Mugford M, Byford S, Drummond M, Eisenstein E, Knapp M. Chapter 15: Incorporating economics evidence. In: Higgins JP, Green S, editor(s). Cochrane Handbook for Systematic Reviews of Interventions Version 5.1.0 (updated March 2011). The Cochrane Collaboration, 2011. Available from handbook.cochrane.org.

\section{SIGN 2018}

Scottish Intercollegiate Guidelines Network. Search Filters. www.sign.ac.uk/search-filters.html (accessed 15 October 2018).

\section{Smith 1990}

Smith AM, Malone JA. Preventing pressure ulcers in institutionalised elders: assessing the effects of small, unscheduled shifts in body position. Decubitus 1990; 3(4):20-4.

\section{Sterne 2011}

Sterne JA, Egger M, Moher D, . Chapter 10: Addressing reporting biases. In: Higgins JP, Green S, editor(s). Cochrane Handbook for Systematic Reviews of Interventions Version 5.1.0 (updated March 2011). The Cochrane Collaboration, 2011. Available from handbook.cochrane.org.

\section{CHARACTERISTICS OF STUDIES}

Characteristics of included studies [ordered by study ID]

\section{Thompson 2005}

Thompson D. An evaluation of the Waterlow pressure ulcer riskassessment tool. British Journal of Nursing 1995; 14(8):455-9.

\section{Trinkoff 2001}

Trinkoff A, Storr C, Lipscomb J. Physically demanding work and inadequate sleep, pain, medication use and absenteeism in registered nurses. Journal of Occupational and Environmental Medicine 2001; 43(4):355-63.

\section{Vieira 2009}

Vieira E, Kumar S. Safety analysis of patient transfers and handling tasks. Quality and Safety in Health Care 2009; 18(5):380-4.

\section{Yap 2018}

Yap TL, Kennerly SM, Horn SD, Bergstrom N, Datta S, ColonEmeric C. TEAM-UP for quality: a cluster randomized controlled trial protocol focused on preventing pressure ulcers through repositioning frequency and precipitating factors. $B M C$ Geriatrics 2018; 18(1):54.

\section{References to other published versions of this review Gillespie 2014b}

Gillespie BM, Chaboyer WP, McInnes E, Kent B, Whitty JA, Thalib L. Repositioning for pressure ulcer prevention in adults. Cochrane Database of Systematic Reviews 2014, Issue 4. [DOI: 10.1002/14651858.CD009958.pub2]

Bergstrom 2013

\title{
Study characteristics
}

Methods

\author{
Study design: randomised clinical trial \\ Quote: "multisite randomised clinical trial" \\ Location: nursing homes in the United States $(n=20)$ and Canada $(n=7)$ \\ Ethics and informed consent: yes \\ Sample size calculation: a priori calculation used to calculate sample size. \\ Quote: "to estimate power and sample size, it was hypothesized that 3- or 4-hour repositioning would \\ be significantly and incrementally different from 2-hour repositioning if the combination of high-densi- \\ ty foam mattresses, repositioning, and documentation was not effective and if PrU incidence increased \\ from $4 \%$ or less to $8 \%$ or greater. Sample size needed to detect this change at a one-tailed alpha of 0.05 \\ and power of 0.80 was 900 participants in a per protocol analysis"
}

ITT analysis: per-protocol analysis used.

Quote: "25 participants who were allocated but did not receive the intervention because of death, hospitalisation, choice, or other reasons before beginning the study were not included in the final per protocol analysis" 
Bergstrom 2013 (Continued)

Participants
Mean ages: reported for females: 85.1 years \pm 7.7 years

Participants stratified according to PU risk: "participants were stratified according to risk level to determine whether moderate- and high-risk individuals have different repositioning requirements"

Total number of participants recruited: 967

Group A

Moderate risk 85.6 years \pm 7.8

High risk 84.8 years \pm 7.8

Group B

Moderate risk 84.3 years \pm 7.7

High risk 84.3 years \pm 7.8

Group C

Moderate risk 85.8 years \pm 7.4

High risk 85.2 years \pm 7.5

Inclusion criteria: nursing home residents either newly admitted ( $\leq 7$ days) or long-stay residents ( $\geq 90$ days); aged $\geq 65$ years; free of PIs; Braden scale either moderate (13 to 14) or high (11 to 12); limited mobility ( $\leq 3$ on Braden subscale of mobility).

Exclusion criteria: individuals deemed not competent to provide consent.

Interventions

$\operatorname{Aim}(\mathbf{s})$ : determine the effectiveness of 3 repositioning (turning) schedules (2-, 3-, 4-hourly) for prevention of $\mathrm{PI}$ in nursing home residents.

Group A: : repositioning every 2 hours $/ \pm 30$ minutes of scheduled time: $(n=335)$

Group B: ; repositioning every 3 hours $\$$ 30 minutes of scheduled time: $(n=333)$

Group C: ; repositioning every 4 hours $\$ 30$ minutes of scheduled time: $(n=299)$

Documentation (for all groups) of:

- each repositioning episode;

- time of repositioning;

- new position (right, left, back, chair);

- heel position (up, yes, no);

- skin condition (normal, red bruised, open);

- brief condition (wet, dry, soiled);

- skin care (washed, barrier cream, brief change).

Standard care across all groups: all groups repositioned on high-density foam mattresses.

Outcomes veloping a PI using the Braden scale as a risk assessment tool.

Primary outcome: "PrUs on sites susceptible to pressure when lying in bed (coccyx or sacrum, trochanter, heel) weekly. Stage 1 PrUs identified on 2 consecutive days excluded false positives caused by reactive hyperemia. The study continued for 3 weeks because $90 \%$ of PrUs developed in the first 3 weeks in a previous study"

Secondary outcomes: none reported.

Time points: weekly follow-up for 3 weeks ( 21 days). 
Bergstrom 2013 (Continued)

Notes 3-week study period (April 2008 to June 2011)

Conflicts of interest declared. Bergstrom is co-owner of Prevention plus website that promotes use of Braden scale.

Funding: funding received by 5 bodies (national and governmental bodies in the US and Canada). Role of funders stated.

\section{Risk of bias}

\begin{tabular}{lll}
\hline Bias & Authors' judgement & Support for judgement \\
\hline $\begin{array}{ll}\text { Random sequence genera- } \\
\text { tion (selection bias) }\end{array}$ & Low risk & $\begin{array}{l}\text { Evidence: "because sites varied in size, repositioning frequency was ran- } \\
\text { domised in blocks of } 6 \text { (two participants per repositioning schedule) to ensure } \\
\text { equal distribution of repositioning at each site, unlike previous studies ran- } \\
\text { domly selecting units" }\end{array}$ \\
\hline
\end{tabular}

\begin{tabular}{|c|c|c|}
\hline $\begin{array}{l}\text { Allocation concealment } \\
\text { (selection bias) }\end{array}$ & Low risk & $\begin{array}{l}\text { Evidence: "Each envelope contained another envelope with the concealed } \\
\text { repositioning frequency" }\end{array}$ \\
\hline
\end{tabular}

Comment: security of allocation concealment.

Blinding of participants High risk and personnel (performance bias)

All outcomes

\section{Evidence for participants: not blinded}

Comment: impossible to blind participants.

Evidence for personnel: "certified nursing assistants (CNAs) in the United States and personal support workers (PSWs) in Canada were trained to carry out the intervention: to turn and check briefs according to assigned schedule and to document position change, heel elevation, skin condition, briefs status, and incontinence care at each repositioning"

Comment: intervention nurses not blinded.

\begin{tabular}{|c|c|c|}
\hline $\begin{array}{l}\text { Blinding of outcome as- } \\
\text { sessment (detection bias) } \\
\text { All outcomes }\end{array}$ & Low risk & $\begin{array}{l}\text { Evidence for outcomes: "licensed nurses blinded to repositioning schedule } \\
\text { assessed the outcome, PrUs on sites susceptible to pressure when lying in bed }\end{array}$ \\
\hline
\end{tabular}

Comment: outcome assessor blinded to group allocation.

\begin{tabular}{|c|c|c|}
\hline $\begin{array}{l}\text { Incomplete outcome data } \\
\text { (attrition bias) } \\
\text { All outcomes }\end{array}$ & Unclear risk & $\begin{array}{l}\text { Evidence: " } 25 \text { participants who were allocated but did not receive the inter- } \\
\text { vention because of death, hospitalisation, choice, or other reasons before be- } \\
\text { ginning the study were not included in the final per protocol analysis" (flow } \\
\text { chart provided, p } 15 \text { of report, p } 1709 \text { of article) }\end{array}$ \\
\hline
\end{tabular}

Comment: per-protocol analysis done, not ITT.

\begin{tabular}{|c|c|c|}
\hline $\begin{array}{l}\text { Selective reporting (re- } \\
\text { porting bias) }\end{array}$ & Low risk & $\begin{array}{l}\text { Comment: clinical outcomes reported in Tables } 1 \text { and } 2 \text {. No protocol avail- } \\
\text { able. Measures reflect the aims of the intervention. }\end{array}$ \\
\hline
\end{tabular}

Other bias

Unclear risk

Evidence: "stage 1 PrUs identified on 2 consecutive days excluded false positives caused by reactive hyperemia. The study continued for 3 weeks because $90 \%$ of PrUs developed in the first 3 weeks in a previous study."

Funding statement COI statement provided.

Comment: difficult to understand how the outcome PI was ascertained because definitions were not supplied and the process of outcome assessment was not outlined. Follow-up period of 3 weeks, but patients' skin only inspected once weekly. Weekly risk and skin assessment of the outcome questions the accuracy of the results. 
Quote: "each ward applied the prevention scheme selected for a period of 4 weeks. The randomisation procedure was repeated for a second period of 4 weeks. During the second period each ward used a different prevention scheme than used in the first period"

Location: 32 wards across 11 nursing homes in Flanders, Belgium.

Ethics and informed consent: ethics approval and consent obtained.

\section{Sample size calculation: yes}

ITT analysis: participants analysed in the groups to which they were assigned, but data were incomplete for 24 participants, and they were not included in the analysis.

Quote: "the observations were incomplete in the case of 24 patients"

\section{Mean ages:}

Group A: 85.2 years \pm 7.2

Group B: 85.2 years \pm 6.2

Group C: 84.7 years \pm 7.7

Group D: 85.4 years \pm 7.3

Inclusion criteria: 838 people fulfilled inclusion criteria. Our review excludes participants from the usual care group, who received care that differed in terms of both support surface AND repositioning.

- Geriatric residents with a Braden score of $<17$ or a Norton score of $<12$

- Informed consent of the patient/family

- No PI at time of recruitment to study

Exclusion criteria: none stated, but total of 1114 people excluded.

$\operatorname{Aim}(\mathbf{s})$ : to investigate the effect of 4 different preventative regimens involving either frequent turning (2- to 3-hourly) or the use of a pressure-reducing mattress in combination with less frequent turning (4to 6-hourly).

Group A: 2-hourly turning regimen on standard mattress (65 randomised, 63 analysed)

Group B: 3-hourly turning regimen on standard mattress (65 randomised, 58 analysed)

Group C: 4-hourly turning regimen on viscoelastic polyurethane (pressure-relieving) mattress (67 randomised, 66 analysed)

Group D: 6-hourly turning regimen on viscoelastic polyurethane (pressure-relieving) mattress (65 randomised, 63 analysed)

Alternating turning positions: semi-Fowler's with feet elevated $30^{\circ}$ alternating with $30^{\circ}$ lateral rotation, pillow placement under back from shoulder on standard mattress.

Specified sitting position: experimental group sitting periods were recorded but not standardised; participants sat on thick air cushions. Backrest tilt on chair, legs on footrest, but heels not supported. Cushion for back. 
Defloor 2005 (Continued)

\section{Group 2 Control: $n=576$ participants}

Care given according to participant's level of risk; water mattresses, alternating mattresses, sheepskins and gel cushions; based on nurses' clinical judgement. No PI risk assessment tool used. We have excluded this group from our review since care was highly heterogeneous and differed systematically from the other groups in terms of BOTH the support surface provision policy AND the (absence of a) repositioning policy.

Study date(s): not stated

Outcomes

Primary outcome: incidence of a PI (any stage) during a 28-day period.

Secondary outcomes: unrelated to review outcomes.

Time points: twice weekly for 4 weeks (28 days).

Notes Not reported whether water mattresses, alternating mattresses, sheepskins and gel cushions were
used singly or in combination with each other.

Funding: not reported.

\section{Risk of bias}

Bias Authors' judgement Support for judgement

Random sequence genera- Low risk tion (selection bias)

Quote: "using computerised randomisation tables, the prevention schemes were randomly allocated to 32 wards (table 1 )"

Comment: randomisation also occurred over a second 4-week period, during which each ward used a different prevention scheme than used in the first 4week period.

Diagram of randomisation schedule included in the paper as a table.

\begin{tabular}{|c|c|c|}
\hline $\begin{array}{l}\text { Allocation concealment } \\
\text { (selection bias) }\end{array}$ & Unclear risk & $\begin{array}{l}\text { Quote: "a sealed envelope containing all the room numbers in a random or- } \\
\text { der was opened. The first } 5 \text { patients who satisfied the inclusion criteria were } \\
\text { included" }\end{array}$ \\
\hline
\end{tabular}

Quote: "labour intensive nature of some of the prevention schemes, the number of patients participating in the experimental groups was limited to 5 per ward"

Comment: concern that allocation not fully concealed.

\begin{tabular}{|c|c|c|}
\hline $\begin{array}{l}\text { Blinding of participants } \\
\text { and personnel (perfor- }\end{array}$ & High risk & $\begin{array}{l}\text { Quote: "it was impossible to blind the nurses for preventative care" } \\
\text { Comment: not blinded. }\end{array}$ \\
\hline
\end{tabular}

mance bias)

All outcomes

Blinding of outcome assessment (detection bias)

All outcomes
High risk dividual patients"

Quote: "the nurses were blinded for the Braden and Norton scores of their in-

Comment: impossible for nursing staff to be blinded due to the differences in the types and varieties of turning regimens.
Flow chart (figure 1, p 41) showed patient attrition across each of the 5 groups.

Quotes: "of the 838 included patients, 761 patients completed the 4-week study period ... the data on three patients were incomplete and it could not be guaranteed that the protocol was strictly followed. Those patients were excluded" 
Defloor 2005 (Continued)

Comment: ITT analysis not implemented.

Selective reporting (re- Low risk porting bias)
Comment: clinical outcomes were presented in Tables 2 and 3 of the paper. A published protocol was not available. Measures used reflect aims of the intervention and outcomes.

\begin{tabular}{lll}
\hline Other bias $\quad$ Low risk & None identified.
\end{tabular}

Ghezeljeh 2017

\title{
Study characteristics
}

Study design: 3-group randomised clinical trial
Quote: "this study was a 3 group controlled randomised clinical trial"
Location: "intensive care unit (ICU) in selected government hospitals in Tehran, Iran. These hospitals
included: Firoozgar, Rasoul-e Akram, and Haft-e Tir"

Ethics and informed consent: yes

\section{Sample size calculation: yes}

Quote: "the sample size was determined to include 35 patients in each group using a sampling formula with the consideration of 0.05 alpha, $80 \%$ beta, and $25 \%$ the effect size for the reduction of VAP according to the previous study (Schallom et al. 2015). The prevalence of VAP among Iranian patients was reported as 0.3 . Furthermore, considering a $10 \%$ probability of subject attrition, a total of 40 people were assigned into each group as the final sample size"

ITT analysis: all participants randomised were analysed, no LTF.

Evidence: PRISMA flow chart presented to show patient flow through the study.

Participants Total 120 participants

Inclusion criteria: 18 years or older, no history of VAP, hospitalised in ICU, undergoing mechanical ventilation support for 8 hours following hospitalisation, no spinal or unstable pelvic fractures.

Exclusion criteria: patient death, remaining in selected positions for less than 6 hours over the last 24 hours, and a history of $\mathrm{PI}$ with elevation of $\mathrm{HOB}$ to $45^{\circ}$.

\author{
Mean ages: \\ Group A: $30^{\circ}$ HOB tilt $(n=40) ; 64.76 \pm 18.35$ years \\ Group B: $45^{\circ}$ HOB tilt $(\mathrm{n}=40): 55.75 \pm 16.41$ years \\ Group C: routine position $(n=40): 64.02 \pm 20.24$ years
}

$\operatorname{Aim}(\mathbf{s})$ : the primary aim was to compare the effect $30^{\circ}$ and $45^{\circ} \mathrm{HOB}$ tilts on the incidence of VAP. Incidence of $\mathrm{PI}$ was a secondary outcome.

Group A: $30^{\circ}$ HOB tilt $(n=40)$

Participants of intervention group received interventions consisting of $\mathrm{HOB}$ elevation to $30^{\circ}$ for 3 consecutive days.

HOB elevation was measured using the goniometer and recorded by nurses in particular forms.

Changes in the patients' positions for performing nursing interventions were recorded and soon after the procedure, $\mathrm{HOB}$ was repositioned to $30^{\circ}$ as instructed. 
Ghezeljeh 2017 (Continued)

Group B: $45^{\circ} \mathrm{HOB}$ tilt $(\mathrm{n}=40)$

Participants of intervention group received interventions consisting of $\mathrm{HOB}$ elevation to $45^{\circ}$ for 3 consecutive days.

HOB elevation was measured using the goniometer and recorded by nurses in particular forms.

Changes in the patients' positions for performing nursing interventions were recorded and soon after the procedure, $\mathrm{HOB}$ was repositioned to $45^{\circ}$ as instructed.

Group C: routine position $(\mathrm{n}=40)$

Participants in the control group were in the routine position in the bed for 3 consecutive days.

In all 3 groups, the slope of the HOB was measured using a calibrated goniometer at each work shift by the nurse and documented in the particular form.

Standard care across all groups: various other interventions in relation to changing bed sheets, lifting patient rather than dragging, and 2-hourly position changes were performed for participants in all groups.

Evidence: "all 3 groups for the prevention of PI and VAP consisting of changing the position every 2hours, assessment of pressure areas during position changing, changing wet sheets, lifting the patient instead of shearing the patient on the bed, washing hands, rinsing with Chlorhexidine, and performing oral as well as tracheal suction when needed"

Outcomes Primary outcome: unrelated to review outcomes

Secondary outcomes: "the mean probability of pressure ulcer within 3 days of the analysis of variance test showed that there was no statistically significant difference in terms of the mean of the probability of pressure ulcers according to the Braden scale $(P=0.652)$. Furthermore, none of the patients in the groups suffered from pressure ulcers after 3 days"

Time points: participants followed through for 3 days and their skin checked 2-hourly.

Notes $\quad$ Funding: Iran University of Medical Sciences, Tehran, Iran

\section{Risk of bias}

\begin{tabular}{lll}
\hline Bias & Authors' judgement & Support for judgement \\
\hline $\begin{array}{l}\text { Random sequence genera- } \\
\text { tion (selection bias) }\end{array}$ & Low risk & $\begin{array}{l}\text { Evidence: "the random permuted block method was used. The patients were } \\
\text { divided into } 3 \text { groups as follows: a control group (routine position in the bed) } \\
\text { and intervention groups (HOB elevation } 30 \text { and } 45 \text { degrees). The eight permut- } \\
\text { ed blocks ..." }\end{array}$
\end{tabular}

\section{Allocation concealment Low risk} (selection bias)

Evidence: "various modes of allocation were written on cards and placed in sealed opaque envelopes in a box. Next, a staff nurse who was unaware of the groups' allocation methods was requested to choose envelopes and determine the allocation of patients into the groups. This was continued until the desired number of patients were chosen and allocated into the groups"

Comment: security of allocation concealment.

Blinding of participants High risk and personnel (performance bias)

All outcomes
Evidence for participants: "the patients in 2 intervention groups received interventions consisting of the HOB elevation to 30 and 45 degrees"

Comment: participants not blinded to group allocation.

Evidence for personnel: "before the intervention, the researcher explained the aim of the study as well as the method, how to measure the slope of the bed using a calibrated goniometer, methods for the prevention of pressure ulcers, and VAP to staff nurses in ICUs ... in all 3 groups, the slope of the HOB was 
measured using a calibrated goniometer at each work shift by the nurse and documented in the particular form. Changes in the patients' positions for performing nursing interventions were recorded and soon after the procedure, HOB was repositioned to 30 or 45 degrees as instructed"

Comment: nurses involved in the administering the intervention an so unable to be blinded to group allocation.

Blinding of outcome as- High risk sessment (detection bias) All outcomes
Evidence for outcomes: nurses were asked to play the role of research assistants

Comment: nurses involved in data collection of the outcome.
Incomplete outcome data Low risk (attrition bias)

All outcomes
Evidence: no recruited participants were excluded, hence no incomplete data

Comment: all participants randomised were analysed, no LTF
Selective reporting (re- Low risk porting bias)
Comments: clinical outcomes were presented in Table 1 of the paper. A published protocol was not available. Measures used reflect aims of the intervention and outcome.

Other bias Low risk None identified.

\section{Study characteristics}

Methods

Study design: randomised clinical trial using 2 groups

Quote: "a pragmatic, single-site, open label, parallel group randomised controlled trial (pressure ulcer prevention by repositioning associated with support surfaces"

Location: 2 mixed ICUs of a university hospital in southern Spain

Ethics and informed consent: yes

Sample size calculation: yes

Quote: "a sample size of 165 per group was estimated to provide $80 \%$ power at a 0.05 (two-sided) level of significance to detect an absolute risk reduction (ARR) of $10 \%$ in PU onset, assuming that PUs would develop in $17 \%$ of the control ( $4 \mathrm{~h}$ ) group, based on previous studies and our own data"

ITT analysis: modified ITT

Quote: "the primary analysis was performed according to a modified intention-to-treat principle (because a patient was excluded after randomisation), and no interim analysis was planned"

Group A: 62.1 years \pm 14.5

Group B: 61.1 years \pm 15.1

Inclusion criteria: all critically ill adults with no PI at ICU admission who received invasive mechanical ventilation for at least 24 hours between February 2009 and January 2011.

Exclusion criteria: pregnancy; < 18 years; not being on an APAM (due to lack of availability); weight greater than $140 \mathrm{~kg}$ or less than $45 \mathrm{~kg}$ (as per APAM specifications); refusal to consent; mechanical ventilation for more than 48 hours before enrolment in the study; and inclusion in a related trial. 
Interventions $\quad \operatorname{Aim}(\mathbf{s})$ : to compare the effectiveness of repositioning every 2 or 4 hours for preventing PI (stage 2 or greater) development in ICU patients under mechanical ventilation.

Secondary aims were to compare clinical outcomes in relation to motility, ICU and hospital length of stay, mechanical ventilation duration, adverse/safety events, and nursing workload.

Group A: 2-hourly repositioning $(\mathrm{n}=165)$

First, left side with $30^{\circ}$ tilt; second, supine with $30^{\circ}$ elevation of the head end and the foot end of the bed; third, right side with $30^{\circ}$ tilt. It was a systematic lateral turning every 2-hourly for the total duration of each period.

Group B: 4-hourly repositioning $(\mathrm{n}=164)$

First, left side with $30^{\circ}$ tilt; second, supine with $30^{\circ}$ elevation of the head end and the foot end of the bed; third, right side with $30^{\circ}$ tilt. It was a systematic lateral turning every 4-hourly for the total duration of each period.

Standard care across all groups: all participants had the same APAM. Standard sedation and analgesia consisted of fentanyl plus propofol or midazolam. The weaning protocol included the daily interruption of sedatives and spontaneous awakening trials.

Note: repositioning schedules could be interrupted in cases of haemodynamic or respiratory instability (see below) or by the decision of the attending physician or patient.

Outcomes Primary outcome: the occurrence of a new PI (at least stage 2) at any anatomic site between enrol-
ment in the study and ICU discharge.

Secondary outcomes: unrelated to review outcomes.

Time points: follow-up for 24 hours.

\begin{tabular}{lll}
\hline Bias & Authors' judgement & Support for judgement \\
\hline $\begin{array}{l}\text { Random sequence genera- } \\
\text { tion (selection bias) }\end{array}$ & Low risk & $\begin{array}{l}\text { Evidence: "eligible patients were randomly assigned (1:1 ratio) to groups for } \\
\text { turning every 2- or 4-hours. Randomization was done in blocks of } 6 \text { in order to } \\
\text { balance the number of patients in the two groups" }\end{array}$ \\
& & b
\end{tabular}

\begin{tabular}{ll}
\hline $\begin{array}{l}\text { Allocation concealment } \\
\text { (selection bias) }\end{array}$ & Low risk \\
opaque, sealed envelopes"
\end{tabular}
(selection bias) opaque, sealed envelopes"

Comment: security of allocation concealment.

\section{Blinding of participants High risk} and personnel (perfor-

mance bias)

All outcomes
Evidence for participants: trial design described as "open-label"

Comment: participants and family members not blinded to intervention.

Evidence for personnel: "a further limitation was the impossibility of blinding the nursing staff and the patients themselves to the turning schedule of the patients"

Comment: could not be blinded. 
Manzano 2014 (Continued)

Blinding of outcome as- Low risk sessment (detection bias)

All outcomes
Evidence for outcomes: "independent study monitors verified the source data in accordance with an established plan ... the five independent evaluators were blinded to allocation"

Comment: outcome assessors blinded to group allocation.

Evidence: "a modified ITT principle (because a patient withdrew consent after randomisation)"

Comment: flow diagram provided.
Incomplete outcome data Low risk (attrition bias)

All outcomes
Evidence: "the study was conducted according to a pre-experimental protocol, which is available as electronic supplementary material (ESM)"

Comment: primary, secondary, and safety outcomes reported in text and in Table 2. Protocol as supplementary file, trial registered on ClinicalTrials.gov NCT00847665.
Selective reporting (re- Low risk porting bias)
Comment: no COI declared.

Moore 2011

\section{Study characteristics}

Methods Study design: 2-arm cluster-RCT with a 4-week (28-day) follow-up period

Location: 12 long-term aged-care facilities (clusters) in Ireland

Ethics and informed consent: ethics approval and consent obtained

\section{Sample size calculation: yes}

ITT analysis: yes, all participants randomised were analysed

Mean age: not reported
Basticipants
Inclusion criteria:
- inpatient in a long-term geriatric facility
- over 65 years of age
- at risk of PI development using the activity and mobility components of Braden scale
- no PI at time of recruitment to study
- no medical condition that would preclude the use of repositioning
- consent

Exclusion criteria: patients with existing PI. Total of 57 patients excluded.

$\operatorname{Aim}(\mathbf{s})$ : to examine whether repositioning using $30^{\circ}$ tilt and 3-hourly repositioning reduces the incidence of PI compared with usual care.

Group 1: $30^{\circ}$ tilt ( $\mathrm{n}=99$ participants randomised, 99 analysed)

Repositioning by clinical staff using $30^{\circ}$ tilt at night (left side, back, right side, back) 3-hourly overnight (8 pm to $8 \mathrm{am}$ ). During the day, position changes occurred 2- to 3-hourly.

Group 2: Usual care ( $\mathrm{n}=114$ participants randomised, 99 analysed) 
Usual care consisted of repositioning by clinical staff every 6 hours using the $90^{\circ}$ tilt (left side, back, right side, back) overnight ( $8 \mathrm{pm}$ to $8 \mathrm{am}$ ). During the day, position changes occurred 2- to 3-hourly.

Co-interventions: participants in both groups nursed as per planned care regarding nutritional regimens, toileting, changing of incontinence pads, preparation for feeding, and pressure redistribution devices on chairs. Repositioned every 2 - to 3-hourly during the day.

\section{Outcomes}

Primary outcome: incidence of all PIs during a 28-day period.

Quote: "the EPUAP PI classification system, ranging from non-blanching erythema of intact skin to full scale tissue destruction" (Grades I to IV)

Quote: "a pressure ulcer was defined as localised areas of tissue damage caused to skin and underlying soft tissue caused by sustained mechanical loading and shearing forces"

\section{Secondary outcomes: unrelated to review outcomes}

- economic outcomes:

* mean daily nurse time for repositioning

* nurse time cost per patient

* cost of patient free of PI

* projected annual cost

Validity of measures: interrater reliability not reported, but quote: "the skin was then assessed by the assigned key staff member, the clinical manager, and the researcher. Agreement between assessors was reached by comparing patients' skin condition to images of the EPUAP grading system"

Time points: weekly follow-up over 4 weeks

Notes PI risk status on study entry not stated by group.

Imbalances in cluster size.

ICC used in analysis and reported in text, Kish design effect reported.

Funding: Health Research Board of Ireland Clinical Nursing \& Midwifery Research Fellowship.

\section{Risk of bias}

\begin{tabular}{lll}
\hline Bias & Authors' judgement & Support for judgement \\
\hline $\begin{array}{l}\text { Random sequence genera- } \\
\text { tion (selection bias) }\end{array}$ & Low risk & $\begin{array}{l}\text { Quote: "the clusters were the specific study sites }(n=12) \text { and these were ran- } \\
\text { domly allocated to either the intervention group or the control group ... the al- } \\
\text { location was generated by a statistician not directly involved with the study } \\
\text { and was determined using computerised randomisation" }\end{array}$
\end{tabular}

Allocation concealment Low risk
(selection bias)

Quote: "the allocation was generated by a statistician not directly involved (selection bias) with the study and was determined using computerised randomisation ... allocation concealment was achieved through use of distance randomisation, meaning that the statistician, not the researcher, controlled the randomisation sequence"

\begin{tabular}{lll}
\hline $\begin{array}{l}\text { Blinding of participants } \\
\text { and personnel (perfor- } \\
\text { mance bias) } \\
\text { All outcomes }\end{array}$ & High risk & $\begin{array}{l}\text { Quote: "the research design employed was ... open label, pragmatic" } \\
\text { Comment: impossible for participants and nurses to be blinded. }\end{array}$ \\
\hline $\begin{array}{l}\text { Blinding of outcome as- } \\
\text { sessment (detection bias) } \\
\text { All outcomes }\end{array}$ & High risk & $\begin{array}{l}\text { Quote: "the skin was then assessed by the assigned key staff member, the clin- } \\
\text { ical nurse manager and the researcher. Agreement between assessors was } \\
\text { achieved by comparing the participant's skin condition to the images on the } \\
\text { EPUAP classification system" }\end{array}$
\end{tabular}


Comment: not stated, but most likely impossible. In an effort to minimise this form of bias, several assessors were used, although interrater reliability data were not presented.

$\begin{array}{ll}\begin{array}{l}\text { Incomplete outcome data } \\ \text { (attrition bias) }\end{array} & \text { Low risk } \\ \text { (ITT) basis" }\end{array}$

All outcomes

Flow chart (Figure 3) showed patient attrition across the 2 groups; the same number of participants who were randomised were analysed.

Selective reporting (re- Low risk porting bias)
Comment: clinical outcome, development of PI was reported. A published protocol was not available. Measures used reflect aims of the intervention and outcome.

Other bias Unclear risk

- No table/data to show baseline comparisons for each group and whether PI risk was equivalent at study entry

- Economic data: the rationale for alternating between outcome measures of "patient free of ulcer" and "pressure ulcer avoided" is unclear. In this instance these outcome measures would appear to be equivalent since the number of participants developing an ulcer and the number of $\mathrm{PI}$ developing during the trial were the same $(n=16)$.

\section{Study characteristics}

Methods

Study design: pragmatic, investigator-initiated, open-label, single-site, randomised clinical trial

Location: 2 ICUs in a large academic medical centre in California, USA

Ethics and informed consent: no

Quote: "Ethics approval with a waiver of individual authorization was granted prior to study commencement. However, patients could exercise their right of refusal" ( $p$ 13)

\section{Power calculation: yes}

Quote: "2.5. Statistical analysis; We planned to enrol 1812 patients to provide $80 \%$ power to detect a 50\% difference in Hospital Acquired Pressure Injuries between study groups (Anon, 1992) (i.e. 5\% with HAPI in the control group vs. $2.5 \%$ with HAPI in the treatment group). Originally, one interim sample-size calibration was planned to be conducted by the principle investigator; to verify whether the study remained sufficiently powered. In data provided by the clinical team, the observed outcomes were less than expected and sample size recalculation demonstrated the need for the enrolment of many more thousands of patients per group ... it was determined that the additional costs and resources now necessary to complete the trial was prohibitive. The study team deemed the study to no longer be viable. The study was abandoned ... An error had been made" ( $p$ 14)

ITT analysis: yes

Quote: "23.3.4. Sensitivity analysis Primary and secondary outcomes were compared using a per-protocol analysis (Harmonisation ICo, 1998)" (p 16)

Comment: both ITT and per-protocol analyses used, flow chart illustrates numbers used in ITT and per-protocol analysis ( $p$ 15).

Participants

Consecutive adult patients admitted to 1 of 2 ICUs were included $(n=1564)$. Of the eligible participants, 1312 (intervention: $n=659$; control: $n=653$ ) underwent randomisation.

Inclusion criteria: critically ill medical, surgical, and trauma patients 


\section{Exclusion criteria:}

- patients less than 18 years of age

- patients with an issue preventing effective sensor adhesion (i.e. a sternal dressing) or known adhesive sensitivity

- acuity precluding participation

- patient refusal

252 excluded from study prior to recruitment.

\section{Reason:}

- not meeting inclusion criteria $(n=49)$

- reason not documented $(n=203)$

\section{Mean ages:}

Intervention group: 60 years (SD 17 years); control group: 60 years (SD 18 years)

Intervention group:

- female: $293 / 659(44 \%)$

- male: $366 / 659(56 \%)$

Control group:

- female: $301 / 653(46 \%)$

- male: $352 / 653(54 \%)$

Interventions

Aims: to assess the clinical effectiveness of a wearable patient sensor to improve care delivery and patient outcomes by increasing the total time with turning compliance and preventing pressure injuries in acutely ill patients.

\section{Experimental:}

- Optimal turning: all participants had a sensor applied. Participants in this arm received care from nurses who had access to a User Dashboard that provides visual advisories for patient turning, based on data obtained from a wearable patient sensor (Leaf Healthcare Inc).

- Turning regimen 2-hourly

\section{Control:}

- All participants had a sensor applied. Participants in this arm received care from nurses who DID NOT have access to a User Dashboard that provides visual advisories for patient turning. Instead, these participants received standard care practices, patient turning initiated by nurses as necessary.

- Turning regimen 2-hourly

Quote: "Minimum thresholds for turning were established based on best available evidence and expert opinion (Herrman et al., 1999; Anon, 2014). For this study these were: turning at minimum every two hours; a minimum turn angle of $20^{\circ}$; with at least 15 min of tissue depressurization - which was a dynamic target." ( $p$ 14)

Outcomes

Primary outcome: a hospital-acquired pressure injury.

Secondary outcomes: the total time with turning compliance.

Time points: first 72 hours in ventilator-dependent participants.

Notes

- Study period: September 2015 to January 2016

- Quote: "Minimum thresholds for turning were established based on best available evidence and expert opinion (Herrman et al., 1999; Anon, 2014). For this study these were: turning at minimum every two hours; a minimum turn angle of $20^{\circ}$; with at least 15 min of tissue depressurization- which was 
a dynamic target. For example, if a patient stayed on his/her newly turned side for half of the minimum expected depressurization time (e.g. seven and half minutes vs. fifteen minutes), then the timeto-next turn was proportionally adjusted (i.e., turn time would be reduced by $50 \%$, such that a turn would be required within one hour instead of two hours). This was performed continuously to achieve at least 15 min of cumulative tissue depressurization time every two hours." ( $p$ 14)

- Funding: "The funder had no role in clinical data collection, management, analysis and interpretation of the data; manuscript preparation and the decision to submit for publication." ( $p$ 18)

\section{Risk of bias}

\begin{tabular}{lll}
\hline Bias & Authors' judgement & Support for judgement \\
\hline $\begin{array}{l}\text { Random sequence genera- } \\
\text { tion (selection bias) }\end{array}$ & Low risk & $\begin{array}{l}\text { Quote: "Randomization was performed by the investigators....Permuted sizes } \\
\text { of blocks of two, four, and six were used to approximate equal sample sizes } \\
\text { for each stratum (ICU unit [A and B] and treating service team [medicine and } \\
\text { surgery])" (p 14) }\end{array}$
\end{tabular}

Comment: 86 participants excluded from study postrandomisation.

\begin{tabular}{ll}
\hline $\begin{array}{l}\text { Allocation concealment } \\
\text { (selection bias) }\end{array}$ & Quote: \\
& \\
& - "Concealment achieved using individual opaque envelopes...." ( $\mathrm{p}$ 14)
\end{tabular}

- "The engineer (Mike Pihulic) was blinded to group allocation"

Comment: allocation concealment achieved.

Blinding of participants High risk Participants

and personnel (perfor-

mance bias)

All outcomes
Quote: "All participants had a patient sensor was applied to the chest applied. Patients were blinded to group allocation" ( $p$ 14)

\section{Personnel}

\section{Quote:}

- "Nurses caring for patients in the treatment group would receive visual warnings if the patient was not turned in accordance with established protocols (i.e. turning frequency of two hours and $20^{\circ}$ turning threshold). Once turned the visual advisory would reset automatically and display the new time-tonext turn"

- "Clinicians were not blinded but were independent to the study team" ( $p$ 14)

Comment: blinding of staff not possible, whilst all participants regardless of group allocation were unaware of the link between the monitor and the turning regimens.
Blinding of outcome as- Low risk sessment (detection bias)

All outcomes

\section{Quote:}

- "Documentation and staging of pressure injuries was performed by the clinical team independent to the study. Any remarkable findings are documented and a daily report is generated for assessment within $24 \mathrm{~h}$ by an independent Certified Wound, Ostomy, and Continence Nurse; This person was independent of the study and blinded to group allocation." ( $p$ 14)

- "The engineer (Mike Pihulic) was blinded to clinical outcomes" ( $p$ 14)

\section{Comment:}

\section{Quote:}

- "Primary treatment efficacy was estimated based on an intention-to-treat analysis" (p 14) 
- "Post-randomisation exclusions.... After accounting for these changes exclusions and adjusting for cross-over 1226 subjects were included in the perprotocol analysis ( $n=671$ treatment, $n=555$ control)" ( $p 1)$

Comment: ITT and per-protocol analyses used.

Selective reporting (re- Low risk Comment: clinical outcomes presented in Table 2.
porting bias)

\begin{tabular}{lll}
\hline Other bias $\quad$ Unclear risk & Funding
\end{tabular}

Quote: "Co-funded by

1. Stanford Health Care, and

2. Leaf Healthcare, Inc." (p 18)

1 of the study researchers/journal author, Mike Pihulic, is employed by Leaf Healthcare Inc. To exclude potential for bias, the engineer (Mike Pihulic) was blinded to group allocation and clinical outcomes.

Comment: manufacturers of the sensor device co-sponsored the trial.

Young 2004

\section{Study characteristics}

Methods

Study design: RCT (groupings for allocation not reported) with a 24-hour follow-up period

Location: medical ward of an acute general hospital in Wales, UK

Ethics and informed consent: ethics approval and consent obtained

Sample size calculation: yes

ITT analysis: reported as ITT

Participants

\section{Mean age:}

Group 1: 70.1 years \pm 11.1

Group 2: 70.5 years \pm 14.7

Baseline data reported in relation to group comparisons for age, gender, weight, height, and Waterlow scale scores.

\section{Inclusion criteria:}

- elderly patients

- at risk of developing a PI using Waterlow score

- able to lie in $30^{\circ}$ tilt position

- given informed consent

- no existing PI

- Caucasian (understood to be white)

Exclusion criteria: not stated. 
Repositioning using $30^{\circ}$ tilt (left side, back, right side, back) 2- to 3-hourly overnight, 2- to 3-hourly during the day.

Sacrum and heels free from contact with support surface.

Group 2: (control); $\mathrm{n}=23$ participants randomised, 21 analysed

$90^{\circ}$ lateral and supine positions 2- to 3-hourly overnight, 2- to 3-hourly during the day.

Standard care across all groups: support mattress: low air loss mattress or alternating air pressure mattresses.

Study date(s): April to July 1999

\begin{tabular}{|c|c|c|}
\hline Outcomes & \multicolumn{2}{|c|}{$\begin{array}{l}\text { Primary outcome: incidence of non-blanchable erythema during a } 24 \text {-hour period. } \\
\text { Quote: "NBE was used as a definition for pressure damage." } \\
\text { Validity of measures: not reported } \\
\text { Time points: } 1 \text {, at } 24 \text { hours }\end{array}$} \\
\hline Notes & Funding: none declar & \\
\hline Risk of bias & & \\
\hline Bias & Authors' judgement & Support for judgement \\
\hline $\begin{array}{l}\text { Random sequence genera- } \\
\text { tion (selection bias) }\end{array}$ & Low risk & $\begin{array}{l}\text { Quote: "the randomisation was based on block allocation" } \\
\text { Comment: no mention of how the blocks were generated (i.e. computer or } \\
\text { random number table) or allocation ratio to each block, thus the process for } \\
\text { electing the blocks is unclear. }\end{array}$ \\
\hline
\end{tabular}

Allocation concealment Low risk (selection bias)

Quote: "specific intervention being selected by sequential opening of sealed opaque envelopes"

Quote: "the ward staff were then handed the sequentially numbered envelopes containing randomisation code and the researcher left the clinical area"

Comment: this trial used blocked randomisation with group assignments being revealed after recruitment, therefore there is the potential to be able to predict future assignments.

Security of allocation concealment.

\section{Blinding of participants High risk} and personnel (perfor-

mance bias)

All outcomes

Blinding of outcome as- Low risk sessment (detection bias)

All outcomes

Quote: "the next morning the researcher was unaware of which method of repositioning had been used, therefore masking the researcher to treatment allocation"

Comment: researcher blinded to treatment group.

Incomplete outcome data High risk
(attrition bias)
All outcomes

Quote: "a total of 7 patients had no post intervention data collected"

Quote: "Statistical comparisons were made on an intention-to-treat basis ... no post-intervention assessment of pressure damage was performed on any of these seven subjects" 
Young 2004 (Continued)

Comment: use of ITT stated, however participants were excluded from the analysis if they discontinued the intervention or were nursed on a foam mattress.

\begin{tabular}{ll}
\hline $\begin{array}{l}\text { Selective reporting (re- } \\
\text { porting bias) }\end{array}$ & Low risk \\
& $\begin{array}{l}\text { Comment: clinical outcome, development of PI, was reported. A published } \\
\text { protocol was not available. Measures used reflect aims of the intervention and } \\
\text { outcome. }\end{array}$
\end{tabular}

Other bias Low risk Comments: none identified.

Zhou 2014

\section{Study characteristics}

\begin{tabular}{ll}
\hline Methods & Study design: 2-armed RCT with a 28-day follow-up period \\
Location: 1 ICU in Beijing, China \\
Ethics and informed consent: ethics approval and consent obtained \\
Sample size calculation: yes \\
ITT analysis: not reported, although all participants randomised were included the analysis \\
\hline Participants & Unclear, details not available from translation \\
\hline
\end{tabular}

Aim(s): to examine the effects of prone positioning on the occurrence of PI (secondary outcome).
Group 1: (intervention); $\mathrm{n}=56$ participants
Prone position for 10 hours, alternating 4 to 6 hours supine, and then repositioned in the prone posi-
tion for another 10 hours.
Group 2: (control); $\mathrm{n}=60$ participants
Supine position with standard care.
Study date(s): July 2012 to July 2013

Outcomes Primary outcome(s): unrelated to review outcomes

Seocndary outcome(s): occurrence of PI

Timepoints: daily for up to 72 hours

\begin{tabular}{|c|c|c|}
\hline Notes & \multicolumn{2}{|c|}{$\begin{array}{l}\text { Comments: none identified } \\
\text { Funding: none declared }\end{array}$} \\
\hline \multicolumn{3}{|l|}{ Risk of bias } \\
\hline Bias & Authors' judgement & Support for judgement \\
\hline $\begin{array}{l}\text { Random sequence genera- } \\
\text { tion (selection bias) }\end{array}$ & Unclear risk & $\begin{array}{l}\text { Quote: "[a] randomisation table was used to randomise the patients to two } \\
\text { groups" }\end{array}$ \\
\hline & & $\begin{array}{l}\text { Comment: description of process, who and when participants were ran- } \\
\text { domised was not reported. }\end{array}$ \\
\hline
\end{tabular}


Zhou 2014 (Continued)

$\begin{aligned} & \text { Allocation concealment } \\ & \text { (selection bias) }\end{aligned} \quad$ Unclear risk Comment: description of process not reported.

\begin{tabular}{lll}
\hline $\begin{array}{l}\text { Blinding of participants } \\
\text { and personnel (perfor- }\end{array}$ & High risk & $\begin{array}{l}\text { Comment: description of process not reported, although impossible to blind } \\
\text { staff and participants given the nature of the intervention. }\end{array}$
\end{tabular}
mance bias)

All outcomes

Blinding of outcome as- Unclear risk Comment: not reported.

sessment (detection bias)

All outcomes

\begin{tabular}{lll}
\hline $\begin{array}{l}\text { Incomplete outcome data } \\
\text { (attrition bias) } \\
\text { All outcomes }\end{array}$ & Low risk & $\begin{array}{l}\text { Comment: all participants randomised were included in the analysis. No loss } \\
\text { to follow-up. }\end{array}$ \\
\hline $\begin{array}{l}\text { Selective reporting (re- } \\
\text { porting bias) }\end{array}$ & Low risk & $\begin{array}{l}\text { Comment: Pl incidence was not reported across the intervention and control } \\
\text { groups. }\end{array}$ \\
\hline Other bias & Low risk & Comment: funding not reported. \\
\hline
\end{tabular}

APAM: alternating air-pressure mattress

COI: conflict of interest

HOB: head-of-bed

ICC: intracluster correlation coefficient

ICU: intensive care unit

ITT: intention-to-treat analysis

LTF: loss to follow-up

MV: mechanical ventilation

NBE: non-blanchable erythema

PI: pressure injury

PU/PrU: pressure ulcer

RCT: randomised controlled trial

SD: standard deviation

VAP: ventilator-acquired pneumonia

Pickham 2018

Study characteristics

Methods

Study design: pragmatic, investigator-initiated, open-label, single-site, randomised clinical trial

Location: 2 ICUs in a large academic medical centre in California, USA

Ethics and informed consent: no

Quote: "Ethics approval with a waiver of individual authorization was granted prior to study commencement. However, patients could exercise their right of refusal" ( $p$ 13)

Power calculation: yes

Quote: "2.5. Statistical analysis; We planned to enrol 1812 patients to provide $80 \%$ power to detect a 50\% difference in Hospital Acquired Pressure Injuries between study groups (Anon, 1992) (i.e. 5\% with HAPI in the control group vs. $2.5 \%$ with HAPI in the treatment group). Originally, one interim sample-size calibration was planned to be conducted by the principle investigator; to verify whether the study remained sufficiently powered. In data provided by the clinical team, the observed outcomes were less than expected and sample size recalculation demonstrated the need for the enrolment of many more thousands of patients per group ... it was determined that the additional costs and re- 
sources now necessary to complete the trial was prohibitive. The study team deemed the study to no longer be viable. The study was abandoned ... An error had been made" ( $p$ 14)

ITT analysis: yes

Quote: "23.3.4. Sensitivity analysis Primary and secondary outcomes were compared using a per-protocol analysis (Harmonisation ICo, 1998)" (p 16)

Comment: both ITT and per-protocol analyses used, flow chart illustrates numbers used in ITT and per-protocol analysis (p 15).

Participants

Consecutive adult patients admitted to 1 of 2 ICUs were included $(n=1564)$. Of the eligible participants, 1312 (intervention: $n=659$; control: $n=653$ ) underwent randomisation.

Inclusion criteria: critically ill medical, surgical, and trauma patients

\section{Exclusion criteria:}

- patients less than 18 years of age

- patients with an issue preventing effective sensor adhesion (i.e. a sternal dressing) or known adhesive sensitivity

- acuity precluding participation

- patient refusal

252 excluded from study prior to recruitment.

\section{Reason:}

- not meeting inclusion criteria $(n=49)$

- reason not documented $(n=203)$

\section{Mean ages:}

Intervention group: 60 years (SD 17 years); control group: 60 years (SD 18 years)

Intervention group:

- female: $293 / 659(44 \%)$

- male: $366 / 659(56 \%)$

Control group:

- female: $301 / 653(46 \%)$

- male: $352 / 653(54 \%)$

Aims: to assess the clinical effectiveness of a wearable patient sensor to improve care delivery and patient outcomes by increasing the total time with turning compliance and preventing pressure injuries in acutely ill patients.

\section{Experimental:}

- Optimal turning: all participants had a sensor applied. Participants in this arm received care from nurses who had access to a User Dashboard that provides visual advisories for patient turning, based on data obtained from a wearable patient sensor (Leaf Healthcare Inc).

- Turning regimen 2-hourly

\section{Control:}

- All participants had a sensor applied. Participants in this arm received care from nurses who DID NOT have access to a User Dashboard that provides visual advisories for patient turning. Instead, these participants received standard care practices, patient turning initiated by nurses as necessary.

- Turning regimen 2-hourly 
Quote: "Minimum thresholds for turning were established based on best available evidence and expert opinion (Herrman et al., 1999; Anon, 2014). For this study these were: turning at minimum every two hours; a minimum turn angle of $20^{\circ}$; with at least 15 min of tissue depressurization - which was a dynamic target." ( $p$ 14)

Outcomes $\quad$ Primary outcome: a hospital-acquired pressure injury.
Secondary outcomes: the total time with turning compliance.

Time points: first 72 hours in ventilator-dependent participants.

- Study period: September 2015 to January 2016
- Quote: "Minimum thresholds for turning were established based on best available evidence and ex-
pert opinion (Herrman et al., $1999 ;$ Anon, 2014). For this study these were: turning at minimum every
two hours; a minimum turn angle of $20^{\circ} ;$ with at least 15 min of tissue depressurization- which was
a dynamic target. For example, if a patient stayed on his/her newly turned side for half of the mini-
mum expected depressurization time (e.g. seven and half minutes vs. fifteen minutes), then the time-
to-next turn was proportionally adjusted (i.e., turn time would be reduced by $50 \%$, such that a turn
would be required within one hour instead of two hours). This was performed continuously to achieve
at least 15 min of cumulative tissue depressurization time every two hours." (p 14)
- Funding: "The funder had no role in clinical data collection, management, analysis and interpretation
of the data; manuscript preparation and the decision to submit for publication." (p 18)

\section{Risk of bias}

Bias Authors' judgement Support for judgement

Random sequence genera- Low risk tion (selection bias)

Quote: "Randomization was performed by the investigators....Permuted sizes of blocks of two, four, and six were used to approximate equal sample sizes for each stratum (ICU unit [A and B] and treating service team [medicine and surgery])" (p 14)

Comment: 86 participants excluded from study postrandomisation.

$\begin{array}{ll}\begin{array}{l}\text { Allocation concealment } \\ \text { (selection bias) }\end{array} & \text { Quote: } \\ & \\ & \text { - "Concealment achieved using individual opaque envelopes...." ( } p \text { 14) }\end{array}$

Comment: allocation concealment achieved.

Blinding of participants and personnel (performance bias)

All outcomes
High risk

Participants

Quote: "All participants had a patient sensor was applied to the chest applied. Patients were blinded to group allocation" ( $p$ 14)

\section{Personnel}

\section{Quote:}

- "Nurses caring for patients in the treatment group would receive visual warnings if the patient was not turned in accordance with established protocols (i.e. turning frequency of two hours and $20^{\circ}$ turning threshold). Once turned the visual advisory would reset automatically and display the new time-tonext turn"

- "Clinicians were not blinded but were independent to the study team" ( $p$ 14)

Comment: blinding of staff not possible, whilst all participants regardless of group allocation were unaware of the link between the monitor and the turning regimens. 
Pickham 2018 (Continued) sessment (detection bias)

All outcomes

Low risk Quote:

- "Documentation and staging of pressure injuries was performed by the clinical team independent to the study. Any remarkable findings are documented and a daily report is generated for assessment within $24 \mathrm{~h}$ by an independent Certified Wound, Ostomy, and Continence Nurse; This person was independent of the study and blinded to group allocation." ( $p$ 14)

- "The engineer (Mike Pihulic) was blinded to clinical outcomes" ( $p$ 14)

\section{Comment:}

Incomplete outcome data Low risk (attrition bias)

All outcomes

\section{Quote:}

- "Primary treatment efficacy was estimated based on an intention-to-treat analysis" (p 14)

- "Post-randomisation exclusions.... After accounting for these changes exclusions and adjusting for cross-over 1226 subjects were included in the perprotocol analysis ( $n=671$ treatment, $n=555$ control)" ( $p 1)$

Comment: ITT and per-protocol analyses used.

Selective reporting (re- Low risk Comment: clinical outcomes presented in Table 2.

porting bias)

Other bias

Unclear risk

\section{Funding}

Quote: "Co-funded by

1. Stanford Health Care, and

2. Leaf Healthcare, Inc." (p 18)

1 of the study researchers/journal author, Mike Pihulic, is employed by Leaf Healthcare Inc. To exclude potential for bias, the engineer (Mike Pihulic) was blinded to group allocation and clinical outcomes.

Comment: manufacturers of the sensor device co-sponsored the trial.

Young 2004

\section{Study characteristics}

\section{Methods}

Study design: RCT (groupings for allocation not reported) with a 24-hour follow-up period

Location: medical ward of an acute general hospital in Wales, UK

Ethics and informed consent: ethics approval and consent obtained

Sample size calculation: yes

ITT analysis: reported as ITT

\section{Mean age:}

Group 1: 70.1 years \pm 11.1

Group 2: 70.5 years \pm 14.7

Baseline data reported in relation to group comparisons for age, gender, weight, height, and Waterlow scale scores. 
Young 2004 (Continued)

\section{Inclusion criteria:}

- elderly patients

- at risk of developing a PI using Waterlow score

- able to lie in $30^{\circ}$ tilt position

- given informed consent

- no existing PI

- Caucasian (understood to be white)

Exclusion criteria: not stated.

Interventions

Aim(s): to examine the effects of the $30^{\circ}$ tilt in reducing non-blanchable erythema.

Group 1: (intervention); $\mathrm{n}=23$ participants randomised, 18 analysed

Repositioning using $30^{\circ}$ tilt (left side, back, right side, back) 2- to 3-hourly overnight, 2- to 3-hourly during the day.

Sacrum and heels free from contact with support surface.

Group 2: (control); $\mathrm{n}=23$ participants randomised, 21 analysed

$90^{\circ}$ lateral and supine positions 2- to 3-hourly overnight, 2- to 3-hourly during the day.

Standard care across all groups: support mattress: low air loss mattress or alternating air pressure mattresses.

Study date(s): April to July 1999

Outcomes Primary outcome: incidence of non-blanchable erythema during a 24-hour period.

Quote: "NBE was used as a definition for pressure damage."

Validity of measures: not reported

Time points: 1 , at 24 hours

Notes Funding: none declared.

\section{Risk of bias}

\begin{tabular}{lll}
\hline Bias & Authors' judgement & Support for judgement \\
\hline $\begin{array}{l}\text { Random sequence genera- } \\
\text { tion (selection bias) }\end{array}$ & Low risk & Quote: "the randomisation was based on block allocation" \\
& $\begin{array}{l}\text { Comment: no mention of how the blocks were generated (i.e. computer or } \\
\text { random number table) or allocation ratio to each block, thus the process for } \\
\text { electing the blocks is unclear. }\end{array}$ \\
\hline
\end{tabular}

Allocation concealment Low risk (selection bias)
Quote: "specific intervention being selected by sequential opening of sealed opaque envelopes"

Quote: "the ward staff were then handed the sequentially numbered envelopes containing randomisation code and the researcher left the clinical area"

Comment: this trial used blocked randomisation with group assignments being revealed after recruitment, therefore there is the potential to be able to predict future assignments.

Security of allocation concealment. 
Young 2004 (Continued)

Blinding of participants High risk Comment: not stated. Impossible for nursing staff to be blinded given the difand personnel (perforferences between intervention and usual care. Difficult to conceal from particimance bias)

All outcomes pants and nursing staff once participants were randomised.

\section{Blinding of outcome as- Low risk} sessment (detection bias) All outcomes
Quote: "the next morning the researcher was unaware of which method of repositioning had been used, therefore masking the researcher to treatment allocation"

\section{Incomplete outcome data High risk (attrition bias)}

All outcomes

Comment: researcher blinded to treatment group.

Quote: "a total of 7 patients had no post intervention data collected"

Quote: "Statistical comparisons were made on an intention-to-treat basis ... no post-intervention assessment of pressure damage was performed on any of these seven subjects"

Comment: use of ITT stated, however participants were excluded from the analysis if they discontinued the intervention or were nursed on a foam mattress.

\begin{tabular}{|c|c|c|}
\hline $\begin{array}{l}\text { Selective reporting (re- } \\
\text { porting bias) }\end{array}$ & Low risk & $\begin{array}{l}\text { Comment: clinical outcome, development of } \mathrm{PI} \text {, was reported. A published } \\
\text { protocol was not available. Measures used reflect aims of the intervention and } \\
\text { outcome. }\end{array}$ \\
\hline
\end{tabular}

Other bias Low risk Comments: none identified.

\title{
Study characteristics
}

Methods

\author{
Study design: 2-armed RCT with a 28-day follow-up period \\ Location: 1 ICU in Beijing, China
}

Ethics and informed consent: ethics approval and consent obtained Sample size calculation: yes

ITT analysis: not reported, although all participants randomised were included the analysis

\begin{tabular}{|c|c|}
\hline Participants & Unclear, details not available from translation \\
\hline \multirow[t]{6}{*}{ Interventions } & $\operatorname{Aim}(\mathbf{s})$ : to examine the effects of prone positioning on the occurrence of PI (secondary outcome). \\
\hline & Group 1: (intervention); $\mathrm{n}=56$ participants \\
\hline & $\begin{array}{l}\text { Prone position for } 10 \text { hours, alternating } 4 \text { to } 6 \text { hours supine, and then repositioned in the prone posi- } \\
\text { tion for another } 10 \text { hours. }\end{array}$ \\
\hline & Group 2: (control); $\mathrm{n}=60$ participants \\
\hline & Supine position with standard care. \\
\hline & Study date(s): July 2012 to July 2013 \\
\hline \multirow[t]{2}{*}{ Outcomes } & Primary outcome(s): unrelated to review outcomes \\
\hline & Seocndary outcome(s): occurrence of PI \\
\hline
\end{tabular}


Zhou 2014 (Continued)

Timepoints: daily for up to 72 hours

$\begin{array}{ll}\text { Notes } & \text { Comments: none identified } \\ \text { Funding: } \text { none declared }\end{array}$

\section{Risk of bias}

\begin{tabular}{|c|c|c|}
\hline Bias & Authors' judgement & Support for judgement \\
\hline $\begin{array}{l}\text { Random sequence genera- } \\
\text { tion (selection bias) }\end{array}$ & Unclear risk & $\begin{array}{l}\text { Quote: "[a] randomisation table was used to randomise the patients to two } \\
\text { groups" }\end{array}$ \\
\hline & & $\begin{array}{l}\text { Comment: description of process, who and when participants were ran- } \\
\text { domised was not reported. }\end{array}$ \\
\hline $\begin{array}{l}\text { Allocation concealment } \\
\text { (selection bias) }\end{array}$ & Unclear risk & Comment: description of process not reported. \\
\hline $\begin{array}{l}\text { Blinding of participants } \\
\text { and personnel (perfor- } \\
\text { mance bias) } \\
\text { All outcomes }\end{array}$ & High risk & $\begin{array}{l}\text { Comment: description of process not reported, although impossible to blind } \\
\text { staff and participants given the nature of the intervention. }\end{array}$ \\
\hline $\begin{array}{l}\text { Blinding of outcome as- } \\
\text { sessment (detection bias) } \\
\text { All outcomes }\end{array}$ & Unclear risk & Comment: not reported. \\
\hline $\begin{array}{l}\text { Incomplete outcome data } \\
\text { (attrition bias) } \\
\text { All outcomes }\end{array}$ & Low risk & $\begin{array}{l}\text { Comment: all participants randomised were included in the analysis. No loss } \\
\text { to follow-up. }\end{array}$ \\
\hline $\begin{array}{l}\text { Selective reporting (re- } \\
\text { porting bias) }\end{array}$ & Low risk & $\begin{array}{l}\text { Comment: PI incidence was not reported across the intervention and control } \\
\text { groups. }\end{array}$ \\
\hline Other bias & Low risk & Comment: funding not reported. \\
\hline
\end{tabular}

APAM: alternating air-pressure mattress

COI: conflict of interest

HOB: head-of-bed

ICC: intracluster correlation coefficient

ICU: intensive care unit

ITT: intention-to-treat analysis

LTF: loss to follow-up

MV: mechanical ventilation

NBE: non-blanchable erythema

$\mathrm{PI}$ : pressure injury

PU/PrU: pressure ulcer

$\mathrm{RCT}$ : randomised controlled trial

SD: standard deviation

VAP: ventilator-acquired pneumonia

Characteristics of excluded studies [ordered by study ID]

Study Reason for exclusion

Beuret 2002

Inclusion/exclusion criteria: ICU patients with existing PI at baseline were also included in the randomisation. Results for participants with and without PI at baseline were not separated in the 


\begin{tabular}{|c|c|}
\hline Study & Reason for exclusion \\
\hline & $\begin{array}{l}\text { analysis, therefore it was not possible to undertake a subgroup analysis of those participants who } \\
\text { were PI-free at baseline. }\end{array}$ \\
\hline Girard 2014 & $\begin{array}{l}\text { Inclusion/exclusion criteria: ICU patients with existing PI at baseline were also included in the } \\
\text { randomisation. Results for participants with and without PI at baseline were not separated in the } \\
\text { analysis, therefore it was not possible to undertake subgroup analyses on those participants who } \\
\text { were PI-free at baseline. }\end{array}$ \\
\hline Su 2015 & $\begin{array}{l}\text { Intervention: use of a positioning device, "a suspension system" (i.e. orthopaedic traction), to po- } \\
\text { sition patients over a period of time, rather than a position or positioning schedule. }\end{array}$ \\
\hline Taccone 2009 & Outcome: PI occurrence not included or reported as a primary or secondary outcome. \\
\hline Voggenreiter 2005 & $\begin{array}{l}\text { Inclusion/exclusion criteria: ICU patients with existing PI at baseline were also included in the } \\
\text { randomisation. Results for participants with and without PI at baseline were not separated in the } \\
\text { analysis, therefore it was not possible to undertake subgroup analyses on those participants who } \\
\text { were PI-free at baseline. }\end{array}$ \\
\hline
\end{tabular}

ICU: intensive care unit

$\mathrm{Pl}$ : pressure injury

Characteristics of ongoing studies [ordered by study ID]

\section{NCT02479425}

\begin{tabular}{|c|c|}
\hline Study name & Two points versus three points turning in prevention of bed sores in critically ill patients \\
\hline Methods & Open-label RCT \\
\hline Participants & 150 ICU patients \\
\hline \multirow[t]{4}{*}{ Interventions } & $\begin{array}{l}\text { - Active comparator: } 3 \text { point turning patients nursed by the traditional repositioning ( } 2 \text { hours on } \\
\text { back, } 2 \text { hours on right, and } 2 \text { hours on left) }\end{array}$ \\
\hline & $\begin{array}{l}\text { - Procedure: patient positioning every } 2 \text { hours, either to standard (right, back, left sides) or only to } \\
\text { right and left sides }\end{array}$ \\
\hline & $\begin{array}{l}\text { - Experimental: } 2 \text { points turning patients nursed on the right and left side only in } 30^{\circ} \circ \text { avoiding } \\
\text { the back }\end{array}$ \\
\hline & $\begin{array}{l}\text { - Procedure: patient positioning every } 2 \text { hours, either to standard (right, back, left sides) or only to } \\
\text { right and left sides }\end{array}$ \\
\hline Outcomes & PI occurrence \\
\hline Starting date & May 2011 \\
\hline Contact information & Ahmed M El-Mehalawy, Faculty of Medicine, University of Alexandria. No contact details supplied. \\
\hline \multirow[t]{3}{*}{ Notes } & Country: Egypt \\
\hline & No funding reported. \\
\hline & Completed, no results available. \\
\hline
\end{tabular}




$\begin{array}{ll}\text { Study name } & \text { A turn and positioning system and standardized incontinence care combined with tailored repo- } \\ \text { sitioning versus a standard repositioning protocol for pressure ulcer prevention: a multicenter } \\ \text { prospective randomised controlled clinical trial and health economical analysis in a hospital set- } \\ \text { ting }\end{array}$

\begin{tabular}{ll}
\hline Methods & Open-label RCT \\
\hline Participants & 227 patients in university and general hospitals enrolled \\
\hline Interventions & Experimental: \\
- & Tailored repositioning + standardised incontinence care + turn and positioning system: a protocol \\
& tailored to individual risk factors will be applied to patients at risk. Comfort Shield barrier cream \\
& cloths will be used for incontinence care every morning and after each episode of incontinence. \\
& The Prevalon Turn and Position System 2.0 (Sage Products) will be used for turning and position- \\
& ing patients at risk when lying in bed. \\
- & Standard repositioning + standardised incontinence care + turn and positioning system: instead \\
& of developing and using a tailored pressure ulcer prevention protocol, participants will receive \\
standard care. Comfort Shield barrier cream cloths will be used for incontinence care every morn- \\
ing and after each episode of incontinence. The Prevalon Turn and Position System 2.0 (Sage Prod- \\
ucts) will be used for turning and positioning participants at risk when lying in bed.
\end{tabular}

Control:

- Usual care: instead of developing and using a tailored pressure ulcer prevention protocol, participants will receive standard care. Instead of using Comfort Shield barrier cream cloths, incontinence care will be administered using the standard procedure on the ward. Instead of using the turn and position system, participants will be turned according to the standard procedure on the ward.

\begin{tabular}{|c|c|}
\hline Outcomes & $\begin{array}{l}\text { Primary outcome } \\
\text { - Turning compliance of nurses within the trial period as assessed by the researcher (unannounced) } \\
\text { [time frame: within } 8 \text { days after the start of the study] } \\
\text { Secondary outcomes } \\
\text { - Turning angle [time frame: within } 8 \text { days after the start of the study] } \\
\text { - Sacrum free of pressure [time frame: within } 8 \text { days after the start of the study] } \\
\text { - Incidence of PI and incontinence-associated dermatitis [time frame: within } 8 \text { days after the start } \\
\text { of the study] } \\
\text { - Comfort and preferences of the caregiver [time frame: on baseline and at day } 8 \text { (the end of the } \\
\text { study)] } \\
\text { - Comfort and tolerance of the participant [time frame: at day } 8 \text { (the end of the study)] } \\
\text { - Cost-effectiveness of the prevention of PI [time frame: for the duration of the study ( } 8 \text { days)] }\end{array}$ \\
\hline Starting date & February 2016 \\
\hline Contact information & D Beeckman, University Ghent. No contact details supplied. \\
\hline Notes & $\begin{array}{l}\text { Country: Belgium } \\
\text { Associated publications: Beeckman 2014; Beeckman } 2016 \\
\text { No funding reported. }\end{array}$ \\
\hline
\end{tabular}


NCT02996331

\begin{tabular}{|c|c|}
\hline Study name & Preventing pressure ulcers with repositioning frequency and precipitating factors \\
\hline Methods & Cluster-RCT \\
\hline Participants & 1386 nursing home residents \\
\hline \multirow[t]{3}{*}{ Interventions } & $\begin{array}{l}\text { - 2-hour repositioning: current PI prevention protocols recommend repositioning moderate, high, } \\
\text { and severe risk residents a minimum of every } 2 \text { hours. }\end{array}$ \\
\hline & $\begin{array}{l}\text { 3-hour repositioning: it is expected that repositioning frequency can be extended for nursing } \\
\text { home residents who are at low, moderate, and high risk for PI development and on viscoelastic } \\
\text { high-density foam support surfaces without compromising PI incidence. This intervention will in- } \\
\text { clude a 3-hour repositioning interval. }\end{array}$ \\
\hline & $\begin{array}{l}\text { 4-hour repositioning: it is expected that repositioning frequency can be extended for nursing } \\
\text { home residents who are at low, moderate, and high risk for PI development and on viscoelastic } \\
\text { high-density foam support surfaces without compromising PI incidence. This intervention will in- } \\
\text { clude a 4-hour repositioning interval. }\end{array}$ \\
\hline
\end{tabular}

\section{Outcomes}

Primary outcome:

- Determine differences in PI incidence amongst nursing homes in study arms [time frame: 4 weeks].

Secondary outcomes:

- Determine how medical severity components, changes in clinically assessed risk level, repositioning schedule, and their interactions are associated with development of PI [time frame: 4 weeks].

- Evaluate cost-effectiveness of PI prevention intervention approach between nursing home groups repositioned at 2-, 3-, or 4-hour intervals [time frame: 4 weeks].

\begin{tabular}{ll}
\hline Starting date & May 2017 \\
\hline Contact information & T Yap, Duke University. No contact details supplied. \\
\hline Notes & Country: USA \\
& Associated publications: Yap 2018 \\
& Funding: NIH 2018 \\
\hline
\end{tabular}

\section{NCT03048357}

Study name

Effectiveness of freedom bed compared to manual turning in prevention of pressure injuries in persons with limited mobility due to traumatic brain injury and/or spinal cord injury

\begin{tabular}{ll}
\hline Methods & Open-label RCT \\
\hline Participants & 8 ventilator-dependent spinal cord injury patients \\
\hline Interventions & Intervention group: device: freedom bed \\
- Fully integrated lateral rotation bed system that automatically turns the patient to a specific angle & in degrees between from 15 to 25 with dwell times between 1 and 120 minutes. \\
Control group: other: standard hospital bed \\
- Caregiver turning patients to 1 side then the other every 2 hours for pressure relief over bony \\
prominences.
\end{tabular}


NCT03048357 (Continued)

Outcomes Incidence of pressure injury [time frame: 12 months]

\begin{tabular}{ll}
\hline Starting date & 1 Setember 2018 \\
\hline Contact information & Study co-ordinator: Lorraine McCallister, Director \\
& Northeast Center for Rehabilitation and Brain Injury \\
\hline Notes & \\
\hline
\end{tabular}

\section{NCT03454230}

\begin{tabular}{ll}
\hline Study name & $\begin{array}{l}\text { Pilot study for evaluation of the procedure impact of mobilization adapted to pressure ulcer risk for } \\
\text { patients in intensive care }\end{array}$
\end{tabular}

\begin{tabular}{|c|c|}
\hline Methods & Open-label RCT \\
\hline Participants & $60 \mathrm{ICU}$ patients \\
\hline Interventions & $\begin{array}{l}\text { Experimental: } \\
\text { - Applying repositioning schedule daily adapted to PI risk assessed with Braden scale. Then, the } \\
\text { nurse will apply oil for PI prevention and repositioning, the frequency which will be defined by } \\
\text { the Braden score. The positions will be the semi-Fowler } 30^{\circ}-30^{\circ} \text {, the half-sitting position with a } 45^{\circ} \\
\text { angle position and patient lying on their back with the head up with a } 30^{\circ} \text { angle for VAP prevention. } \\
\text { Control: } \\
\text { - PI prevention care is provided according to usual practice. Frequency and modality of positioning } \\
\text { applied to the patients are collected. }\end{array}$ \\
\hline Outcomes & $\begin{array}{l}\text { Primary outcome: } \\
\text { - Positioning schedule efficacy [time frame: } 28 \text { days] } \\
\text { Secondary outcomes: } \\
\text { - Caregivers' commitment to the standardised positioning schedule in adult ICU (1) [time frame: } \\
28 \text { days] } \\
\text { - Caregivers' commitment to the standardised positioning schedule in adult ICU (2) [time frame: } \\
28 \text { days] } \\
\text { - Nursing workload [time frame: } 28 \text { days] } \\
\text { - Clinical safety of the positioning schedule [time frame: } 28 \text { days] }\end{array}$ \\
\hline Starting date & March 2018 \\
\hline Contact information & $\begin{array}{l}\text { D Mehay, Service de réanimation médico-chirurgicale, Hôpital Tenon (AP-HP), Paris No contact de- } \\
\text { tails supplied. }\end{array}$ \\
\hline Notes & $\begin{array}{l}\text { Country: France } \\
\text { No funding reported. }\end{array}$ \\
\hline
\end{tabular}

ICU: intensive care unit

$\mathrm{PI}$ : pressure injury

$\mathrm{RCT}$ : randomised controlled trial

VAP: ventilator-acquired pneumonia

Repositioning for pressure injury prevention in adults (Review) 


\section{DATA AND ANALYSES}

Comparison 1. 2-hourly repositioning versus 4-hourly repositioning on any type of support surface

\begin{tabular}{lllll}
\hline Outcome or subgroup title & $\begin{array}{l}\text { No. of } \\
\text { studies }\end{array}$ & $\begin{array}{l}\text { No. of par- } \\
\text { ticipants }\end{array}$ & Statistical method & Effect size \\
\hline 1.1 Pressure injury occurrence (stage 1 to 4) & 3 & 1074 & Risk Ratio (M-H, Fixed, 95\% Cl) & $1.06[0.80,1.41]$ \\
\hline
\end{tabular}

Analysis 1.1. Comparison 1: 2-hourly repositioning versus 4-hourly repositioning on any type of support surface, Outcome 1: Pressure injury occurrence (stage 1 to 4)

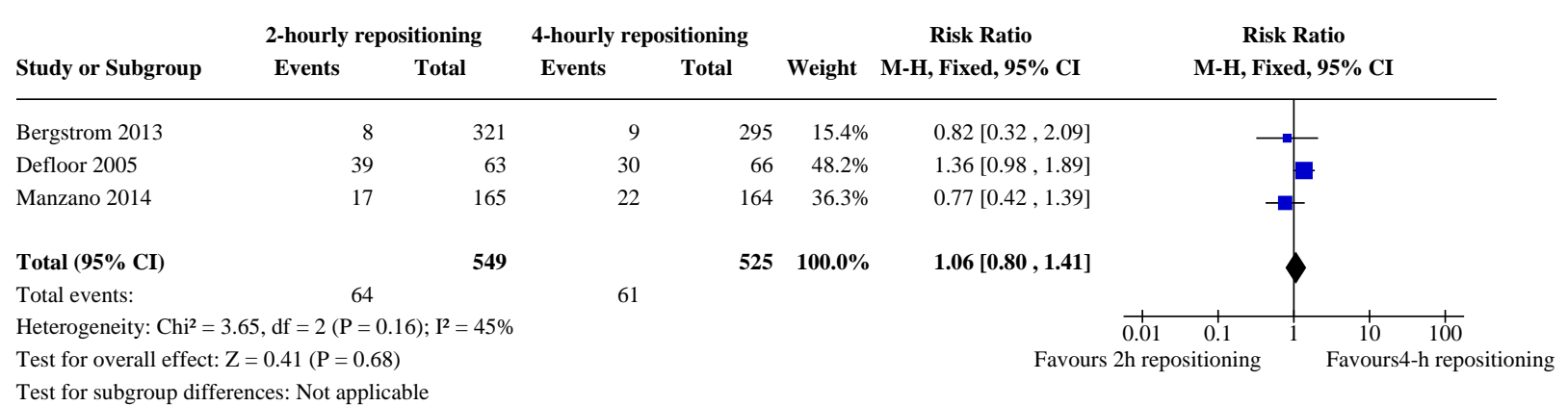

\section{Comparison 2. $30^{\circ}$ tilt 3-hourly overnight versus $90^{\circ}$ tilt overnight}

\begin{tabular}{llllll}
\hline Outcome or subgroup title & $\begin{array}{l}\text { No. of } \\
\text { studies }\end{array}$ & $\begin{array}{l}\text { No. of par- } \\
\text { ticipants }\end{array}$ & Statistical method & Effect size \\
\hline 2.1 Pressure injury occurrence (stage 1 to 4$)$ & 2 & 252 & Risk Ratio (M-H, Random, 95\% Cl) & $0.62[0.10,3.97]$ \\
\hline
\end{tabular}

Analysis 2.1. Comparison 2: $30^{\circ}$ tilt 3-hourly overnight versus $90^{\circ}$ tilt overnight, Outcome 1: Pressure injury occurrence (stage 1 to 4 )

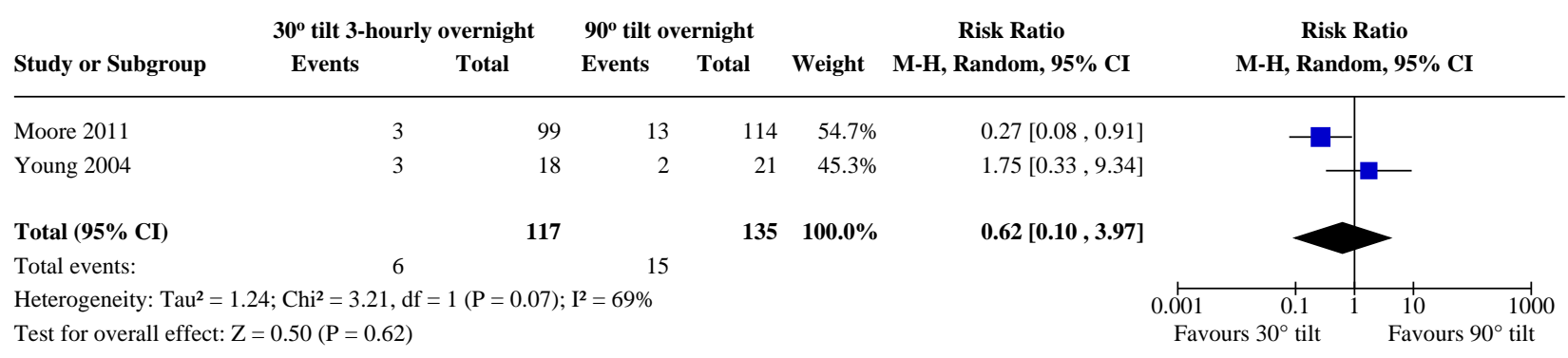




\section{AP PE N DICES}

\section{Appendix 1. 'Risk of bias' criteria}

\section{Was the allocation sequence adequately generated?}

\section{Low risk of bias}

The investigators describe a random component in the sequence generation process such as: referring to a random number table; using a computer random number generator; coin tossing; shuffling cards or envelopes; throwing dice; drawing of lots.

\section{High risk of bias}

The investigators describe a non-random component in the sequence generation process. Usually, the description would involve some systematic, non-random approach, for example: sequence generated by odd or even date of birth; sequence generated by some rule based on date (or day) of admission; sequence generated by some rule based on hospital or clinic record number.

\section{Unclear}

Insufficient information about the sequence generation process to permit judgement of low or high risk of bias.

\section{Was the treatment allocation adequately concealed?}

\section{Low risk of bias}

Participants and investigators enrolling participants could not foresee assignment because one of the following, or an equivalent method, was used to conceal allocation: central allocation (including telephone, web-based, and pharmacy-controlled randomisation); sequentially numbered drug containers of identical appearance; sequentially numbered, opaque, sealed envelopes.

\section{High risk of bias}

Participants or investigators enrolling participants could possibly foresee assignments and thus introduce selection bias, such as allocation based on: using an open random allocation schedule (e.g. a list of random numbers); assignment envelopes were used without appropriate safeguards (e.g. if envelopes were unsealed or non-opaque or not sequentially numbered); alternation or rotation; date of birth; case record number; any other explicitly unconcealed procedure.

\section{Unclear}

Insufficient information to permit judgement of low or high risk of bias. This is usually the case if the method of concealment is not described or not described in sufficient detail to allow a definitive judgement, for example if the use of assignment envelopes is described, but it remains unclear whether envelopes were sequentially numbered, opaque, and sealed.

\section{Blinding - was knowledge of the allocated interventions adequately prevented during the study?}

\section{Low risk of bias}

Any one of the following.

- No blinding, but the review authors judge that the outcome and the outcome measurement were not likely to be influenced by lack of blinding.

- Blinding of participants and key study personnel ensured, and unlikely that the blinding could have been broken.

- Either participants or some key study personnel were not blinded, but outcome assessment was blinded and the non-blinding of others unlikely to introduce bias.

\section{High risk of bias}

Any one of the following.

- No blinding or incomplete blinding, and the outcome or outcome measurement is likely to be influenced by lack of blinding.

- Blinding of key study participants and personnel attempted, but likely that the blinding could have been broken.

- Either participants or some key study personnel were not blinded, and the non-blinding of others likely to introduce bias.

\section{Unclear}

Either of the following.

- Insufficient information to permit judgement of low or high risk of bias.

- The study did not address this outcome. 


\section{Were incomplete outcome data adequately addressed?}

\section{Low risk of bias}

Any one of the following.

- No missing outcome data.

- Reasons for missing outcome data unlikely to be related to true outcome (for survival data, censoring unlikely to be introducing bias).

- Missing outcome data balanced in numbers across intervention groups, with similar reasons for missing data across groups.

- For dichotomous outcome data, the proportion of missing outcomes compared with observed event risk not enough to have a clinically relevant impact on the intervention effect estimate.

- For continuous outcome data, plausible effect size (difference in means or standardised difference in means) amongst missing outcomes not enough to have a clinically relevant impact on observed effect size.

- Missing data have been imputed using appropriate methods.

\section{High risk of bias}

Any one of the following.

- Reason for missing outcome data likely to be related to true outcome, with either imbalance in numbers or reasons for missing data across intervention groups.

- For dichotomous outcome data, the proportion of missing outcomes compared with observed event risk enough to induce clinically relevant bias in intervention effect estimate.

- For continuous outcome data, plausible effect size (difference in means or standardised difference in means) amongst missing outcomes enough to induce clinically relevant bias in observed effect size.

- 'As-treated' analysis done with substantial departure of the intervention received from that assigned at randomisation.

- Potentially inappropriate application of simple imputation.

\section{Unclear}

Either of the following.

- Insufficient reporting of attrition/exclusions to permit judgement of low or high risk of bias (e.g. number randomised not stated, no reasons for missing data provided).

- The study did not address this outcome.

\section{Are reports of the study free of suggestion of selective outcome reporting?}

\section{Low risk of bias}

Either of the following.

- The study protocol is available and all of the study's prespecified (primary and secondary) outcomes that are of interest in the review have been reported in the prespecified way.

- The study protocol is not available, but it is clear that the published reports include all expected outcomes, including those that were prespecified (convincing text of this nature may be uncommon).

\section{High risk of bias}

Any one of the following.

- Not all of the study's prespecified primary outcomes have been reported.

- One or more primary outcomes are reported using measurements, analysis methods, or subsets of the data (e.g. subscales) that were not prespecified.

- One or more reported primary outcomes were not prespecified (unless clear justification for their reporting is provided, such as an unexpected adverse effect).

- One or more outcomes of interest in the review are reported incompletely so that they cannot be entered in a meta-analysis.

- The study report fails to include results for a key outcome that would be expected to have been reported for such a study.

\section{Unclear}

Insufficient information to permit judgement of low or high risk of bias. It is likely that the majority of studies will fall into this category. 


\section{Other potential sources of bias}

\section{Low risk of bias}

The study appears to be free of other sources of bias.

\section{High risk of bias}

There is at least one important risk of bias. For example, the study:

- had a potential source of bias related to the specific study design used;

- has been claimed to have been fraudulent; or

- had some other problem.

\section{Unclear}

There may be a risk of bias, but there is either:

- insufficient information to assess whether an important risk of bias exists; or

- insufficient rationale or evidence that an identified problem will introduce bias.

\section{Appendix 2. Search strategies}

\section{Cochrane Wounds Specialised Register}

1 MESH DESCRIPTOR Pressure Ulcer EXPLODE ALL AND INREGISTER

2 (pressure next (ulcer* or sore $^{\star}$ or injur $\left.^{\star}\right)$ ) AND INREGISTER

3 (decubitus next (ulcer ${ }^{\star}$ or sore $\left.{ }^{\star}\right)$ ) AND INREGISTER

4 (bed next sore ${ }^{\star}$ ) or bedsore ${ }^{\star}$ AND INREGISTER

\section{5 \#1 OR \#2 OR \#3 OR \#4}

\section{MESH DESCRIPTOR Posture EXPLODE ALL AND INREGISTER}

7 MESH DESCRIPTOR Patient Positioning EXPLODE ALL AND INREGISTER

8 MESH DESCRIPTOR Moving and Lifting Patients EXPLODE ALL AND INREGISTER

9 (reposition* or re-position*) AND INREGISTER

10 position* AND INREGISTER

11 (turn* near5 patient*) AND INREGISTER

12 (turn* near5 interval*) AND INREGISTER

13 (turn* near5 frequen*) AND INREGISTER

14 (body near5 postur*) AND INREGISTER

15 turning AND INREGISTER

16 tilting AND INREGISTER

17 (lateral next tilt*) AND INREGISTER

18 (lateral next rotat $\left.{ }^{\star}\right)$ AND INREGISTER

19 (degree next tilt*) AND INREGISTER

20 (pressure next relie*) AND INREGISTER

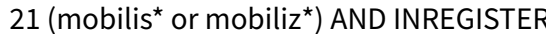

22 \#6 OR \#7 OR \#8 OR \#9 OR \#10 OR \#11 OR \#12 OR \#13 OR \#14 OR \#15 OR \#16 OR \#17 OR \#18 OR \#19 OR \#20 OR \#21 
23 \#5 AND \#22

The Cochrane Central Register of Controlled Clinical Trials (CENTRAL) and NHS Economic Evaluation Database (NHS EED)

\#1 MeSH descriptor: [Pressure Ulcer] explode all trees

\#2 pressure next (ulcer* or sore* or injur*):ti,ab,kw

\#3 decubitus next (ulcer* or sore*):ti,ab,kw

\#4 (bed next sore*) or bedsore*:ti,ab,kw

\#5 \#1 or \#2 or \#3 or \#4

\#6 MeSH descriptor: [Posture] explode all trees

\#7 MeSH descriptor: [Patient Positioning] explode all trees

\#8 MeSH descriptor: [Moving and Lifting Patients] explode all trees

\#9 (reposition* or re-position $\left.{ }^{\star}\right): t i, a b, k w$

\#10 position*:ti,ab,kw

\#11 (turn* near/5 patient $\left.{ }^{\star}\right): t i, a b, k w$

\#12 (turn $^{\star}$ near/5 interval ${ }^{\star}$ ):ti,ab,kw

\#13 (turn* near/5 frequen $\left.{ }^{\star}\right): t i, a b, k w$

\#14 (body near/5 postur $\left.{ }^{\star}\right): t i, a b, k w$

\#15 turning:ti,ab,kw

\#16 tilting:ti,ab,kw

\#17 (lateral next tilt*):ti,ab,kw

\#18 (lateral next rotat $\left.{ }^{\star}\right): t i, a b, k w$

\#19 (degree next tilt*):ti,ab,kw

\#20 (pressure next relie*):ti,ab,kw

\#21 (mobilis* or mobiliz $\left.{ }^{\star}\right):$ ti,ab,kw

$\# 22 \# 6$ or \#7 or \#8 or \#9 or \#10 or \#11 or \#12 or \#13 or \#14 or \#15 or \#16 or \#17 or \#18 or \#19 or \#20 or \#21

\#23 \#5 and \#22

\section{Ovid MEDLINE (RCT)}

1 exp Pressure Ulcer/

2 (pressure adj (ulcer ${ }^{\star}$ or sore or injur $\left.\left.^{\star}\right)\right) . t w$.

3 (decubitus adj (ulcer* or sore $\left.{ }^{\star}\right)$ ).tw.

4 (bedsore* $^{\star}$ or (bed adj sore $\left.\left.{ }^{\star}\right)\right) . t w$.

5 or $/ 1-4$

6 exp Posture/

7 exp Patient Positioning/

8 "Moving and Lifting Patients"/

9 (reposition* or re-position*).tw.

Repositioning for pressure injury prevention in adults (Review) 
10 position*.tw

11 (turn $^{\star}$ adj5 patient $\left.{ }^{\star}\right)$.tw.

$12\left(\right.$ turn $^{\star}$ adj5 interval $\left.{ }^{\star}\right)$. tw.

13 (turn* adj5 frequen*).tw.

14 (body adj5 posture*).tw.

15 turning.tw.

16 tilting.tw.

17 (lateral adj tilt*).tw.

18 (lateral adj rotat $\left.^{\star}\right)$. tw.

19 (degree adj tilt $\left.{ }^{\star}\right) . t w$.

20 pressure relie*.tw.

21 (mobilis $^{\star}$ or mobiliz*).tw.

22 or/6-21

235 and 22

24 randomized controlled trial.pt.

25 controlled clinical trial.pt.

26 randomi?ed.ab.

27 placebo.ab.

28 clinical trials as topic.sh.

29 randomly.ab.

30 trial.ti.

31 or $/ 24-30$

32 exp animals/ not humans.sh.

3331 not 32

3423 and 33

\section{Ovid MEDLINE (Health economics)}

1 exp Pressure Ulcer/

2 (pressure adj (ulcer ${ }^{\star}$ or sore ${ }^{\star}$ or injur $\left.^{\star}\right)$ ).tw.

3 (decubitus adj (ulcer* or sore $\left.{ }^{\star}\right)$ ).tw.

4 (bedsore ${ }^{\star}$ or (bed adj sore $\left.\left.{ }^{\star}\right)\right)$. tw.

5 or $/ 1-4$

6 exp Posture/

7 exp Patient Positioning/

8 exp Moving/ and Lifting Patients/

9 (reposition ${ }^{\star}$ or re-position*).tw.

Repositioning for pressure injury prevention in adults (Review) 
10 position*.tw

11 (turn $^{\star}$ adj5 patient $\left.{ }^{\star}\right)$.tw.

$12\left(\right.$ turn $^{\star}$ adj5 interval $\left.{ }^{\star}\right)$. tw.

13 (turn* adj5 frequen*).tw.

14 turning.tw.

15 tilting.tw.

16 (lateral adj tilt*).tw.

17 (lateral adj rotat $\left.{ }^{\star}\right)$. tw.

18 (degree adj tilt*).tw.

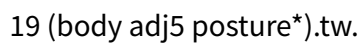

20 pressure relie*.tw.

21 (mobilis* or mobiliz*).tw.

22 or/6-21

235 and 22

24 economics/

25 exp "costs and cost analysis"/

26 economics, dental/

27 exp "economics, hospital"/

28 economics, medical/

29 economics, nursing/

30 economics, pharmaceutical/

31 (economic $^{\star}$ or cost or costs or costly or costing or price or prices or pricing or pharmacoeconomic ${ }^{\star}$ ).ti,ab.

32 (expenditure* not energy).ti,ab.

33 value for money.ti,ab.

34 budget $^{\star} . t i, a b$.

35 or $/ 24-34$

36 ((energy or oxygen) adj cost).ti,ab.

37 (metabolic adj cost).ti,ab.

38 ((energy or oxygen) adj expenditure).ti,ab.

39 or/36-38

4035 not 39

41 letter.pt.

42 editorial.pt.

43 historical article.pt.

44 or $/ 41-43$

Repositioning for pressure injury prevention in adults (Review) 
4540 not 44

46 Animals/

47 Humans/

$4846 \operatorname{not}(46$ and 47$)$

4945 not 48

\section{Ovid Embase (RCT)}

1 exp Decubitus/

2 (pressure adj (ulcer ${ }^{\star}$ or sore ${ }^{\star}$ or injur $\left.{ }^{\star}\right)$ ).tw.

3 (decubitus adj (ulcer ${ }^{\star}$ or sore $\left.{ }^{\star}\right)$ ).tw.

4 (bedsore ${ }^{\star}$ or (bed adj sore $\left.\left.{ }^{\star}\right)\right)$.tw.

5 or/1-4

6 exp patient positioning/

7 exp body position/

8 (reposition ${ }^{\star}$ or re-position $\left.{ }^{\star}\right)$.tw.

9 position*.tw.

10 (turn $^{\star}$ adj5 patient $\left.{ }^{\star}\right)$.tw.

11 (turn $^{\star}$ adj5 interval $\left.{ }^{\star}\right) . t w$.

12 (turn $^{\star}$ adj5 frequen $\left.{ }^{\star}\right)$.tw.

13 (body adj5 posture ${ }^{\star}$ ).tw.

14 turning.tw.

15 tilting.tw.

16 (lateral adj tilt*).tw.

17 (lateral adj rotat $\left.{ }^{\star}\right)$. tw.

18 (degree adj tilt*).tw.

19 (pressure adj relie ${ }^{\star}$ ).tw.

20 (mobilis $^{\star}$ or mobiliz ${ }^{\star}$ ).tw.

21 or $/ 6-20$

225 and 21

23 Randomized controlled trials/

24 Single-Blind Method/

25 Double-Blind Method/

26 Crossover Procedure/

27 (random $^{\star}$ or factorial ${ }^{\star}$ or crossover ${ }^{\star}$ or cross over $^{\star}$ or cross-over ${ }^{\star}$ or placebo* or assign $^{\star}$ or allocat ${ }^{\star}$ or volunteer $\left.{ }^{\star}\right)$.ti,ab.

28 (doubl $^{\star}$ adj blind $\left.{ }^{\star}\right) \cdot$ ti,ab.

29 (singl ${ }^{\star}$ adj blind $\left.{ }^{\star}\right) . t i, a b$.

Repositioning for pressure injury prevention in adults (Review) 
30 or $/ 23-29$

31 exp animals/ or exp invertebrate/ or animal experiment/ or animal model/ or animal tissue/ or animal cell/ or nonhuman/

32 human/ or human cell/

33 and/31-32

3431 not 33

3530 not 34

3622 and 35

\section{Ovid Embase (Health economics)}

1 exp Decubitus/

2 (pressure adj (ulcer ${ }^{\star}$ or sore ${ }^{\star}$ or injur $\left.\left.^{\star}\right)\right)$.tw.

3 (decubitus adj (ulcer ${ }^{\star}$ or sore $\left.{ }^{\star}\right)$ ).tw.

4 (bedsore* or (bed adj sore $\left.\left.{ }^{\star}\right)\right) . t w$.

5 or/1-4

6 exp patient positioning/

7 exp body position/

8 (reposition ${ }^{\star}$ or re-position*).tw.

9 position*.tw.

$10\left(\right.$ turn $^{\star}$ adj5 patient $\left.{ }^{\star}\right)$. tw.

11 (turn $^{\star}$ adj5 interval $\left.{ }^{\star}\right)$. tw.

$12\left(\right.$ turn $^{\star}$ adj5 frequen $\left.{ }^{\star}\right)$.tw.

13 (body adj5 posture*).tw.

14 turning.tw.

15 tilting.tw.

16 (lateral adj tilt $\left.{ }^{\star}\right) . t w$.

17 (lateral adj rotat $\left.{ }^{\star}\right)$.tw.

18 (degree adj tilt $\left.{ }^{\star}\right) . t w$.

19 (pressure adj relie $\left.{ }^{\star}\right) . t w$.

20 (mobilis $^{\star}$ or mobiliz*).tw.

21 or/6-20

225 and 21

23 health-economics/

24 exp economic-evaluation/

25 exp health-care-cost/

26 exp pharmacoeconomics/

27 or $/ 23-26$

Repositioning for pressure injury prevention in adults (Review) 
28 (econom* or cost or costs or costly or costing or price or prices or pricing or pharmacoeconomic $\left.{ }^{\star}\right)$.ti,ab.

29 (expenditure* not energy).ti,ab.

30 (value adj2 money).ti,ab.

31 budget $^{\star} . \mathrm{ti}, \mathrm{ab}$.

32 or $/ 28-31$

3327 or 32

34 letter.pt.

35 editorial.pt.

36 note.pt.

37 or $/ 34-36$

3833 not 37

39 (metabolic adj cost).ti,ab.

40 ((energy or oxygen) adj cost).ti,ab.

41 ((energy or oxygen) adj expenditure).ti,ab.

42 or/39-41

4338 not 42

44 exp animal/

45 exp animal-experiment/

46 nonhuman/

47 (rat or rats or mouse or mice or hamster or hamsters or animal or animals or dog or dogs or cat or cats or bovine or sheep).ti,ab,sh.

48 or $/ 44-47$

49 exp human/

50 exp human-experiment/

51 or/49-50

5248 not $(48$ and 51$)$

5343 not 52

5422 and 53

\section{EBSCO CINAHL Plus}

S37 S23 AND S36

S36 S24 OR S25 OR S26 OR S27 OR S28 OR S29 OR S30 OR S31 OR S32 OR S33 OR S34 OR S35

S35 TI allocat* random* or AB allocat* random*

S34 MH "Quantitative Studies"

S33 TI placebo* or AB placebo*

S32 MH "Placebos"

S31 TI random* ${ }^{\star}$ allocat* or AB random ${ }^{\star}$ allocat*

Repositioning for pressure injury prevention in adults (Review) 
S30 MH "Random Assignment"

S29 TI randomi?ed control* trial $^{\star}$ or $\mathrm{AB}$ randomi?ed control* trial $^{\star}$

S28 AB ( singl ${ }^{\star}$ or doubl ${ }^{\star}$ or trebl ${ }^{\star}$ or tripl ${ }^{\star}$ ) and AB ( blind $^{\star}$ or mask $^{\star}$ )

S27 TI ( singl ${ }^{*}$ or doubl* or trebl* or tripl ${ }^{*}$ ) and TI ( blind* or mask ${ }^{\star}$ )

S26 TI clinic* N1 trial $^{\star}$ or AB clinic* N1 trial ${ }^{\star}$

S25 PT Clinical trial

S24 MH "Clinical Trials+"

S23 S5 AND S22

S22 S6 OR S7 OR S8 OR S9 OR S10 OR S11 OR S12 OR S13 OR S14 OR S15 OR S16 OR S17 OR S18 OR S19 OR S20 OR S21

S21 TI ( (mobilis* or mobiliz*) ) OR AB ( (mobilis ${ }^{\star}$ or mobiliz $\left.{ }^{\star}\right)$ )

S20 TI (pressure relie*) OR AB (pressure relie*)

S19 TI (degree tilt ${ }^{\star}$ ) OR AB (degree tilt $\left.{ }^{\star}\right)$

S18 TI (lateral rotat $\left.{ }^{\star}\right)$ OR AB (lateral rotat*)

S17 TI (lateral tilt ${ }^{\star}$ ) OR AB (lateral tilt*)

S16 TI tilting OR AB tilting

S15 TI turning OR AB turning

S14 TI (body N5 postur ${ }^{\star}$ OR AB (body N5 postur ${ }^{\star}$ )

S13 TI (turn* N5 frequen*) OR AB (turn* N5 frequen*)

S12 TI (turn* N5 interval $\left.{ }^{\star}\right)$ OR AB (turn* N5 interval $\left.{ }^{\star}\right)$

S11 TI (turn* N5 patient $\left.{ }^{\star}\right)$ OR AB (turn* N5 patient*)

S10 TI position* OR AB position*

S9 $\mathrm{TI}$ ( reposition* or re-position* ) OR AB ( reposition* or re-position* )

S8 (MH "Patient Handling+")

S7 (MH "Patient Positioning+")

S6 (MH "Posture+")

S5 S1 OR S2 OR S3 OR S4

S4 TI ( bed sore* or bedsore* ) OR AB ( bed sore* or bedsore* )

S3 TI ( decubitus ulcer ${ }^{\star}$ or decubitus sore ${ }^{\star}$ ) OR AB ( decubitus ulcer* or decubitus sore $^{\star}$ )

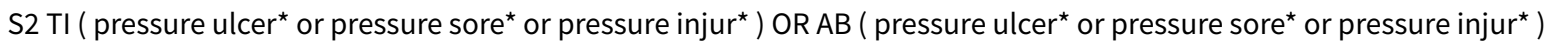

S1 (MH "Pressure Ulcer+")

\section{EBSCO CINAHL Plus (Health economics)}

S42 S23 AND S41

S41 S36 NOT S40

S40 S37 or S38 or S39

S39 PT commentary

Repositioning for pressure injury prevention in adults (Review) 
S38 PT letter

S37 PT editorial

S36 S34 OR S35

S35 TI (cost or costs or economic or pharmacoeconomic $^{\star}$ or price* or pricing ${ }^{\star}$ ) OR AB (cost or costs or economic or pharmacoeconomic $^{\star}$ or price or pricing $^{\star}$ )

S34 S30 OR S33

S33 S31 OR S32

S32 MH "Health Resource Utilization"

S31 MH "Health Resource Allocation"

S30 S24 NOT S29

S29 S25 OR S26 or S27 OR S28

S28 MH "Business+"

S27 MH "Financing, Organized+"

S26 MH "Financial Support+"

S25 MH "Financial Management+"

S24 MH "Economics+"

S23 S5 AND S22

S22 S6 OR S7 OR S8 OR S9 OR S10 OR S11 OR S12 OR S13 OR S14 OR S15 OR S16 OR S17 OR S18 OR S19 OR S20 OR S21

S21 TI ( (mobilis* or mobiliz*) ) OR AB ( (mobilis* or mobiliz*))

S20 TI (pressure relie*) OR AB (pressure relie*)

S19 TI (degree tilt*) OR AB (degree tilt $\left.{ }^{\star}\right)$

S18 TI (lateral rotat*) OR AB (lateral rotat*)

S17 TI (lateral tilt*) OR AB (lateral tilt*)

S16 TI tilting OR AB tilting

S15 TI turning OR AB turning

S14 TI (body N5 postur ${ }^{\star}$ ) OR AB (body N5 postur ${ }^{\star}$ )

S13 TI (turn* N5 frequen*) OR AB (turn* N5 frequen*)

S12 TI (turn* N5 interval $\left.{ }^{\star}\right)$ OR AB (turn* N5 interval $\left.{ }^{\star}\right)$

S11 TI (turn* N5 patient ${ }^{\star}$ ) OR AB (turn* N5 patient*)

S10 TI position* OR AB position*

S9 TI ( reposition* or re-position* ) OR AB ( reposition* or re-position* )

S8 (MH "Patient Handling+")

S7 (MH "Patient Positioning+")

S6 (MH "Posture+")

S5 S1 OR S2 OR S3 OR S4 
S4 TI ( bed sore* or bedsore ${ }^{\star}$ ) OR AB ( bed sore* or bedsore* )

S3 TI ( decubitus ulcer ${ }^{\star}$ or decubitus sore ${ }^{\star}$ ) OR AB ( decubitus ulcer ${ }^{\star}$ or decubitus sore $^{\star}$ )

S2 TI ( pressure ulcer ${ }^{\star}$ or pressure sore ${ }^{\star}$ or pressure injur ${ }^{\star}$ ) OR AB ( pressure ulcer ${ }^{\star}$ or pressure sore ${ }^{\star}$ or pressure injur ${ }^{\star}$ )

S1 (MH "Pressure Ulcer+")

US National Institutes of Health Ongoing Trials Register (ClinicalTrials.gov)

Tilts OR turns OR positioning OR repositioning AND pressure injury OR pressure ulcer OR pressure sore OR decubitus

World Health Organization International Clinical Trials Registry Platform

Tilts OR turns OR positioning OR repositioning AND pressure injury OR pressure ulcer OR pressure sore OR decubitus

\section{EU Clinical Trials Register}

Tilts OR turns OR positioning OR repositioning AND pressure injury OR pressure ulcer OR pressure sore OR decubitus

WHAT'S NEW

\begin{tabular}{lll}
\hline Date & Event & Description \\
\hline 28 May 2020 & New search has been performed & $\begin{array}{l}\text { First update. New search with five new studies and one econom- } \\
\text { ic substudy added. }\end{array}$ \\
\hline 28 May 2020 & $\begin{array}{l}\text { New citation required but conclusions } \\
\text { have not changed }\end{array}$ & Conclusions unchanged. \\
\hline
\end{tabular}

\section{H I S T ORY}

Protocol first published: Issue 7, 2012

Review first published: Issue 4, 2014

\section{CONTRIBUTIONS OF AUTHORS}

Brigid Gillespie: conceived the review; designed the review update; co-ordinated the review update; extracted data; checked the quality of data extraction; analysed or interpreted data; undertook quality assessment; checked quality assessment; performed statistical analysis; checked the quality of the statistical analysis; produced the first draft of the review update; contributed to writing or editing the review update; advised on the review update; performed previous work that was the foundation of the current review update; performed economic analysis; approved the final review update prior to submission; is a guarantor of the review update.

Rachel Walker: designed the review update; extracted data; analysed or interpreted data; checked quality assessment; contributed to writing or editing the review update; advised on the review update; approved the final review update prior to submission.

Sharon Latimer: designed the review update; extracted data; analysed or interpreted data; checked quality assessment; contributed to writing or editing the review update; advised on the review update; approved the final review update prior to submission.

Lukman Thalib: conceived the review; designed the review update; analysed or interpreted data; performed statistical analysis; checked the quality of the statistical analysis; contributed to writing or editing the review update; advised on the review update; performed previous work that was the foundation of the current review update; approved the final review update prior to submission.

Jennifer Whitty: conceived the review; designed the review update; extracted data; checked the quality of data extraction; analysed or interpreted data; contributed to writing or editing the review update; advised on the review update; performed previous work that was the foundation of the current review update; performed economic analysis; approved the final review update prior to submission.

Elizabeth McInnes: conceived the review; designed the review update; analysed or interpreted data; checked the quality of the statistical analysis; contributed to writing or editing the review update; advised on the review update; performed previous work that was the foundation of the current review update; approved the final review update prior to submission. 
Wendy Chaboyer: conceived the review; designed the review update; checked the quality of data extraction; analysed or interpreted data; checked quality assessment; checked the quality of the statistical analysis; contributed to writing or editing the review update; advised on the review update; performed previous work that was the foundation of the current review update; approved the final review update prior to submission; is a guarantor of the review update.

\section{Contributions of editorial base}

Nicky Cullum (Co-ordinating Editor): edited the previous version of this review, advised on methodology, interpretation, and content; approved the final review prior to submission.

Gill Norman (Editor): edited this updated version of the review, advised on methodology, interpretation, and content; approved the final review prior to submission.

Gill Rizzello and Sally Bell-Syer (Managing Editors): coordinated the editorial process; advised on interpretation and content and edited the review and the update.

Naomi Shaw and Sophie Bishop (Information Specialists): designed the search strategy; ran the searches and edited the search methods sections.

Ursula Gonthier and Tom Patterson (Editorial Assistants): edited the Plain language summary and reference sections of the review.

\section{DECLARATIONS OF INTEREST}

Brigid Gillespie: none known.

Rachel Walker: none known.

Sharon Latimer: none known.

Lukman Thalib: none known.

Jennifer Whitty: none known.

Elizabeth McInnes: none known.

Wendy Chaboyer: none known.

\section{SOURCES OF SUPPORT}

\section{Internal sources}

- Griffith University, Australia

The School of Nursing and Midwifery has provided in-kind support relative to time and overheads.

- Qatar University, Qatar

Department of Public Health, College of Health Sciences has provided in-kind support relative to time and overheads.

- University of East Anglia, UK

The Health Economics Group, Norwich Medical School, Faculty of Medicine and Health Sciences has provided in-kind support relative to time and overheads.

- Gold Coast Health, Australia

Gold Coast Health has provided in-kind support relative to time and overheads.

\section{External sources}

- The National Institute from Health Research (NIHR), UK

This project was supported by the National Institute for Health Research, via Cochrane Infrastructure funding to Cochrane Wounds. The views and opinions expressed are those of the authors and not necessarily those of the NIHR, NHS, or the Department of Health and Social Care. 


\section{DIFFERENCES BETWEEN PROTOCOLAND REVIEW}

- We had planned to undertake subgroup analyses based on type of setting (long-term and acute care) and the type of patient. For this update, four studies were conducted in acute care settings, whilst the others were set in long-term care facilities, and all with geriatric patients. However there was low/moderate heterogeneity between the estimates, thus a subgroup analysis was not undertaken.

\section{Changes in the 2020 update}

- We added the outcome 'patient satisfaction' to the 'Summary of findings' tables.

- We changed our inclusion criteria to exclude studies if incidence of pressure ulcers were not included as a primary or secondary outcome because this outcome is central to the purpose of the review.

- We updated our search terms by adding new intervention names and relevant database indexing terms.

- We changed the term 'pressure ulcer' to 'pressure injury', in keeping with the National Pressure Ulcer Advisory Panel Pressure Injury Staging System. This change more accurately reflects pressure injuries to both intact and ulcerated skin.

\section{INDEX TERMS}

\section{Medical Subject Headings (MeSH)}

Beds; Cost-Benefit Analysis; Patient Positioning [economics] [ ${ }^{\star}$ methods]; Pressure Ulcer [ ${ }^{\star}$ prevention \& control]; Randomized Controlled Trials as Topic; Time Factors

\section{MeSH check words}

Adult; Aged; Humans; Middle Aged 